\title{
Daniela Ferreira
}

Efeitos da deficiência de vitamina $D$ na função renal de ratos tratados com Anfotericina B em emulsão lipídica.

\author{
Programa de Nefrologia \\ Orientador: Prof. Dr. Antonio Carlos Seguro \\ Coorientadora: Dra. Daniele Canale \\ Cavicchioli
}

São Paulo

2019 


\section{Dados Internacionais de Catalogação na Publicação (CIP)}

Preparada pela Biblioteca da

Faculdade de Medicina da Universidade de Săo Paulo

Creproduçāo autorizada pelo autor

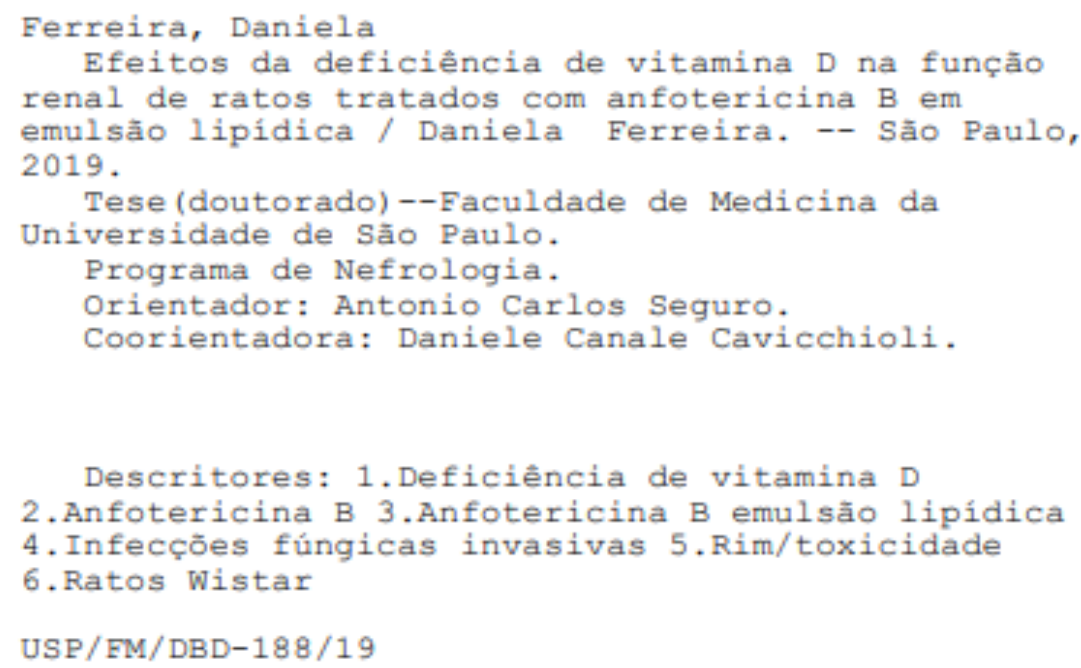

Responsável: Erinalva da Conceição Batista, CRB-8 6755 
Trabalho realizado no Laboratório de Pesquisa Básica em Doenças Renais (LIM12), Departamento de Nefrologia, da Faculdade de Medicina da Universidade de São Paulo, com apoio financeiro da FAPESP (Fundação de Amparo à Pesquisa do Estado de São Paulo), através dos auxílios à pesquisa (Proc. n 2015/05513-1 e 2015/11933-3). 


\section{Dedicatória}

À minha mãe Odília, a quem amo profundamente, pelo amor, dedicação incondicional, participação em todos os momentos da minha vida, e por me fazer, a cada dia, uma pessoa melhor.

Á minha vovó Didi (in memorian).

"Chega um momento em sua vida, que você sabe:

Quem é imprescindível para você,

quem nunca foi, quem não é mais, quem será sempre!" Charles Chaplin. 


\section{Agradecimentos}

Uma tese de doutorado é o resultado de muitos esforços, dedicação, aprendizados e ensinamentos de pessoas que compartilham direta ou indiretamente do nosso sonho. Com esta tese, não seria diferente. Este então é o momento em que posso com muita felicidade, entusiasmo e carinho apresentar a minha imensa gratidão:

À Deus, por ser meu sustento, me guiar, iluminar, proteger e me fortalecer em todos os momentos. Por me permitir realizar tantos sonhos nesta vida. Gratidão por Sua eterna compreensão e tolerância, por Seu infinito amor, pela Sua voz "invisível" acalentando meu coração.

Ao meu orientador, médico, professor e grande pesquisador, o Prof. Dr. Antonio Carlos Seguro (Prof. Seguro, Segurinho, Toninho), por ter aberto as portas do LIM-12, contribuído imensamente para o meu crescimento e aprendizado. Grata pela orientação, competência, disponibilidade, ensinamentos, entusiasmo e compromisso com a pesquisa e ensino.

Á minha co-orientadora, Dra. Daniele Canale, pela orientação, amizade, competência, profissionalismo, dedicação, ensinamentos e direcionamentos sobre como fazer pesquisa com ética e responsabilidade. Gratidão por seu suporte, carinho e atenção em todas as etapas do meu aprendizado.

Á equipe que deu imenso suporte, estavam o tempo todo na bancada, nas orientações preciosas de todas as etapas, que me ensinaram a realizar um trabalho científico, compartilharam bolachinhas e risadas Dr. Rildo Aparecido Volpini (Rildo), Dra. Ana Carolina de Bragança Viciana (Carol), Dra. Maria Heloisa Massola Shimizu (Helô).

Á minha família, parte importantíssima nesta jornada. Imensamente agradeço aos meus pais Odilia e Damázio, por contribuírem em todos os momentos da minha vida, direta ou indiretamente. Gratidão por me conceberem, pelo amor, carinho, broncas, suporte emocional e financeiro. Esta conquista é de vocês também.

Ao meu querido e amado irmão, Júnior, que sempre está ao meu lado ajudando e salvando. E, juntamente com minha querida cunhada Bianca, 
presenteou à nossa família com nossos pequeninos Júlio e Caio, que nos enchem de alegrias, orgulho e ânimo.

Ao meu companheiro amoroso e carinhoso, Marcus Vinícius, grata pelos conselhos, pelo apoio, compreensão nos meus momentos de isolamento, por me ouvir, por acalmar meu coração e mente, pelos sorrisos e por estar ao meu lado sempre.

Á Isabel Sala Corral, minha amiga/irmã que compartilha comigo o "dom" de falar demais, de viajar demais, de aproveitar a vida. Sobretudo, me incentivar, acalmar, me fazer refletir e dar muitas gargalhadas. Aos meus queridos amigos Maína Alexandre, Gustavo Rocha, Dra. Juliana Araújo (Juju), Stephan Milhorini Pio (Ste), Carol Marquês (Gêmola), Carol Nogueira, Ricardo Takeo (Japinha), Fábio Sano, Flávia Baggio (Gúria), Fátima K. Hayashi, Tati Satie e Adriana Silva (Drica), gratidão pela torcida diária, pelo carinho e amizade.

Ao Prof. Dr. Roberto Moreira Souza, responsável por insistir que eu conhecesse o Prof. Seguro e por me apresentar ao LIM-12. Grata pela amizade, apoio e confiança. Você é responsável por essa conquista.

Aos amigos que conquistei no LIM-12, Dra. Talita Sanches (Tali), Ms. Leticia Urbano (Lets), à bioterista Denise Ariane de Jesus (Dê), aos secretários Nivaldo (Niva) e Eloá (Lo), à nossa organizadora de eventos e querida Mirela Santinho (Mi), Dr. José Manuel Cóndor Capcha (José), vocês foram importantes e contribuíram com momentos de muita alegria, risadas, suporte (emocional e tecnológico), conselhos, comidas, festas, diversão e palavras amigas.

À querida Ana Paula Viveiros que foi Sine Qua Non para minha saúde mental e física, sem falar das risadas, no decorrer dessa jornada.

Aos amigos Dr. Weverton Luchi e Ms. Monique Martinez que foram muito importantes em minha caminhada. Gratidão pelos ensinamentos, amizade e pelos momentos de reflexão e risos.

Ao meu amigo Dr. Pedro Henrique França Góis pela amizade, pela sua generosidade, pelos ensinamentos, pela confiança e estímulo para escrever um 
artigo tão importante. Por ter apresentado sua "parzinha" Ms.Claudia Facuri, delícia de pessoa.

Agradeço Igor Oliveira, Dra. Camila Eleutério Rodrigues (Camilinha), e Dr. Marcelo Augusto da Sllveira, pelo carinho e amizade. Aos professores do LIM-12, Profa. Dra. Lucia Andrade, Profa. Dra. Cláudia Helou, Dr. Antonio José de Barros Magaldi, aos responsáveis pela pós-graduação da Nefrologia, Dr. Luiz Yu e Dr. Emmanuel de Almeida Burdmann e a FAPESP pelo apoio financeiro.

Aos meus colegas de trabalho e a chefia direta das Unidades de Terapia Intensiva Clínicas do Instituto do Coração de São Paulo - InCor, que inúmeras vezes estiveram presentes. Seja organizando, viabilizando ou cobrindo minhas folgas e perguntando carinhosamente dos meus ratinhos e da minha pesquisa.

Às minhas amigas de trabalho da Universidade Paulista pelo apoio, carinho, pelas palavras amigas e por sermos uma equipe Ms. Ana Maria Auricchio, Ms. Ana Carolina Ferreira, Ms. Josiane Piccolo, Ms. Karen M. Yano, Dra. Kitéria Ferreira, Dra. Magda Silva e Ms. Suzana Cursino.

Finalmente, não poderia deixar de agradecer, os ratos Wistar, que foram fundamentais para esse trabalho e para o desenvolvimento da ciência experimental.

"Cada pessoa que passa em nossa vida passa sozinha e não nos deixa só porque deixa um pouco de si e leva um pouquinho de nós. Essa é a mais bela responsabilidade da vida e a prova de que as pessoas não se encontram por acaso."

Charles Chaplin 
"Deus nos concede, a cada dia, uma página de vida nova no livro do tempo. Aquilo que colocarmos nela, corre por nossa conta." 


\section{Sumário}

\section{Lista de abreviaturas e siglas}

\section{Lista de figuras}

Lista de tabelas

\section{RESUMO}

\section{SUMMARY}

1. INTRODUÇÃO 1

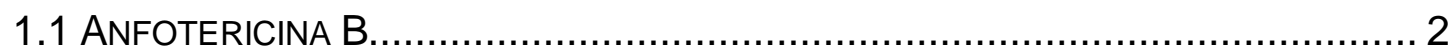

1.2 ANFOtERICINA B E A NEFROTOXICIDADE........................................... 2

1.3 A Deficiência de Vitamina D E A Progressão da Lesão RENAL ................. 6

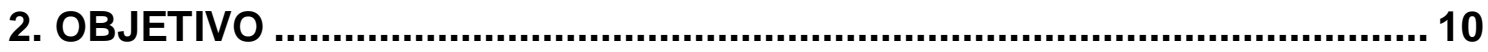

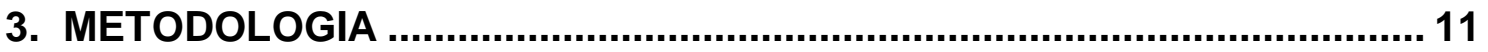

3.1 GRUPOS EXPERIMENTAIS .......................................................... 12

3.2 RepresentaÇÃo ESQuemáticA do Protocolo ExPeRIMENTAL ................. 12

3.3 Estudos de Gaiola MetabólicA ................................................. 13

3.4 DETERMINAÇÃO DA TAXA DE FILTRAÇÃO GLOMERULAR: CLEARANCE DE INULINA

3.5 ANÁLISE HISTOMORFOMÉTRICA.................................................... 15

3.6 ANÁLISE DA EXPRESSÃO PROTEICA: WESTERN BLOTTING.......................... 15

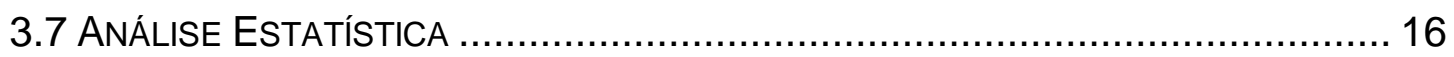

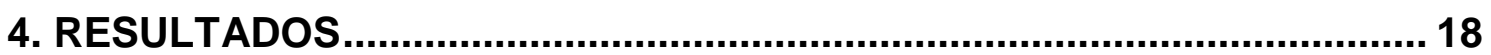

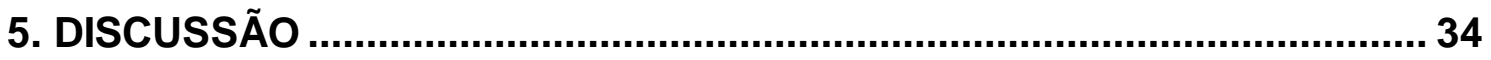

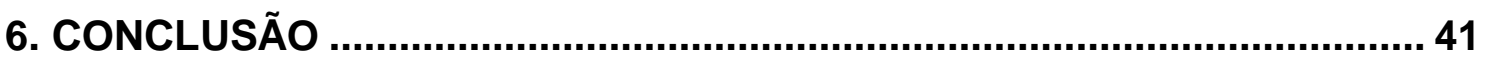


7. ANEXOS

8. REFERÊNCIAS BIBLIOGRÁFICAS ....................................................... 44 


\section{LISTA DE ABREVIATURAS E SIGLAS}

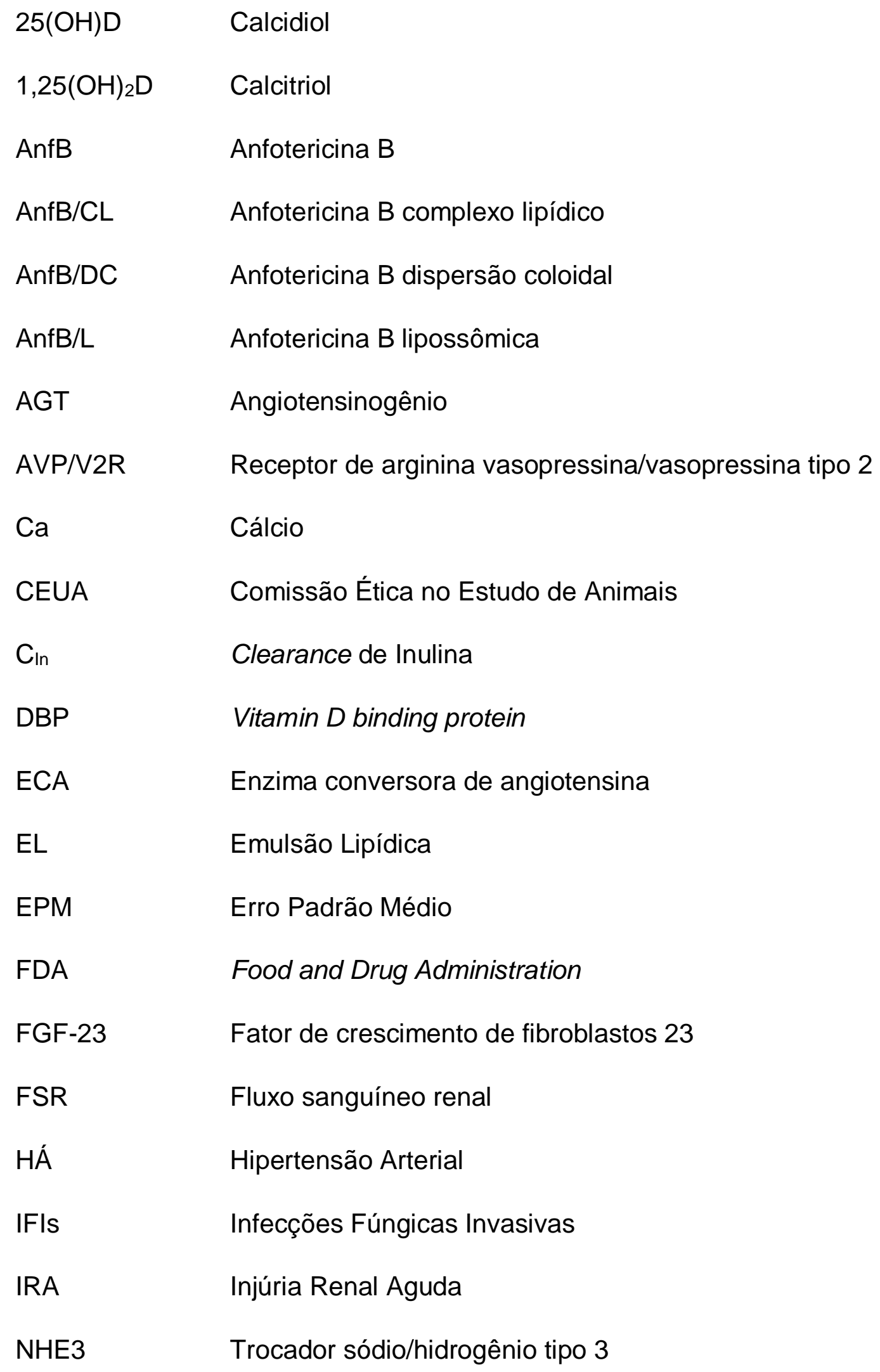




\begin{tabular}{|c|c|}
\hline NaPi-Ila & Cotransportador sódio/fosfato subtipo II-a \\
\hline PAM & Pressão arterial média \\
\hline PC & Peso Corpóreo \\
\hline $\mathrm{P}_{\mathrm{Ca}}$ & Concentração plasmática de cálcio \\
\hline$P_{k}$ & Concentração plasmática de potássio \\
\hline $\mathrm{P}_{\mathrm{Mg}}$ & Concentração plasmática de magnésio \\
\hline $\mathrm{P}_{\mathrm{Na}}$ & Concentração plasmática de sódio \\
\hline$P_{P}$ & Concentração plasmática de fósforo \\
\hline PTH & Paratormônio \\
\hline RAAS & Sistema Renina-Angiotensina-Aldosterona \\
\hline REN & Renina \\
\hline TP & Túbulo Proximal \\
\hline TRPM6 & Transportador de magnésio \\
\hline $\mathrm{U}_{\mathrm{Ca}} \mathrm{V}$ & Excreção urinária de cálcio \\
\hline$U_{k} V$ & Excreção urinária de potássio \\
\hline$U_{K} / U_{\mathrm{Na}}$ & Relação da excreção urinária de potássio e sódio \\
\hline $\mathrm{U}_{\mathrm{mg}} \mathrm{V}$ & Excreção urinária de magnésio \\
\hline Uosm & Osmolalidade urinária \\
\hline$U_{P V}$ & Excreção urinária de fósforo \\
\hline$U_{\text {Prot }} V$ & Excreção urinária de proteínas \\
\hline VDR & Receptor de vitamina $D$ \\
\hline VDRE & Vitamin D Responsive Elements \\
\hline Vitamina $D_{2}$ & Ergocalciferol \\
\hline Vitamina $D_{3}$ & Colecalciferol \\
\hline
\end{tabular}




\section{LISTA DE FIGURAS}

Figura 1. Esquema do Protocolo Experimental.................................... 12

Figura 2. Níveis plasmáticos de 25(OH)D ......................................... 18

Figura 3. Taxa de filtração glomerular ................................................ 19

Figura 4. Excreção urinária de proteína................................................ 20

Figura 5. Concentração plasmática de ureia.......................................... 21

Figura 6. Escore de lesão tubular................................................... 22

Figura 7. Pressão Arterial Média ........................................................ 23

Figura 8. Imunoblotting semiquantitativo do tecido renal para angiotensinogênio (AGT) e enzima conversora de

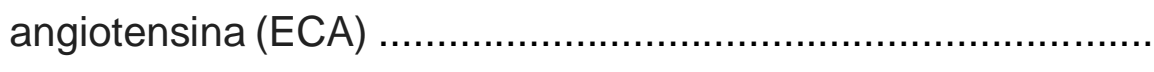

Figura 9. Concentração de aldosterona plasmática................................. 24

Figura 10. Volume e Osmolalidade urinária .......................................... 25

Figura 11. Imunoblotting semiquantitativo do tecido renal para expressão 26 proteica de Aquaporina 2

Figura 12. Concentrações plasmáticas de fósforo e cálcio ........................ 27

Figura 13. Excreção urinária de fósforo ……………............................ 28

Figura 14. Imunoblotting semiquantitativo do tecido renal para expressão 29 proteica do cotransportador sódio/fosfato (NaPI-IIa)

Figura 15. Concentrações plasmáticas de PTH e FGF-23 ........................ 30

Figura 16. Imunoblotting semiquantitativo do tecido renal para expressão 31 proteica de Klotho

Figura 17. Concentração plasmática e excreção urinária de magnésio.... 
Figura 18. Imunoblotting semiquantitativo do tecido renal para expressão 33 proteica do transportador TRPM6 


\section{LISTA DE TABELAS}

Tabela 1. Peso corporal, parâmetros funcionais e hemodinâmicos.................. 42

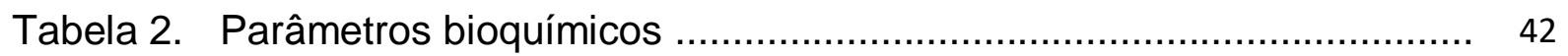

Tabela 3. Avaliação da expressão proteica no tecido renal e análise histo- 43 morfológica. 


\section{Resumo}

Ferreira D. Efeitos da deficiência de vitamina $D$ na função renal de ratos tratados com anfotericina B em emulsão lipídica [tese]. São Paulo: Faculdade de Medicina, Universidade de São Paulo; 2019.

As infecções fúngicas invasivas (IFIs) são um problema de saúde pública e representam uma importante causa de morbidade e mortalidade. A Anfotericina $B$ (AnfB) é a droga de escolha no tratamento das IFIs. Apesar da sua eficácia, a AnfB está associada com efeitos adversos como a nefrotoxicidade. Com o número elevado de pacientes suscetíveis às IFIs, estudos foram desenvolvidos e demonstraram que a nefrotoxicidade pode ser prevenida através do uso de AnfBs modificadas. Dessas modificações, a AnfB incorporada à uma emulsão lipídica $(A n f B / E L)$ apresenta baixo custo e similar eficácia. Existe uma alta prevalência de deficiência de vitamina $D(d V D)$ na população mundial. Sendo assim, a hipovitaminose $\mathrm{D}$ pode acelerar a progressão da doença renal e refletir em mau prognóstico em casos de nefrotoxicidade. Esse trabalho visa analisar se a deficiência da vitamina $D$ pode induzir a nefrotoxicidade da AnfB/EL. Ratos Wistar foram divididos em quatro grupos: controle, animais que receberam dieta padrão por 34 dias; $A n f B / E L$, animais que receberam dieta padrão por 34 dias e injeção intraperitoneal de AnfB/EL ( $5 \mathrm{mg} / \mathrm{kg} / \mathrm{dia})$ nos últimos 4 dias; dVD, animais que receberam dieta depletada em vitamina $D$ por 34 dias; e $\mathrm{dVD}+\mathrm{AnfB} / \mathrm{EL}$, animais que receberam dieta depletada em vitamina $\mathrm{D}$ por 34 dias e a injeção intraperitoneal de AnfB/EL $(5 \mathrm{mg} / \mathrm{kg} / \mathrm{dia})$ nos últimos 4 dias. Amostras de sangue, urina e tecido renal foram coletadas para a análise dos efeitos da droga sobre a função, hemodinâmica e morfologia renal. A associação de $A n f B / E L$ com a hipovitaminose $D$ levou a injúria renal, lesão tubular discreta, hiperfosfatúria, hipermagnesiúria, hipertensão e comprometimento do mecanismo de concentração urinária. Dessa forma, é essencial monitorar os níveis de vitamina $D$ em pacientes tratados com $A n f B / E L$, uma vez que a deficiência dessa vitamina é um fator indutor de nefrotoxicidade associada ao uso da AnfB/EL.

Descritores: Deficiência de vitamina D; Anfotericina B; Anfotericina B emulsão lipídica; Infecções fúngicas invasivas; Rim/toxicidade; Ratos Wistar. 


\section{Summary}

Ferreira D. Vitamin $D$ deficiency induces acute kidney injury in rats treated with lipid formulation of amphotericin $B$ [thesis]. São Paulo: "Faculdade de Medicina, Universidade de São Paulo"; 2019.

Invasive fungal infections (IFI) have become a worldwide serious health problem and represent a significant cause of morbidity and mortality. Amphotericin B $(A m B)$ is the drug of choice for the treatment of IFI. Despite its efficacy, use of $A m B$ has been associated with adverse reactions such as nephrotoxicity The increasing number of high-risk patients, who are more susceptible to IFI and are more likely to use $\mathrm{AmB}$, has enabled the development of modified AmBs in order to reduce nephrotoxicity. Among these formulations, an extemporaneous lipid emulsion preparation of $\mathrm{AmB}(\mathrm{AmB} / \mathrm{LE})$ is a lower cost alternative with similar benefits. Moreover, studies have shown a high prevalence of vitamin $D$ deficiency (VDD) in immunocompromised individuals and patients hospitalized in intensive care units. Thus, vitamin $\mathrm{D}$ deficiency or insufficiency may hasten the progression of kidney disease and reflect on a worse prognosis in cases of acute kidney injury and drug-induced nephrotoxicity. In view of the high worldwide incidence of hypovitaminosis $D$, the aim of this study was to investigate whether vitamin $D$ deficiency may induce AmB/LE-related nephrotoxicity. Wistar rats were divided into four groups: control, received a standard diet for 34 days; AmB/LE, received a standard diet for 34 days and $\mathrm{AmB} / \mathrm{LE}(5 \mathrm{mg} / \mathrm{kg} /$ day) intraperitoneally in the last 4 days; VDD, received a vitamin D-free diet for 34 days; and VDD+AmB/LE, received a vitamin D-free diet for 34 days and $A m B / L E(5 \mathrm{mg} / \mathrm{kg} /$ day) intraperitoneally in the last 4 days. Blood, urine and renal tissue samples were collected in order to evaluate the effects of the drug on renal function, hemodynamic and morphology. Association of AmB/LE and vitamin D deficiency led to impaired renal function, mild tubular injury, hypertension and urinary concentration defect. Hence, it is important to monitor vitamin D levels in AmB/LE treated patients, since vitamin $D$ deficiency induces AmB/LE nephrotoxicity.

Descriptors: Vitamin D deficiency; Amphotericin B; Amphotericin B lipid emulsion; Invasive fungal infections; Kidney toxicity; Wistar rats. 


\section{Introdução}

Apesar dos grandes avanços médicos e da disponibilidade de terapias antifúngicas de amplo espectro, as infecções fúngicas invasivas (IFIs) são um problema de saúde pública de grande importância [1]. As IFIs apresentam altas taxas de morbimortalidade nos pacientes imunocomprometidos, em pacientes hospitalizados e com doenças graves tais como as doenças autoimunes, cânceres e transplantes. Nos Estados Unidos (EUA) houve um crescimento de 5,7\% nas infecções de pacientes por fungos nas décadas de 80 e 90. Em 2004, 64.480 casos de IFIs foram registrados, contribuindo para um aumento de custos hospitalares em torno de $\bigcup \$ \$ 1,89$ bilhão de dólares [1, 2]. Dentre os $40 \%$ de mortalidade no mundo relacionada as IFIs adquiridas em hospitais, as Américas Latina e Central apresentam entre 20 a 63\%, sendo as infecções por Candida ssp um grande exemplo [1-3].

Os tipos de IFls variam de acordo com a patologia e exposição epidemiológica do paciente, mas podem ser divididas basicamente em Infecções fúngicas (IF) endêmica ou oportunista. As endêmicas são as que invadem os tecidos de um hospedeiro normal, e oportunistas, são as que invadem os tecidos de imunocomprometidos $[3,4]$. Os patógenos mais comuns, Aspergillus ssp e Candida ssp, são responsáveis por cerca de $87 \%$ das infecções $[1,3,5]$. Outros patógenos menos comuns, mas que também são observados incluem Cryptococcus ssp e Histoplasma ssp [1, 2]. Para o tratamento de muitas das IFIs, uma das drogas mais frequentemente recomendadas é a Anfotericina B (AnfB) $[2,3,5,6]$. 


\subsection{Anfotericina B}

A AnfB tem sido utilizada há 30 anos permanecendo como droga referência para o tratamento das IFls. A AnfB é um antibiótico antifúngico da classe dos polienos e foi produzida naturalmente como subproduto de fermentação do actinomiceto de solo, o Streptomyces nodosus, em meados de $1955[6,7]$. No final dos anos 50, a AnfB já era utilizada em alguns casos clínicos e, em 1965, a Food and Drug Administration (FDA) a aprovou como primeiro agente antifúngico [8].

A AnfB é pouco absorvida pelo trato gastrointestinal e, após administração parenteral, é fortemente ligada às proteínas plasmáticas. A meia vida no plasma é de 24-48h, mas a sua eliminação leva aproximadamente 15 dias. Altas concentrações da droga são encontradas no fígado $(14-41 \%$ da dose administrada), nos rins (0,3-2\%) e nos pulmões (1,2-6\%) [9]. A eliminação urinária conta com apenas 2- $4 \%$ logo que o fármaco é administrado e, 40\% durante os 7 dias seguintes. A dose máxima tolerada é de 0,7-1,0 mg/Kg/dia. Após descontinuação do medicamento ainda pode-se encontrar resíduos na urina até 8 semanas [9-11].

\subsection{Anfotericina B e a Nefrotoxicidade}

Um fator altamente limitante para o uso da AnfB é a toxicidade. O efeito adverso mais importante é a nefrotoxicidade que ocorre em $80 \%$ dos pacientes tratados com a Anf $B$, sendo muitas vezes relacionado com a alta taxa de morbidade [12-14]. A AnfB interage principalmente com o ergosterol, que é um esteroide exclusivo da parede celular fúngica, levando à formação de poros 
através da membrana lipídica. A alteração da permeabilidade celular da membrana fúngica permite o rápido efluxo de potássio, inibição da glicólise fúngica e subsequente efluxo de magnésio. Essas perdas, juntamente com o influxo de prótons da célula fúngica causam acidificação em seu interior com precipitação do citoplasma, vazamento de componentes citoplasmáticos vitais e morte celular $[6,13-17]$.

A fisiopatologia da nefrotoxicidade induzida pela AnfB não está completamente esclarecida [7, 11, 17-19]. O mecanismo envolve tanto ações diretas de membrana celular para aumentar permeabilidade quanto efeitos secundários à ativação de mecanismos intrarrenais (feedback túbulo-glomerular) e/ou liberação de mediadores (tromboxano A2) [5, 6, 9].

No momento em que a AnfB está inserida na célula, observa-se a criação de poros na membrana lipídica, o que permite um aumento na permeabilidade da membrana, causando um escape de íons e metabólitos, diminuição do fluxo de sangue renal (FSR) e da taxa de filtração glomerular (TFG) podendo evoluir para uma injúria renal aguda (IRA) $[5,6,13,20,21]$. Embora haja uma afinidade com os esteróis, especialmente pelo ergosterol, nota-se que em menor escala, a AnfB tem ligação também com o colesterol da membrana das células humanas, alterando-as e provocando os efeitos adversos envolvidos no processo de toxicidade renal $[6,14,17,19]$.

A formação desses poros compromete a reabsorção renal dos eletrólitos tanto nas células tubulares proximais quanto nas distais causando inúmeros distúrbios hidroeletrolíticos como hipocalemia, hipomagnesemia e acidose 
metabólica $[5,9,20]$. Além disso, um estudo em nosso laboratório demonstrou que a AnfB inibe a ação do hormônio antidiurético no ducto coletor medular interno, diminuindo a permeabilidade a água e ureia nesse segmento. Esses eventos alteram os mecanismos de concentração urinária levando a poliúria [22].

Com o aumento dos casos de pacientes de alto risco, que são mais suscetíveis às IFls e que tornam o uso da AnfB mais frequente, estudos experimentais foram desenvolvidos no Brasil e no mundo no intuito de gerar alternativas menos tóxicas para o seu uso, podendo aumentar ou não o potencial de ação da droga. Inúmeros estudos demonstram que a modificação da AnfB através do desenvolvimento de formulações lipídicas pode diminuir os seus efeitos nefrotóxicos $[13,17,21,23-26]$. Essas modificações permitem que a droga seja infundida de forma parenteral devido a solubilidade baixa, protege da degradação enzimática e altera a farmacocinética da AnfB diminuindo a liberação da droga para outros tecidos.

Outro fator que favorece o uso da apresentação lipídica é o fato do transportador lipídico se associar a AnfB. Isso impede sua dispersão não controlada e facilita a absorção do complexo de células do sistema fagocitário, aumentando sua eficácia e especificidade no depósito da droga nos sítios alvos da infecção $[6,13,25,26]$. As formulações lipídicas da AnfB que apresentam menores efeitos adversos e que foram desenvolvidas pela indústria farmacêutica são o complexo lipídico de $A n f B(A n f B / C L)$, dispersão coloidal de $A n f B(A n f B / D C)$ e AnfB lipossômica (AnfB/EL). 
O AnfB/CL é um complexo lipídico com AnfB de estrutura multilamelar "ribbon-like". Foi a primeira formulação lipídica desenvolvida, licenciada no Reino Unido, sendo aprovada em 1995 pelo FDA $\left(\right.$ Abelcet $\left.^{\circledR}\right)$ [6, 26]. Com a dose terapêutica recomendada de $5 \mathrm{mg} / \mathrm{kg} / \mathrm{dia}$, a $\mathrm{AnfB} / \mathrm{CL}$ foi considerada segura e eficaz para IFIs, apresentou baixa toxicidade renal e baixos índices de eventos adversos em adultos, crianças e neonatos. Diferentemente da AnfB convencional, a AnfB/CL pode ser administrada a pacientes com doença renal pré-existente [26, 27].

A AnfB/DC é uma dispersão coloidal de AnfB em sulfato de colesterila sódica, aprovada pelo FDA em $1996\left(\right.$ Amphocil $\left.^{\circledR}\right)$. A dose recomendada é diária e única de 3 a $4 \mathrm{mg} / \mathrm{kg} / \mathrm{dia}$. Embora seja menos nefrotóxica que a AnfB convencional, são comuns as reações imediatas sistêmicas, devendo ser infundida lentamente $[6,27,28]$.

A AnfB/EL é uma formulação liofilizada que consiste na incorporação da AnfB na bicamada lipídica de lipossomas $\left(\right.$ Ambisome $\left.^{\circledR}\right)$. Recomendam-se doses diárias de 3-5 mg/kg/dia. Apresenta a menor toxicidade dentre todas as formulações [2]. Foi aprovada pelo FDA em 1997. Da mesma forma que a AnfB/CL, estudos clínicos demonstram que o impacto da $A n f B / E L$ na função renal é menor, porém com grau de eficácia semelhante para o tratamento das IFIs, quando comparado com a AnfB convencional [6, 21, 28-30].

Apesar da baixa toxicidade das formulações lipídicas da AnfB, essas modificações ainda apresentam efeitos adversos e alto custo, trazendo um grande obstáculo para as instituições com recursos mais restritos [26, 31, 32]. 0 
uso da AnfB convencional com a adição de uma emulsão lipídica (AnfB/EL) vem sendo uma alternativa em vários países para baixar custos [13, 27, 31, 32]. Estudos demonstraram eficácia e segurança dessa formulação interna da AnfB/EL quando comparadas às preparações da indústria farmacêutica $[13,27$, 31, 32]. Portanto, é importante considerar os elevados custos das formulações lipídicas, uma vez que este é aproximadamente 10-20 vezes maior quando comparado ao da AnfB convencional [31].

\subsection{A Deficiência de Vitamina D e a Progressão da Lesão Renal}

A deficiência de vitamina $D$ atualmente é reconhecida como uma pandemia. A sua maior fonte é a exposição solar moderada em humanos, mas fatores individuais como gênero, idade, obesidade, cor da pele e estilo de vida também são importantes. Na Europa, a hipovitaminose D é maior nos países mais ensolarados da região do mediterrâneo do que nos países escandinavos. Assim, mesmo em países ensolarados como o Brasil, o nível de vitamina $D$ na população é inferior ao que seria desejável [33, 34].

Além da discreta toxicidade e dos custos associados com o uso das AnfB lipídicas, é importante ressaltar que 30-50\% dos adultos saudáveis são deficientes em vitamina $D$ [35]. Essa alta prevalência também é encontrada em hipertensos, pacientes com doenças infecciosas [36] imunocomprometidos, HIV positivos [36, 37] ou tratados com quimioterápicos [35].

A Vitamina D é conhecida como reguladora do metabolismo do cálcio $(\mathrm{Ca})$ e fósforo $(P)$, tendo assim, um papel bastante conhecido na homeostase óssea. 
Não menos importante é o seu papel como imunomodulador de várias células do sistema imunológico como monócitos, macrófagos, células dendríticas (DC), linfócitos T e os linfócitos B. Para obtenção da vitamina $D$, temos duas fontes distintas: por dieta ou por síntese mediada por raios ultravioletas (UV) na camada epidérmica da pele. $\mathrm{Na}$ ingestão nutricional, têm-se duas vias: vitamina $D_{2}$ ou ergocalciferol e vitamina $D_{3}$ ou colecalciferol, ou ainda, calcitriol (1,25 dihidroxicolecalciferol) que é encontrada nos alimentos de origem animal [35, 38]. Apesar de ser obtida pela alimentação, a melhor fonte de vitamina $D$ é a pele, pois tem a capacidade para a produção de vitamina $D_{3}$, forma ativa da vitamina D, após exposição solar [39].

$\mathrm{Na}$ pele, os raios UV promovem a clivagem fotolítica da 7dihidrocolesterol originando a pré-vitamina D. Esta última se converte em vitamina $D_{3}$ após isomerização térmica espontânea e é transportada através da sua ligação com a Vitamin $D$ binding protein (DBP). Para tornar-se bioativa, a vitamina $D$ sofre dois processos de hidroxilação. A primeira hidroxilação ocorre no fígado e é catalisada pela enzima 25-hidroxilase ou calcidiol - 25(OH)Dresultando na forma circulante, sendo usada como marcador de vitamina $D$ no organismo. A segunda hidroxilação ocorre principalmente no rim, mais especificamente nas células tubulares proximais. É catalisada pela 1-alfahidroxilase e gera o metabólito ativo 1,25 -di-hidroxivitamina $D_{3}$ ou calcitriol $(1,25$ $\left.(\mathrm{OH})_{2} \mathrm{D}_{3}\right)$, que tem relação com a regulação do cálcio e fósforo sérico [36, 3842].

A atividade da 1- $\alpha$ - hidroxilase é regulada por vários fatores, tais como, os níveis de cálcio, fosfato, paratormônio (PTH), calcitonina, hormônio do 
crescimento $(\mathrm{GH})$ e $1,25(\mathrm{OH})_{2} \mathrm{D}_{3}$. A diminuição do nível sérico de cálcio promove a liberação de PTH pelas glândulas paratireoides, estimulando o rim a produzir mais 1- $\alpha$ - hidroxilase, que, por sua vez, aumenta a produção de $1,25(\mathrm{OH})_{2} \mathrm{D}_{3} . \mathrm{O}$ mecanismo usado pela $1,25(\mathrm{OH})_{2} \mathrm{D}_{3}$ para corrigir os níveis séricos do cálcio incluem redução da excreção renal de cálcio e aumento da sua absorção pelo intestino. Além disso, a 1,25 (OH ${ }_{2} \mathrm{D}_{3}$ estimula a maturação dos osteoclastos para liberação de cálcio pelos ossos [36, 38-40, 42].

Outros importantes reguladores da presente enzima incluem o fator de crescimento de fibroblastos (FGF-23) e a proteína Klotho que representam um eixo endócrino envolvido na regulação do metabolismo do cálcio e fosfato [43]. Níveis elevados de fosfato aumentam a produção de FGF-23 tendo como resultado a diminuição da atividade de 1- $\alpha$ - hidroxilase e, como consequência, a redução da absorção de cálcio e fósforo $[43,44]$. A $1,25(\mathrm{OH})_{2} \mathrm{D}_{3}$ diminui sua produção através da supressão da produção de mRNA da 1-a- hidroxilase provavelmente via geração do gene klotho [36].

O rim possui um papel importante no metabolismo da vitamina $D$ e esta, por sua vez, é responsável pela sua proteção e pela regulação de inúmeras atividades fisiológicas. Sendo assim, a deficiência $(<10 \mathrm{ng} / \mathrm{mL})$ ou insuficiência (10-30 $\mathrm{ng} / \mathrm{mL})$ de vitamina $D$ pode agravar a lesão da doença renal e refletir em um mau prognóstico em casos de injúria renal aguda e nefrotoxicidade por medicamentos, conforme estudos realizados em nosso laboratório [40, 41].

Além do seu grande e tradicional papel na regulação do metabolismo mineral, estudos mostraram que o declínio da função renal está associado a uma 
redução nos níveis de calcitriol e que este pode ser utilizado como tratamento, diminuindo a morbidade e mortalidade em pacientes dialíticos e não dialíticos com doença renal crônica (DRC). Uma vez que a DRC afeta de $10-15 \%$ da população adulta, uma maior compreensão da importância dos efeitos da vitamina $D$ no organismo pode, em muito, melhorar a qualidade de vida dessa população $[13,43]$.

Tendo em vista o aumento da deficiência de $D$ na população mundial e consequentemente nos indivíduos imunocomprometidos ou hospitalizados, que são mais suscetíveis ao uso de agentes antifúngicos, esse trabalho visa analisar se a deficiência da vitamina $D$ é um fator de risco para o desenvolvimento da nefrotoxicidade de uma das formulações lipídicas da AnfB, a AnfB/EL, considerada mais segura e tão eficaz quanto a AnfB convencional. 


\section{Objetivo}

Avaliar se a deficiência da vitamina $D$ pode induzir a nefrotoxicidade da $\mathrm{AnfB} / \mathrm{EL}$ em ratos. 


\section{Metodologia}

Foram utilizados ratos Wistar (Rattus novergicus) com peso corpóreo em torno de 180-200 g, obtidos do biotério central da Faculdade de Medicina da Universidade de São Paulo. Os animais foram mantidos no biotério do laboratório em temperatura ambiente $\left(23 \pm 1^{\circ} \mathrm{C}\right)$ com ciclo claro/escuro de $12 / 12$ horas. Os procedimentos experimentais utilizados neste estudo foram enviados e aprovados pela Comissão de Ética no Estudo em Animais (CEUA) da Faculdade de Medicina da Universidade de São Paulo (Protocolo no 134/15).

Foram utilizados ratos machos que receberam dieta padrão ou depletada em vitamina D (MP Biomedicals, Irvine, CA, EUA) durante 34 dias. Para avaliarmos se a quantidade de dieta consumida foi equivalente, os grupos de animais foram colocados em gaiolas individuais onde receberam dieta, com livre acesso à água. Foi efetuado, diariamente, o balanço da ingestão de dieta e água. O peso dos animais foi verificado semanalmente. Após 30 dias do início do tratamento com dieta padrão ou depletada em vitamina $D$, os animais receberam injeções intraperitoneais de AnfB na dose de $5 \mathrm{mg} / \mathrm{kg} / \mathrm{dia}$ adicionada a emulsão lipídica (EL) (óleo de soja 200 mg/mL, glicerol $25 \mathrm{mg} / \mathrm{ml}$, lecitina de ovo 12 mg/mL - Lipovenos ${ }^{\circledR} 20 \%$, Fresenius, Graz, Áustria) por 4 dias. Essa dose foi baseada em estudos prévios realizados neste laboratório [13]. A emulsão lipídica foi gentilmente cedida pela Fresenius ${ }^{\circledR}$ e a AnfB pelo Hospital das Clínicas da Faculdade de Medicina da Universidade de São Paulo. 


\subsection{Grupos experimentais}

Foram estudados quatro grupos de animais:

1) Controle (C): ratos que receberam dieta padrão por 34 dias

2) Anfotericina B emulsão lipídica (AnfB/EL): ratos que receberam dieta padrão por 34 dias e a AnfB/EL na dose de $5 \mathrm{mg} / \mathrm{kg} / \mathrm{dia}$ (intraperitoneal) nos últimos 4 dias.

3) Deficiência de vitamina $D$ (dVD): ratos que receberam dieta depletada em vitamina $\mathrm{D}$ por 34 dias.

4) Deficiência de vitamina D e Anfotericina B emulsão lipídica (dVD+AnfB/EL): ratos que receberam dieta depletada em vitamina $D$ por 34 dias e a AnfB/EL na dose de $5 \mathrm{mg} / \mathrm{kg} / \mathrm{dia}$ (intraperitoneal) nos últimos 4 dias.

\subsection{Representação Esquemática do Protocolo Experimental}

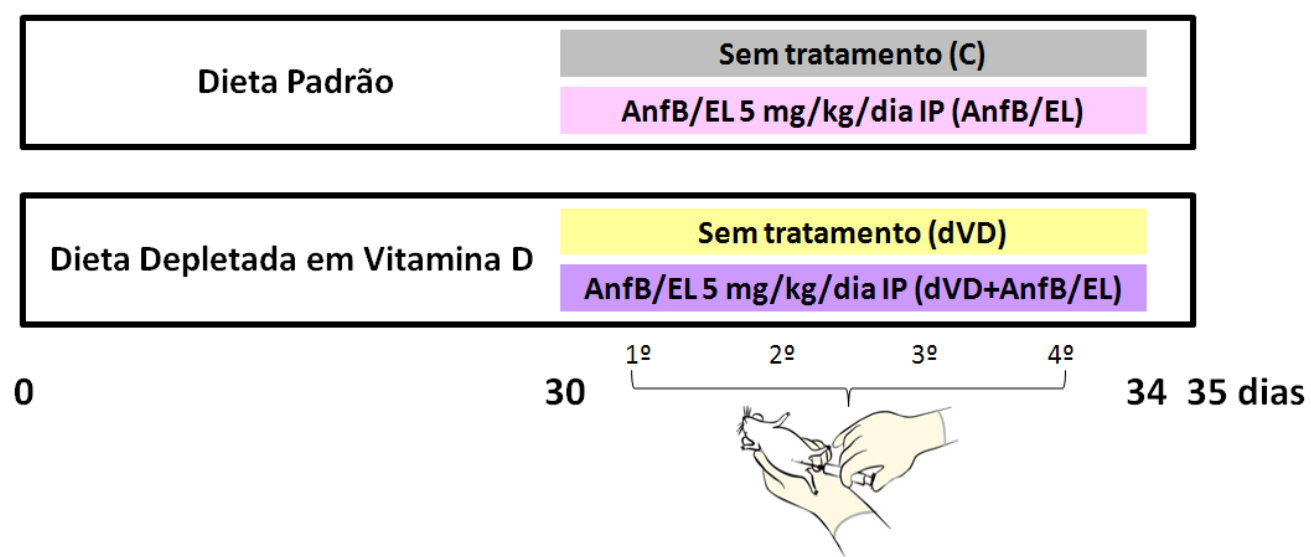

Figura 1 - Esquema do Protocolo Experimental. 


\subsection{Estudos de Gaiola Metabólica}

Após 34 dias de acompanhamento experimental, os animais foram colocados em gaiolas metabólicas para a coleta de urina de 24 horas. O volume urinário foi avaliado gravimetricamente e as amostras de urina foram centrifugadas para remoção de material suspenso. O sobrenadante foi utilizado para análise dos eletrólitos. As concentrações urinárias de magnésio, fósforo e proteína foram mensuradas por sistema colorimétrico usando kit comercial (LabTest, MG, Brasil). As excreções urinárias de fósforo $\left(\mathrm{U}_{\mathrm{P} V}\right)$, magnésio $\left(\mathrm{U}_{\mathrm{Mg}} \mathrm{V}\right)$ e proteína $\left(U_{\text {Prot }} \mathrm{V}\right)$ foram determinadas. A osmolalidade urinária (UOsm) foi verificada através da análise de ponto de congelamento (The Advanced TMOSMOMETHER 3D3).

\subsection{Determinação da taxa de filtração glomerular: Clearance de Inulina}

Os animais foram anestesiados com tiopental sódico 50 mg/Kg (Cristália, São Paulo, Brasil). A traqueia foi canulada com cateter PE-240, e a respiração foi mantida espontaneamente. A veia jugular foi canulada com cateter PE-60 para a infusão de inulina e de fluidos. Para o controle da pressão arterial média (PAM) e para a coleta de amostras de sangue, a artéria carótida foi cateterizada com cateter PE-50. Para a coleta de amostras de urina, foi feita uma incisão abdominal e a bexiga do animal foi canulada com cateter PE-240. Após o procedimento cirúrgico, uma dose única de inulina $(100 \mathrm{mg} / \mathrm{kg}$ diluída em $1 \mathrm{~mL}$ de solução salina $0,9 \%$ ) foi administrada pela veia jugular. Em seguida, uma infusão constante de inulina foi mantida (10 mg/kg em solução salina $0,9 \%$ ) a 
0,04 $\mathrm{mL} / \mathrm{min}$ do início ao fim do experimento. Foram coletadas três amostras de urina a cada 30 minutos e amostras de sangue no início e no fim do experimento. Os valores do clearance de inulina representam a média de três períodos de experimento. As concentrações de inulina no sangue e na urina foram determinadas pelo método colorimétrico da Antrona. $O$ clearance de inulina $\left(\mathrm{C}_{\text {in }}\right)$ foi expresso corrigindo-se por $100 \mathrm{~g}$ de peso corpóreo [45].

Ao final do experimento de clearance, o sangue total dos animais foi colhido para as seguintes análises no plasma: sódio $\left(P_{N a}\right)$, potássio $\left(P_{K}\right)$ e cálcio ( $\left.P_{C a}\right)$ por eletrodo sensível (AVL 9180 Electrolyte Analyser - Roche ${ }^{\circledR}$, RischRotkreuz, Suíça); fósforo $\left(\mathrm{P}_{\mathrm{P}}\right)$ e magnésio $\left(\mathrm{P}_{\mathrm{Mg}}\right)$ por sistema colorimétrico (LabTest, MG, Brasil). A ureia plasmática foi verificada pelo método de Crocker modificado [46]. A concentração plasmática de 25-hidroxivitamina D $(25(\mathrm{OH}) \mathrm{D})$ foi avaliada pelo método de ELISA usando o kit comercial 25-Hydroxyvitamin $D$ $\left(\right.$ ALPCO $^{\circledR}$, Salen, NH, EUA). Os níveis plasmáticos de Aldosterona, PTH e FGF23 foram determinados pelo método de Elisa, usando kits comerciais Aldosterone ELISA Kit (Enzo, Life Sciences Inc., NY, EUA), Rat Intact PTH ELISA kit (Immutopics, Inc., CA, EUA) e Mouse/Rat FGF-23 Intact ELISA kit (Immutopics, Inc., CA, EUA), respectivamente.

Após a coleta do sangue, os rins foram perfundidos com solução de tampão fosfato salino (PBS, $\mathrm{NaCl} 0,15 \mathrm{M}$, tampão fosfato $0,01 \mathrm{M}, \mathrm{pH} 7,4$ ). Em seguida, o rim direito foi removido, congelado em nitrogênio líquido e estocado a $-80^{\circ} \mathrm{C}$ para análise da expressão de proteínas pela técnica de Western blotting. O rim esquerdo foi pesado e em seguida fixado em formalina tamponada $10 \%$ ou solução de methacarn e mantido nestes mesmos fixadores por um período 
de 24 horas. Após esse período, os fixadores foram substituídos por álcool 70\% e o tecido foi embebido em parafina e cortado em secções de $4 \mu \mathrm{m}$ para estudos de histo-morfometria.

\subsection{Análise Histomorfométrica}

As amostras de tecidos renais foram desidratadas, diafanizadas e incluídas em parafina. Após inclusão em parafina, foram feitos cortes de $4 \mu \mathrm{m}$, que foram corados pela reação de hematoxilina-eosina (HE) para avaliação das lesões renais.

Para avaliação da extensão das áreas acometidas por lesões renais, entre 40 a 60 campos medindo $0,245 \mathrm{~mm}^{2}$ serão sequencialmente analisados. Cada campo foi avaliado através de escores que variam de 0 a 4 , de acordo com 0 seguinte critério: 0 , menos do que $5 \%$ da área apresentando edema celular, degeneração vacuolar, necrose e descamação; I, entre 5-25\% da área com comprometimento; II, 25-50\% da área apresentando lesões renais; III, alterações envolvendo entre $50-75 \%$ do campo analisado; IV, mais do que $75 \%$ da área analisada apresentando lesões renais. Em seguida, um escore médio para cada rato foi calculado [47, 48].

\subsection{Análise da expressão proteica: Western Blotting}

Para a realização da técnica de Western blotting foram utilizadas as amostras de tecido renal dos animais, previamente congeladas em nitrogênio líquido e estocadas a $-80^{\circ} \mathrm{C}$. 
A extração da proteína seguiu o protocolo descrito por Burnette, com pequenas modificações [46]. As amostras dos tecidos renais foram homogeneizadas (Polytron PT 10-35, Power Control Unit) em solução K-Hepes (20 mM Mannitol; 80 mM Hepes; $41 \mathrm{KOH}, \mathrm{pH} 7,5$ ) com coquetel de inibidores de protease (Cocktail Protease Inhibitor, Sigma Chemical Company, St. Louis, MO, EUA). Em seguida, foram centrifugadas a $4.000 \mathrm{rpm}$ por 30 minutos a $4^{\circ} \mathrm{C}$ para remover núcleo, mitocôndrias e debris celulares. As proteínas totais foram quantificadas pelo método de Bradford (Bioagency). As amostras foram separadas de acordo com o peso molecular em minigéis SDS-PAGE (SDSpolyacrylamide gel electrophoresis) em tampão de corrida (Tris/Glicina/SDS $10 \%, \mathrm{pH} 8,3)$ e a transferência para membrana de nitrocelulose foi feita com tampão de transferência (Tris/Glicina/metanol 20\%). A membrana foi bloqueada com 5\% de leite em pó desnatado (Molico) em TBS-T (24,2 g Tris base, 29,2 g $\mathrm{NaCl}$, 3,36 g EDTA para $1 \mathrm{~L}$ de água destilada) por 1 hora. A incubação primária foi feita com os anticorpos anti-aquaporina 2 (Santa Cruz, Biotechnology Inc., CA, EUA), anti-NaPI-Ila, (Santa Cruz, Biotechnology Inc., CA, EUA) e antiTRPM6 (Santa Cruz, Biotechnology Inc., CA, EUA), angiotensinogênio (AGT, 1/100), enzima conversora da angiotensina (ECA, 1/100) e $\alpha$-Klotho (1/500). em solução de TBS-T, overnight a $4^{\circ} \mathrm{C}$. A incubação secundária foi realizada com anticorpos anti-goat e anti-rabbit (Sigma Chemical, St. Louis, MO, EUA) também em solução de TBS-T com $0,1 \%$ de leite desnatado. O procedimento de detecção foi baseado em quimioluminescência (ECL, Amersham). A normatização foi feita com uma nova hibridização das membranas com anticorpo anti-ßactina (Sigma Chemical, St. Louis, MO, EUA). A semi-quantificação das proteínas foi realizada pelo software Image $\mathrm{J}$ for Windows (Image $\mathrm{J}-\mathrm{NIH}$ Image). 


\subsection{Análise Estatística}

A análise estatística dos dados dos grupos estudados foi o One-Way ANOVA, seguido pelo teste de Newman-Keuls. Todas as análises foram realizadas através do programa de estatística GraphPad Prism 5 e foram expressos em média \pm erro padrão da média $(E P M)$. Os valores de $p<0,05$ foram considerados significantes. 


\section{Resultados}

Os animais que receberam dieta depletada de vitamina $\mathrm{D}$ por 30 dias apresentaram níveis plasmáticos baixos dessa vitamina (dVD 4,3 $\pm 0,4 \mathrm{ng} / \mathrm{ml}$ e $\mathrm{dVD}+\mathrm{AnfB} / \mathrm{EL} 4,4 \pm 0,7 \mathrm{ng} / \mathrm{ml}$ ) quando comparado aos animais que receberam a dieta padrão no mesmo período (C $44,3 \pm 2,4 \mathrm{ng} / \mathrm{ml}$ e $\mathrm{AnfB} / \mathrm{EL} 45,4 \pm 5,2 \mathrm{ng} / \mathrm{ml}$ ). Esses resultados mostram que o modelo experimental de deficiência de vitamina D foi implementado com eficácia. A determinação dos níveis plasmáticos de vitamina D estão representados na tabela 2 e na figura 2.

\section{Niveis Plasmáticos de $25(\mathrm{OH}) \mathrm{D}$}

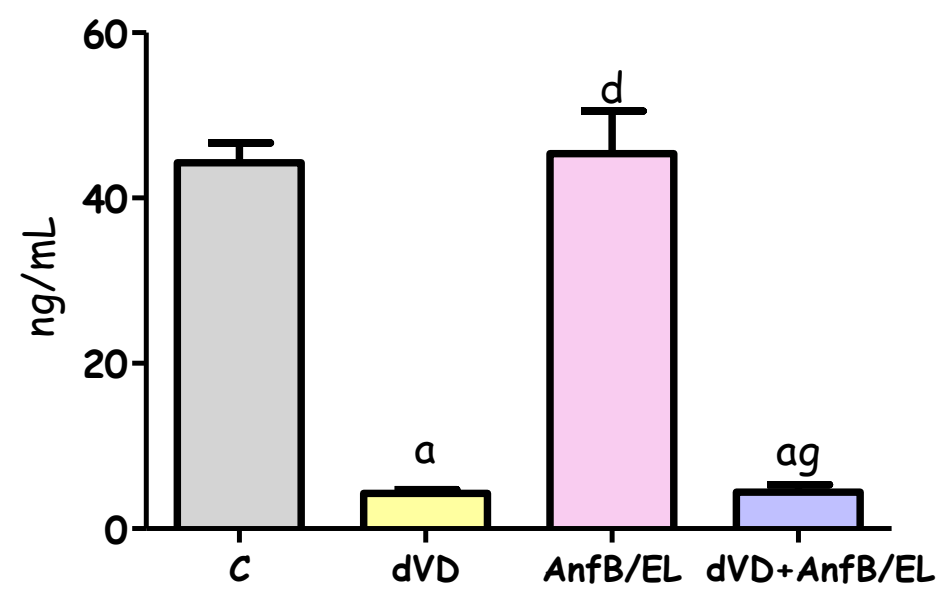

Figura 2 - Níveis plasmáticos de 25(OH)D. Gráfico de barras dos níveis plasmáticos de 25(OH)D de ratos controles $(C, n=8)$, deficientes em vitamina $D(d V D, n=6)$, controles que receberam Anfotericina $B$ Emulsão Lipídica, $(A n f B / E L, n=6)$ e deficientes em vitamina $D$ que receberam Anfotericina $B$ Emulsão Lipídica (dVD+AnfB/LE, $n=6)$. Valores expressos em média \pm EPM. ${ }^{a} p<0.001$ vs. $C,{ }^{d} p<0.001$ vs. dVD e ${ }^{9} p<0.001$ vs. AnfB/EL.

O peso corpóreo de todos os grupos estudados não apresentou diferenças significativas, lembrando que não houve diferença na ingestão entre os grupos (aproximadamente $25 \mathrm{~g} / \mathrm{rato} / \mathrm{dia}$ ) e a dieta era livre demanda e equitativa para todos os grupos. Em relação ao comprometimento da função 
renal, os animais que receberam dieta deficiente em vitamina $D$ apresentaram uma taxa de filtração glomerular menor quando comparado ao grupo C $(0,79 \pm 0,02$ vs. $0,97 \pm 0,04 \mathrm{~mL} / \mathrm{min} / 100 \mathrm{~g})$.

É importante ressaltar que o tratamento por si só com AnfB/EL não alterou a taxa de filtração glomerular quando comparado com os animais do grupo controle $(0,99 \pm 0,06$ vs. $0,97 \pm 0,04 \mathrm{~mL} / \mathrm{min} / 100 \mathrm{~g})$. Os animais do grupo dVD+AnfB/EL apresentaram uma perda maior da função renal $(0,55 \pm 0,04$ $\mathrm{mL} / \mathrm{min} / 100 \mathrm{~g}$ ), demonstrando que a deficiência da vitamina $\mathrm{D}$ agrava ainda mais a lesão renal quando somada a utilização da AnfB mesmo em emulsão lipídica. Os dados de peso corpóreo e da taxa de filtração glomerular estão representados na tabela 1 e na figura 3.

\section{Clearance de Inulina}

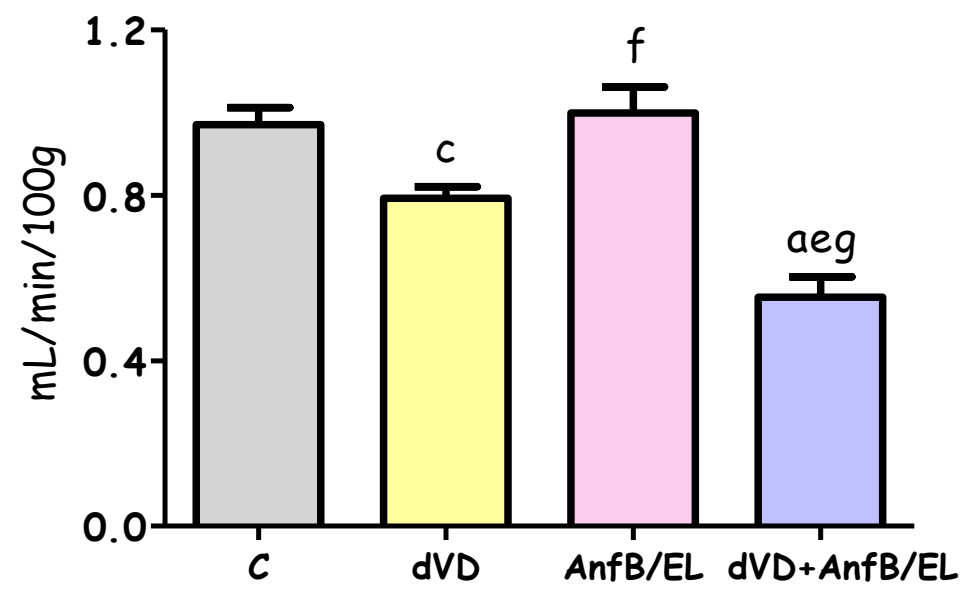

Figura 3 - Taxa de filtração glomerular (TFG). Gráfico em barras da TFG avaliada pelo clearance de inulina de ratos controles $(C, n=8)$, deficientes em vitamina $D(d V D, n=6)$, controles que receberam Anfotericina $B$ Emulsão Lipídica, (AnfB/EL, $n=7$ ) e deficientes em vitamina $D$ que receberam Anfotericina $B$ Emulsão Lipídica (dVD+AnfB/LE, $n=9$ ). Valores expressos em média $\pm E P M$. ${ }^{a} p<0.001$ vs. $C,{ }^{c} p<0.05$ vs. $C$, ${ }^{e} p<0.01$ vs. dVD e ${ }^{f} p<0.05$ vs. dVD e ${ }^{g} p<0,001$ vs. AnfB/EL 
A proteinúria é um marcador sensível e aplicável para detecção precoce de lesão renal. Os animais do grupo dVD+AnfB/EL (12,7 $\pm 1,0 \mathrm{mg} / 24 \mathrm{~h})$ apresentaram maior elevação na excreção de proteínas urinárias quando comparados com o grupo $\mathrm{C}(7,54 \pm 0,53 \mathrm{mg} / 24 \mathrm{~h})$. A proteinúria também foi maior no grupo dVD $(13,1 \pm 0,5 \mathrm{mg} / 24 \mathrm{~h})$ quando comparado com o grupo $\mathrm{C}$. Os animais do grupo AnfB/EL não apresentaram alteração na excreção de proteínas $(9,6 \pm 0,7 \mathrm{mg} / 24 \mathrm{~h})$. É importante ressaltar que se avaliássemos a fração de excreção urinária de proteínas nos animais depletados em vitamina $D$ que receberam a AnfB/EL, este grupo apresentaria um aumento dessa fração de excreção devido à menor filtração glomerular com consequente menor carga filtrada de proteína. A tabela 2 e a figura 4 demonstram a excreção urinária de proteínas.

\section{Proteinúria}

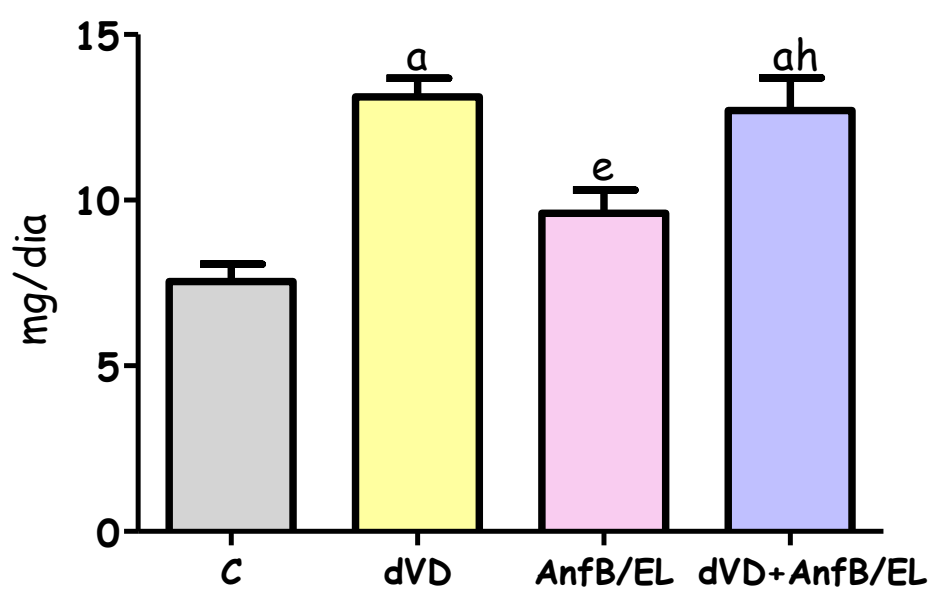

Figura 4 - Excreção urinária de proteína. Gráfico em barras da excreção urinária de proteínas de ratos controles $(C, n=8)$, deficientes em vitamina $D(d V D, n=6)$, controles que receberam Anfotericina $B$ Emulsão Lipídica, (AnfB/EL, $n=7$ ) e deficientes em vitamina $D$ que receberam Anfotericina B Emulsão Lipídica (dVD+AnfB/LE, $n=9$ ). Valores expressos em média \pm EPM. ${ }^{a} p<0.001$ vs. $C,{ }^{e} p<0.01$ vs. $d V D$ e ${ }^{h} p<0.01$ vs. AnfB/EL. 
Outro marcador de disfunção renal é a concentração plasmática de ureia,

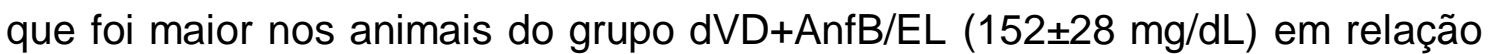
aos animais do grupo C $(49 \pm 1 \mathrm{mg} / \mathrm{dL}), \mathrm{dVD}(51 \pm 4 \mathrm{mg} / \mathrm{dL})$ e AnfB/EL $(77 \pm 9$ $\mathrm{mg} / \mathrm{dL})$. Os dados referentes a uremia estão representados na tabela 2 e na figura 5.

\section{Ureia Plasmática}

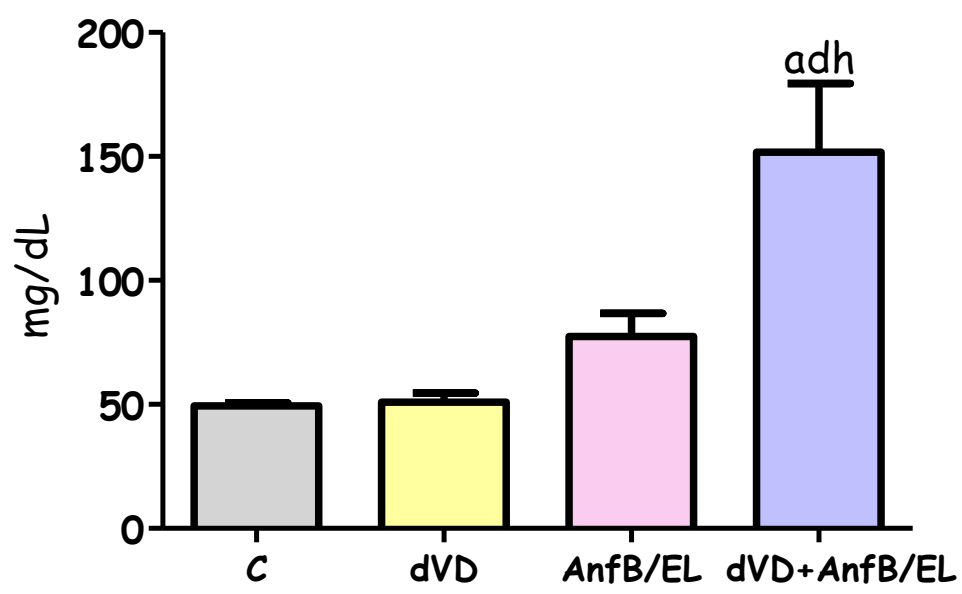

Figura 5 - Concentração plasmática de ureia. Gráfico em barras da concentração plasmática de ureia de ratos controles $(C, n=8)$, deficientes em vitamina $D(d V D, n=6)$, controles que receberam Anfotericina $B$ Emulsão Lipídica, (AnfB/EL, $n=7$ ) e deficientes em vitamina $D$ que receberam Anfotericina $B$ Emulsão Lipídica (dVD+AnfB/LE, $n=9$ ). Valores expressos em média \pm EPM. ${ }^{a} p<0.001$ vs. $C,{ }^{d} p<0,001$ vs. dVD, ${ }_{\mathrm{h}} \mathrm{p}<0.01$ vs. AnfB/EL.

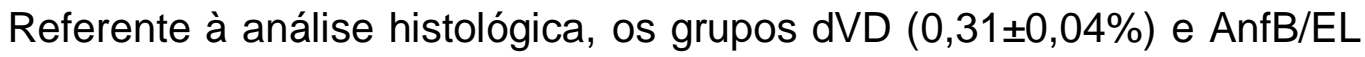
$(0,25 \pm 0,05 \%)$ não apresentaram diferença estatística em relação ao escore de lesão tubular renal. Entretanto, os animais dVD+AnfB/EL $(0,40 \pm 0,07 \%)$ exibiram um aumento nesse parâmetro quando comparados aos animais do grupo C $(0,13 \pm 0,02 \%)$. A avaliação histológica do córtex renal mostra as alterações na estrutura dos néfrons tais como: edema intersticial, perda da borda em escova, necrose tubular, achatamento das células tubulares e dilatação dos túbulos renais. Essas alterações sugerem que a $A n f B / E L$ associada a deficiência de 
vitamina D aumenta a toxicidade. A figura 6 e a tabela 3 representam os achados de todos os grupos experimentais em relação ao escore de lesão.
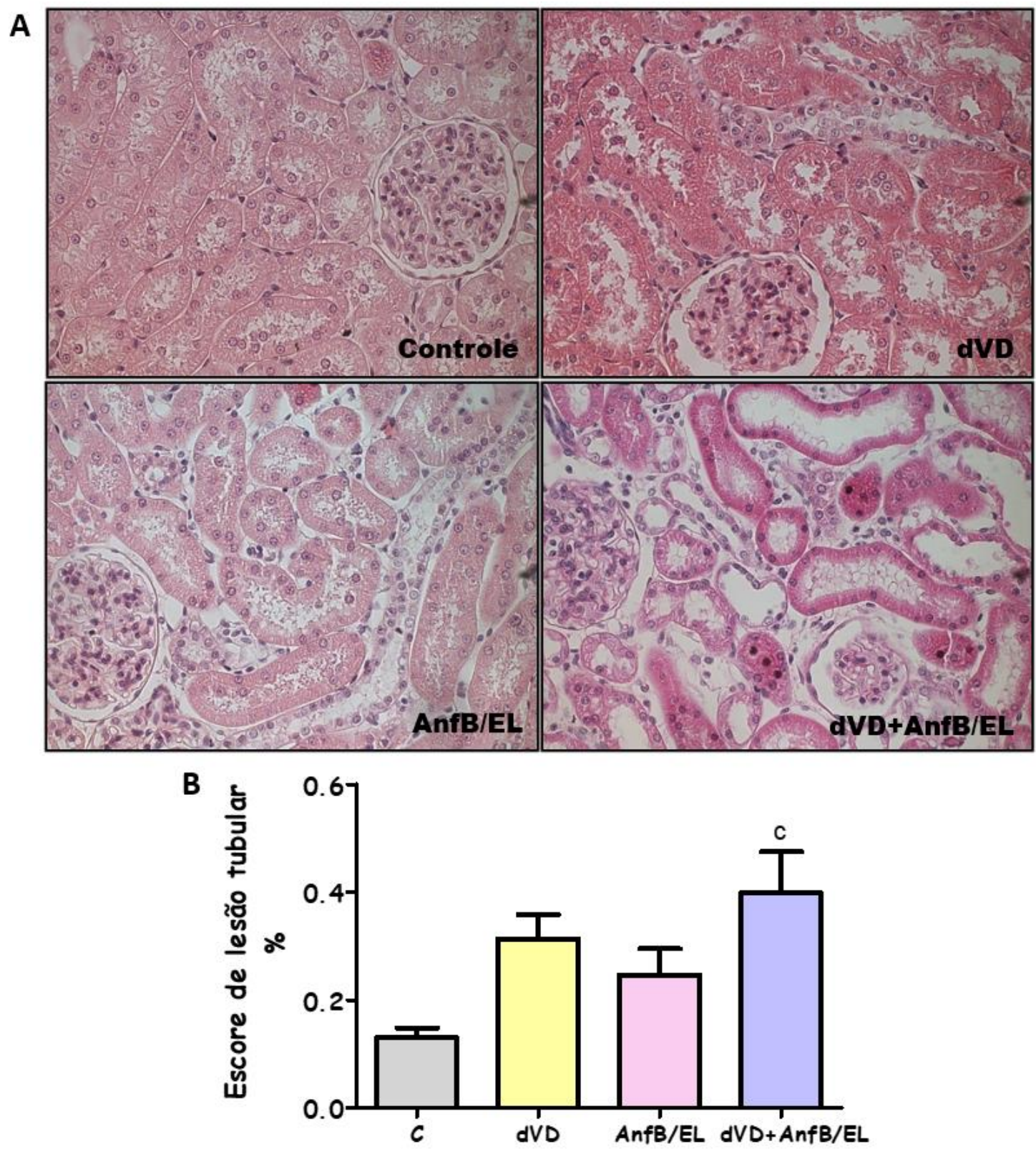

Figura 6 - Escore de lesão tubular. (A) Fotomicrografias representativas de lesão tubular em ratos Controle, dVD, AnfB/EL e dVD+AnfB/EL. 400x. (B) Gráfico de barras do escore de lesão tubular em ratos controle $(C, n=5)$, deficientes em vitamina $D(d V D, n=6)$, controles que receberam Anfotericina $B$ Emulsão Lipídica, (AnfB/EL, $n=6)$ e deficientes em vitamina $D$ que receberam Anfotericina B Emulsão Lipídica (dVD+AnfB/LE, $n=6)$. Valores expressos em média \pm EPM. ${ }^{c} p<0.05$ vs. $C$.

O grupo dVD+AnfB/EL (148 $\pm 5 \mathrm{mmHg})$ mostrou um maior aumento da PAM quando comparado aos grupos dVD $(129 \pm 4 \mathrm{mmHg})$ e AnfB/EL $(131 \pm 5$ 
$\mathrm{mmHg}$ ), apresentando um aumento ainda maior quando comparado ao grupo $\mathrm{C}$

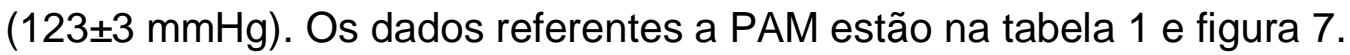

\section{Pressão Arterial Média}

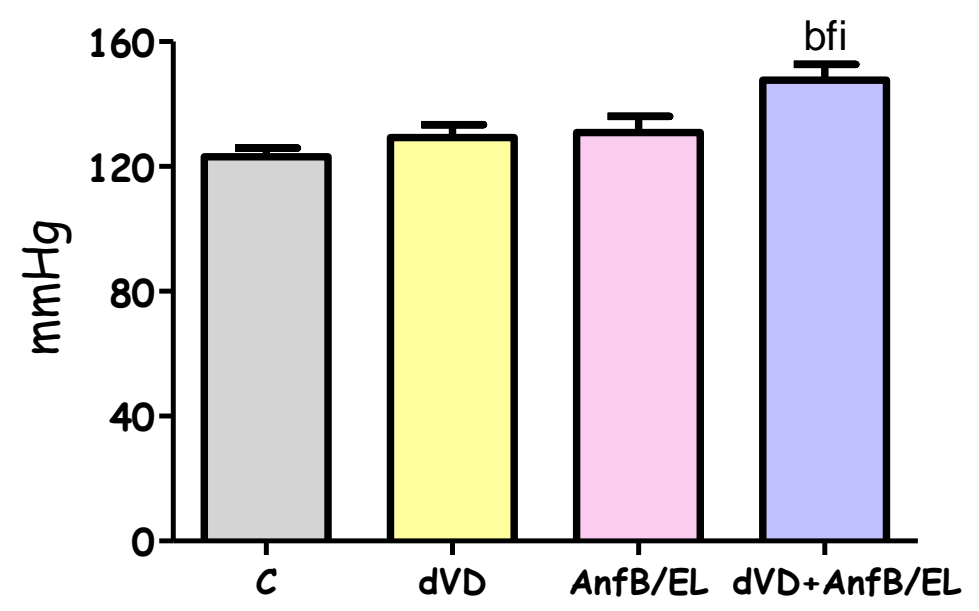

Figura 7 - Pressão Arterial Média. Gráfico de barras da pressão arterial média de ratos controles $(C, n=8)$, deficientes em vitamina $\mathrm{D}(\mathrm{dVD}, \mathrm{n}=6)$, controles que receberam Anfotericina B Emulsão Lipídica, (AnfB/EL, $n=7$ ) e deficientes em vitamina $D$ que receberam Anfotericina $B$ Emulsão Lipídica (dVD+AnfB/LE, $n=9$ ). Valores expressos em média \pm EPM. ${ }^{b} p<0.01$ vs. $C$ e ${ }^{f} p<0,05$ vs. dVD e ${ }^{i} p<0,05$ vs. AnfB/EL.

A expressão renal dos componentes do sistema renina-angiotensina é dada na Figura 8. O AGT e a ECA exibiram um aumento bastante significativo nos grupos experimentais em relação ao controle. A aldosterona plasmática apresentou níveis aumentados no grupo dVD+AnfB/EL (4274 $\pm 345 \mathrm{pg} / \mathrm{mL})$ quando comparado aos grupos C (1465 $\pm 126 \mathrm{pg} / \mathrm{mL}), \mathrm{dVD}(1656 \pm 72 \mathrm{pg} / \mathrm{mL})$ e AnfB/EL (3572 \pm 304 pg/mL), corroborando os dados relacionados a elevação da pressão arterial e demonstrando a influência da aldosterona no desenvolvimento da hipertensão arterial. Importante ressaltar que os animais dos grupos tratados com AnfB/EL exibiram um aumento ainda maior nesse parâmetro. Os dados referentes aos níveis de aldosterona plasmática estão representados na figura 9 e na tabela 2. Em conjunto, estes dados confirmam um possível envolvimento 


\section{Expressão Proteica de AGT}

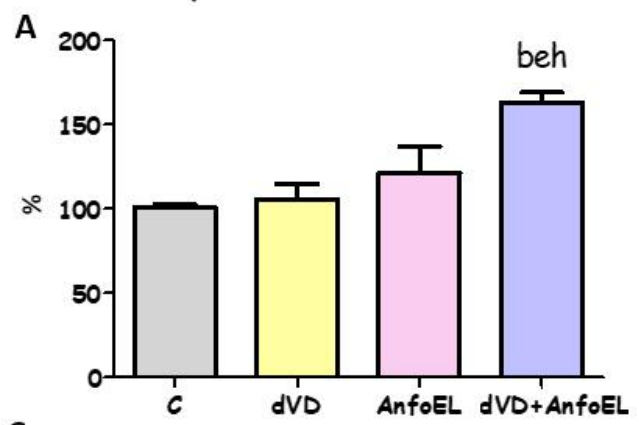

C

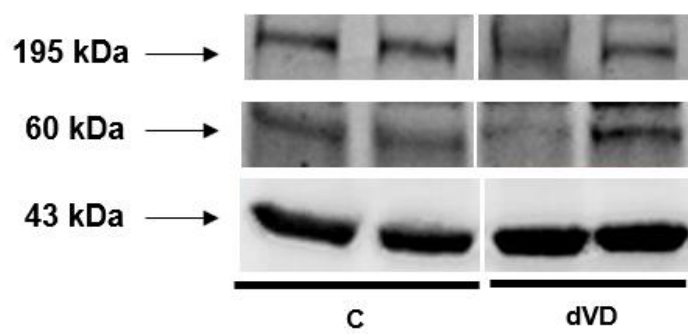

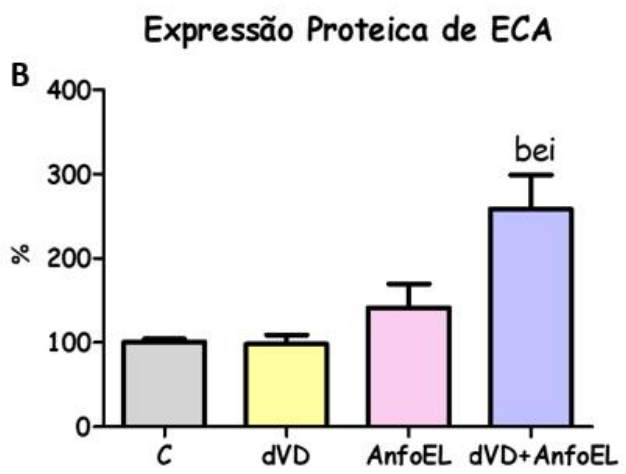

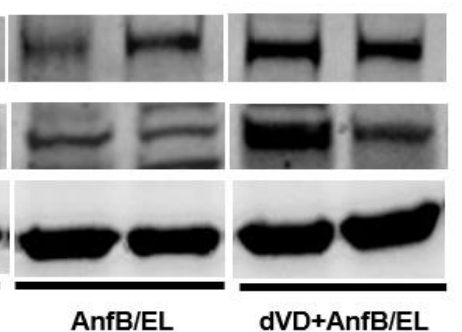

ECA

AGT

Actina

Figura 8 - Imunoblotting semiquantitativo do tecido renal para angiotensinogênio (AGT) e enzima conversora de angiotensina (ECA). (A) Análises densitométricas de amostras de ratos controle $(C, n=8$, deficientes em vitamina $D(d V D, n=8)$, controles que receberam $A n f B / E L(A n f B / E L, n=8)$ e deficientes em vitamina $D$ que receberam $A n f B / E L(d V D+A n f B / E L, n=8)$. (B) Imunotransferências reagiram com anti-AGT e anti-ACE revelando uma banda de $60 \mathrm{kDa}$ e $195 \mathrm{kDa}$, respectivamente. Valores expressos em média \pm EPM. ${ }^{b} p 0,01$ vs. C; ${ }^{e} p<0,01$ vs. dVD; ${ }^{h} p<0,01$ e $p<0,05$ vs. AnfB / EL

\section{Aldosterona Plasmática}

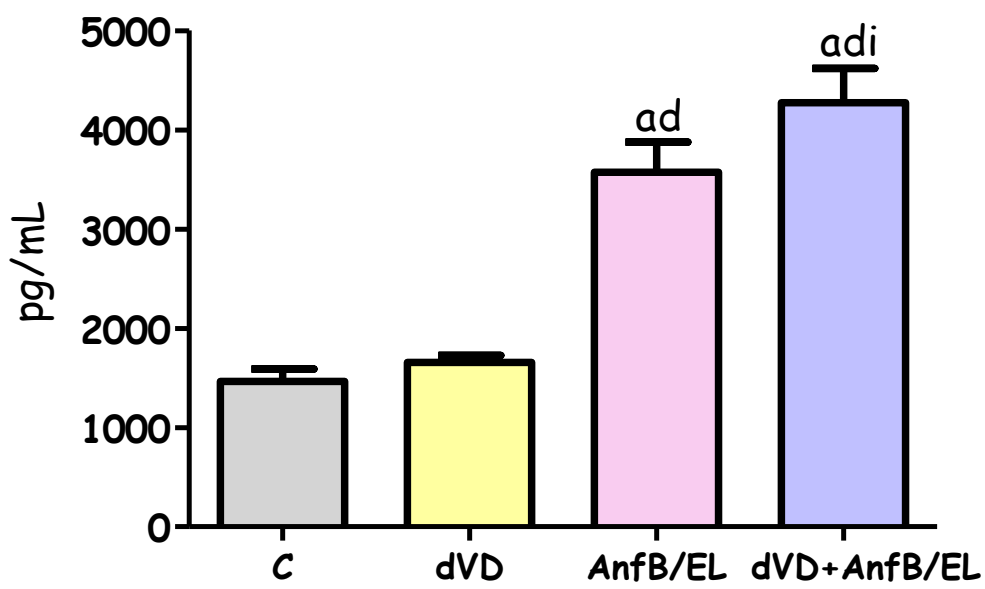

Figura 9 - Concentração de aldosterona plasmática. Gráfico em barras da concentração de aldosterona plasmática de ratos controles $(C, n=6)$, deficientes em vitamina $D(d V D, n=6)$, controles que receberam Anfotericina $B$ Emulsão Lipídica, $(A n f B / E L, n=6)$ e deficientes em vitamina $D$ que receberam Anfotericina $B$ Emulsão Lipídica (dVD+AnfB/LE, $n=6$ ). Valores expressos em média $\pm E P M$. ${ }^{a} p<0.001$ vs. $C ;{ }^{d} p<0.001$ vs. dVD e ' $\mathrm{p}<0.05$ vs. AnfB/EL. 
A associação da deficiência de vitamina $D$ e o tratamento com AnfB/EL resultou em um aumento significativo do volume urinário $(31,6 \pm 2,1 \mathrm{mg} / 24 \mathrm{~h})$ em relação aos grupos estudados $(C=17,63 \pm 1,1, \quad d V D=26,0 \pm 1,3 \quad e$ $A n f B / E L=24,1 \pm 0,7 \mathrm{mg} / 24 \mathrm{~h})$. Os grupos dVD e AnfB/EL também apresentaram uma elevação do volume urinário quando comparados ao grupo C. Essa alteração foi acompanhada de uma discreta diminuição da osmolalidade urinária nos grupos dVD (656 $\pm 64 \mathrm{mOsm} / \mathrm{kgH} 2 \mathrm{O})$ e AnfB/EL $(635 \pm 32 \mathrm{mOsm} / \mathrm{kgH} 2 \mathrm{O})$ quando comparados com o grupo controle (1028 $\pm 89 \mathrm{mOsm} / \mathrm{kgH} 2 \mathrm{O})$. O aumento do volume urinário no grupo $\mathrm{dVD}+\mathrm{AnfB} / \mathrm{EL}$ vai de encontro com a diminuição importante da osmolalidade urinária nesse mesmo grupo (367 \pm 21 $\mathrm{mOsm} / \mathrm{kgH} 2 \mathrm{O}$ ). A figura 10 e a tabela 2 ilustram os dados referentes ao volume e osmolalidade urinários.
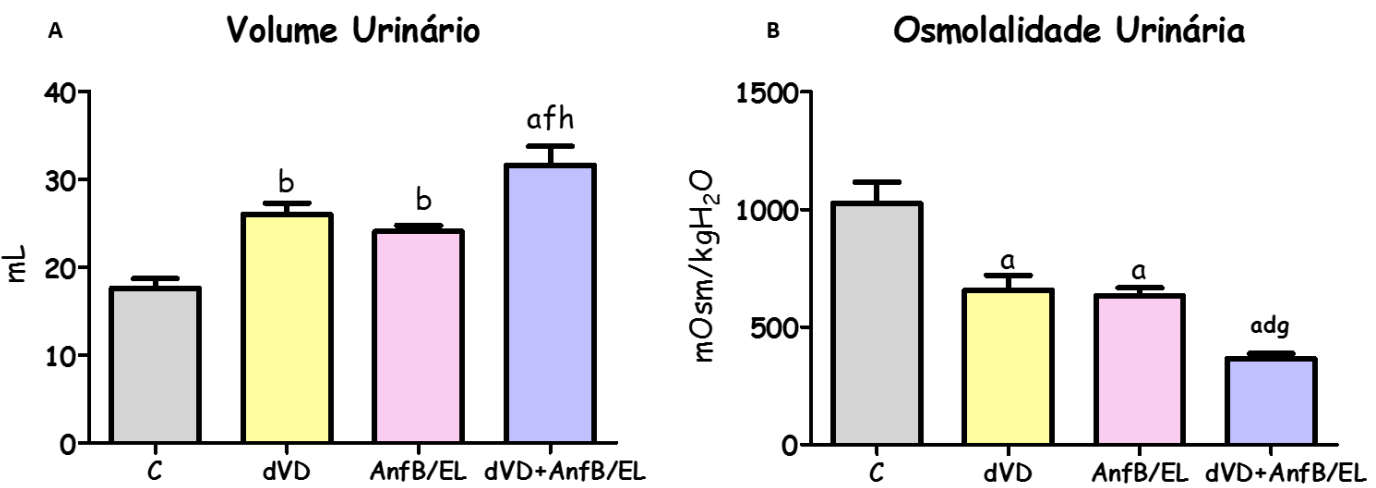

Figura 10 - Volume e Osmolalidade Urinaria. Gráfico em barras do Volume Urinário $(\mathrm{A})$ e Osmolalidade Urinaria $(B)$ de ratos controle $(C, n=8)$, deficientes em vitamina $D(d V D, n=6)$, controles que receberam anfotericina $B$ Emulsão Lipídica (AnfB/EL, $n=7$ ) e deficientes em vitamina $D$ que receberam Anfotericina $B$ Emulsão Lipídica (dVD+AnfB/LE, $n=9$ ). Valores expressos em média \pm EPM. ${ }^{a} p<0.001$ e ${ }^{b} p<0.01$ vs. $C$, ${ }^{d} p<0,001 e^{f} p<0,05$ vs. $d V D,{ }^{g} p<0,001 e^{h} p<0,01$ vs. AnfB/EL.

Os dados da expressão de aquaporina 2 (AQP2) no tecido renal reforçam os dados obtidos no que se refere ao balanço de água. A AQP2 apresentou-se 
diminuída nos grupos dVD, AnfB/EL e dVD+AnfB/EL $(75 \pm 15 \%$, 43 $\pm 2 \%$ e $46 \pm 6 \%$,

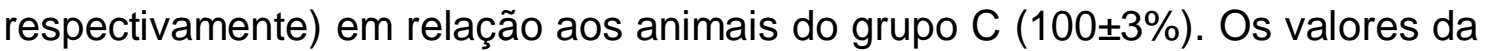
expressão de AQP2 estão representados na figura 11 e na tabela 3.

A Expressão Proteica de Aquaporina 2

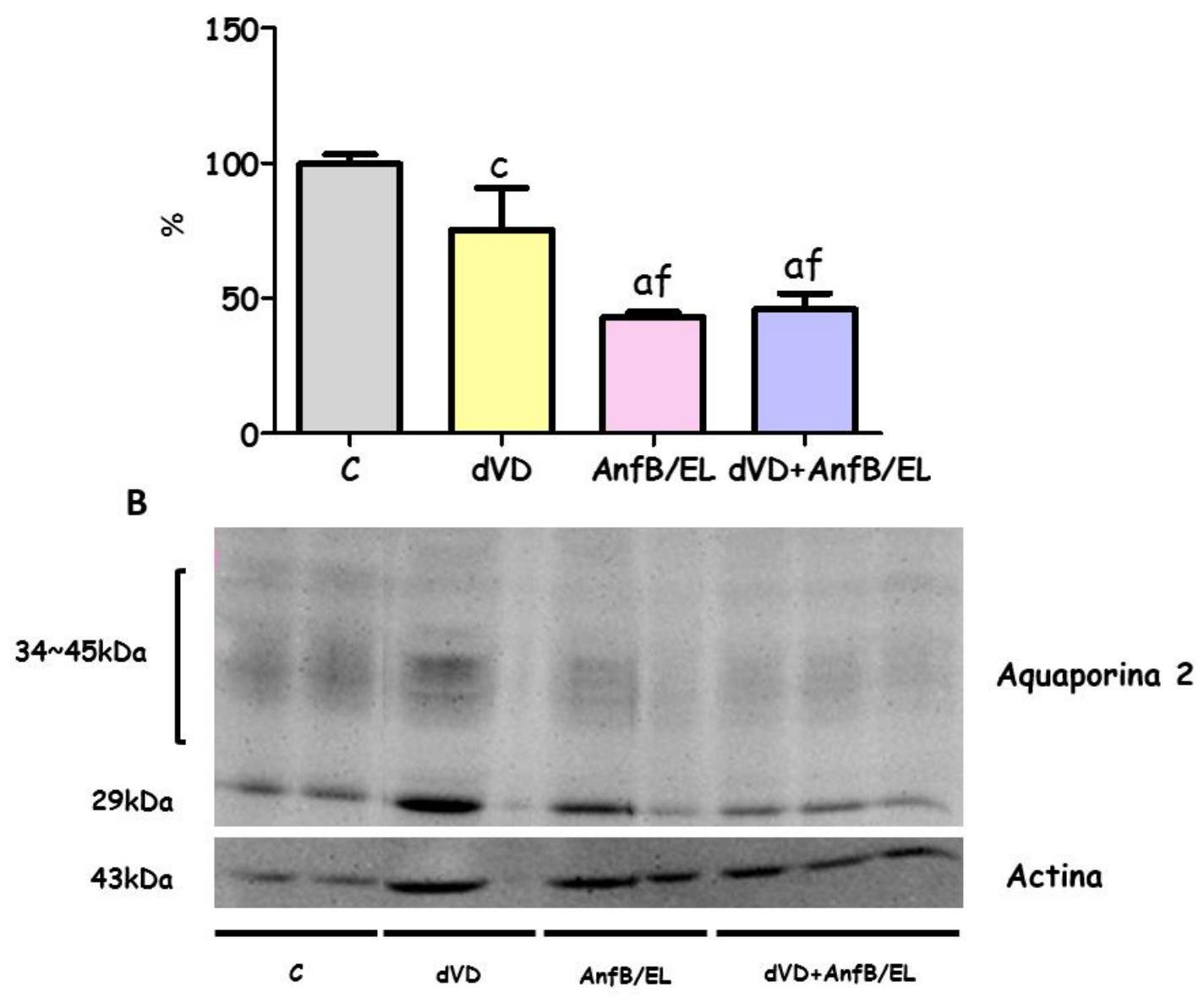

Figura 11 - Imunoblotting semiquantitativo do tecido renal para expressão proteica de Aquaporina 2. (A) Densitometria das amostras de ratos controles $(C, n=4)$, deficientes em vitamina $D(d V D, n=6)$, controles que receberam $A n f B / E L(A n f B / E L, n=6)$ e deficientes em vitamina $D$ que receberam $A n f B / E L$ (dVD+AnfB/EL, $n=6)$. (B) Foto ilustrativa da expressão de AQP2 e actina no tecido renal. Valores expressos em média \pm EPM. ${ }^{a} p<0,001 e^{c} p<0,05$ vs. $C ;{ }^{f} p<0,05$ vs. dVD.

Os níveis plasmáticos de sódio e potássio não apresentaram alterações entre os grupos estudados. As concentrações plasmáticas de cálcio e de fósforo estavam reduzidas nos grupos que receberam a dieta livre de vitamina D. Esses resultados eram esperados, uma vez que a composição da dieta tem menor 
concentração de cálcio e fósforo $(0,4 \%$ CA e $0,4 \% \mathrm{P})$ em comparação com a dieta padrão. Os animais dos grupos dVD $(6,4 \pm 0,3 \mathrm{mg} / \mathrm{dL})$ e AnfB/EL $(5,5 \pm 0,4$ $\mathrm{mg} / \mathrm{dL}$ ) apresentaram uma diminuição das concentrações de fósforo em relação ao grupo $C(8,3 \pm 0,34 \mathrm{mg} / \mathrm{dL})$, indicando que tanto a dieta depletada em vitamina D quanto o tratamento com $A n f B / E L$ por si só induzem a hipofosfatemia. A associação da deficiência de vitamina $D$ e o tratamento com AnfB/EL $(4,6 \pm 0,3 \mathrm{mg} / \mathrm{dL})$ levou a uma diminuição importante na concentração plasmática de fósforo.

A concentração de cálcio plasmático também foi diminuída nos animais deficientes em vitamina $D(d V D=0,94 \pm 0,03$ e $d V D+A n f B / E L=0,96 \pm 0,04)$, independente do tratamento com $A n f B / E L$, em relação aos animais do grupo controle $(1,21 \pm 0,03 \mathrm{mmol} / \mathrm{L})$. O grupo AnfB/EL $(1,17 \pm 0,02 \mathrm{mmol} / \mathrm{L})$ manteve seus índices de cálcio próximos aos do controle. Os valores referentes as concentrações plasmáticas dos íons sódio, potássio, fósforo e cálcio estão representados na tabela 2 e na figura 12.
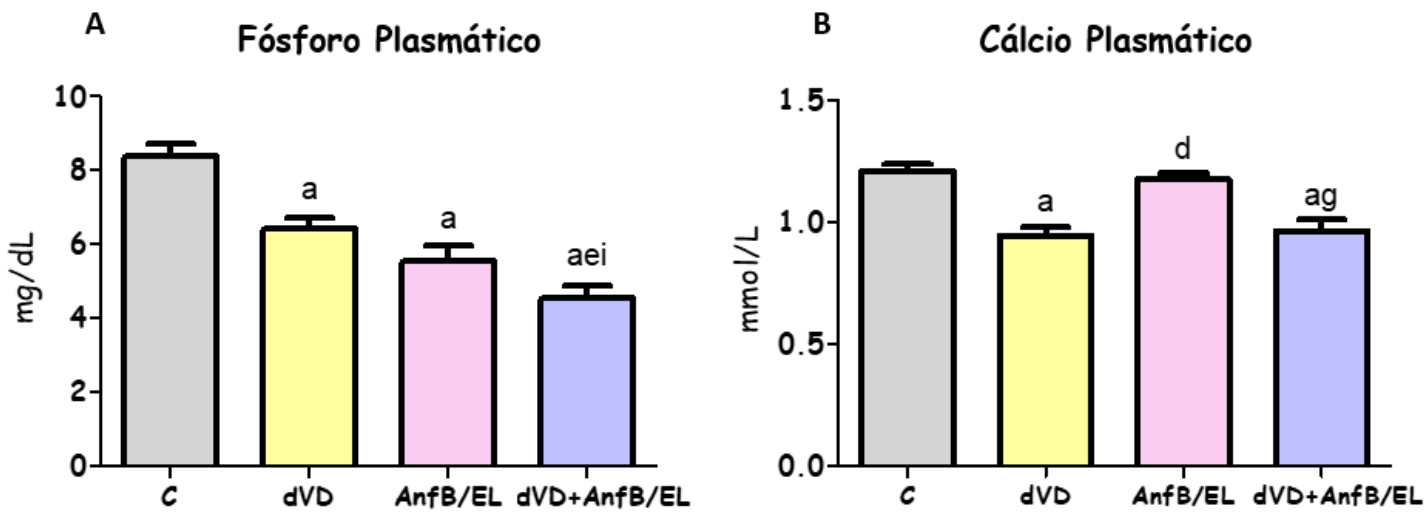

Figura 12 - Concentrações plasmáticas de fósforo e cálcio. Gráfico em barras da concentrações plasmáticas de fósforo $(A)$ e cálcio $(B)$ de ratos controles $(C, n=8)$, deficientes em vitamina $D(d V D, n=6)$, controles que receberam anfotericina B Emulsão Lipídica, AnfB/EL, $n=7$ ) e deficientes em vitamina $D$ que receberam Anfotericina B Emulsão Lipídica (dVD+AnfB/LE, $n=9$ ). ${ }^{a} p<0,001$ vs. $C,{ }^{d} p<0,001$ e ${ }^{e} p<0,01$ vs. $d V D,{ }^{9} p<0,001$ e ip<0,05 vs. AnfB/EL. 
A excreção urinária de fósforo apresentou uma elevação nos grupos dVD (23,9 $\pm 1,5 \mathrm{mg} / \mathrm{dia})$, AnfB/EL $(21,7 \pm 1,0 \mathrm{mg} / \mathrm{dia})$ e dVD+AnfB/EL $(20,9 \pm 1,3 \mathrm{mg} / \mathrm{dia})$ em relação ao grupo $C(16,8 \pm 1,4 \mathrm{mg} / \mathrm{dia})$. Corroborando esses achados, a expressão do NaPI-Ila está diminuída em aproximadamente 30\% no grupo que recebeu $A n f B / E L$ e $40 \%$ nos animais deficientes em vitamina $D$ que receberam a $A n f B / E L$, demonstrando que o aparecimento da hiperfosfatúria nesses animais está relacionada com o comprometimento do cotransportador sódio/fosfato. Os dados relacionados a excreção urinária de fósforo e da expressão proteica do NaPI-Ila estão descritos nas tabelas 2 e 3 e nas figuras 13 e 14 .

\section{Excreção Urinária de Fósforo}

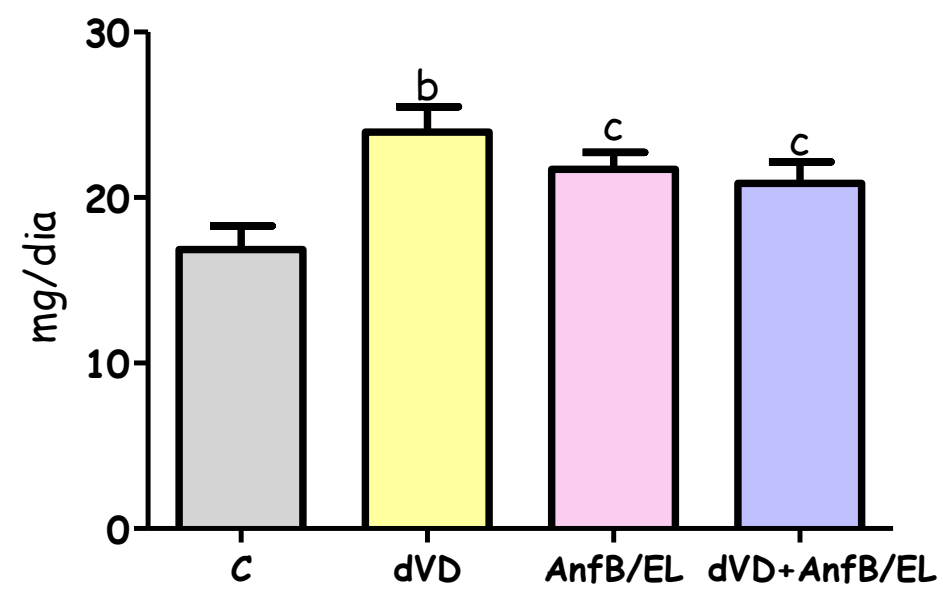

Figura 13 - Excreção Urinária de Fósforo. Gráfico em barras da excreção Urinária de Fósforo de ratos controles $(C, n=8)$, deficientes em vitamina $D(d V D, n=8)$, controles que receberam Anfotericina $B$ Emulsão Lipídica, (AnfB/EL, $n=8$ ) e deficientes em vitamina $D$ que receberam Anfotericina $B$ Emulsão Lipídica $(\mathrm{dVD}+\mathrm{AnfB} / \mathrm{LE}, \mathrm{n}=8)$. Valores expressos em média \pm EPM. ${ }^{b} \mathrm{p}<0.01 \mathrm{e}^{\mathrm{c}} \mathrm{p}<0,05 \mathrm{vs}$. $C$. 
A

\section{Expressão Proteica de NaPi-IIa}

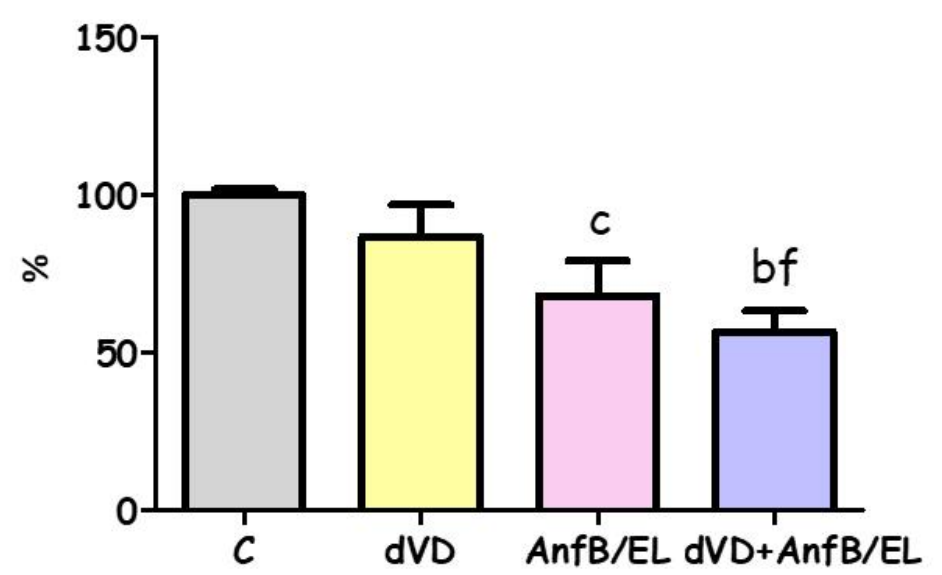

B

c dVD AnfB/EL dVD+AnfB/EL

$83 \mathrm{kDa}$

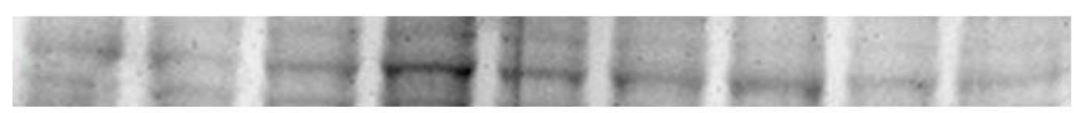

$\mathrm{NaPi}-\mathrm{IIa}$

$43 \mathrm{kDa}$

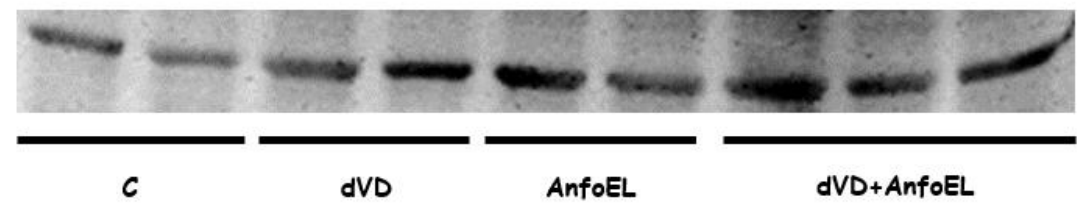

Actina

Figura 14 - Imunoblotting semiquantitativo do tecido renal para expressão proteica do cotransportador sódio/fosfato (NaPI-lla). (A) Gráfico de barras da expressão proteica do cotransportador $\mathrm{NaPI}$-lla no tecido renal de ratos controles $(C, n=4)$, deficientes em vitamina $D(d V D, n=6)$, controles que receberam AnfB/EL (AnfB/EL, $n=6$ ) e deficientes em vitamina $D$ que receberam AnfB/EL ( $d V D+A n f B / E L$, $\mathrm{n}=6$ ). (B) Foto ilustrativa da expressão de TRPM6 e actina no tecido renal. Valores expressos em média \pm EPM. ${ }^{b} p<0,01$ e ${ }^{c} p<0,05$ vs. C, ${ }^{f} p<0,05$ vs. dVD.

Adicionalmente, algumas alterações foram encontradas no eixo PTHKlotho-FGF-23. Referente à concentração plasmática de PTH intacto, os grupos dVD $(465,8 \pm 87,1 \mathrm{pg} / \mathrm{mL}), \quad$ AnfB/EL $(400,9 \pm 58,4 \mathrm{pg} / \mathrm{mL})$ e dVD+AnfB/EL $(406,5 \pm 112,5 \mathrm{pg} / \mathrm{mL})$ evidenciaram um aumento quando relacionados ao grupo C $(86,5 \pm 11,2 \mathrm{pg} / \mathrm{mL})$. Os níveis plasmáticos do hormônio FGF-23 exibiram uma redução nos grupos dVD (80,2 $\pm 7,2 \mathrm{pg} / \mathrm{mL})$ e dVD+AnfB/EL $(70,8 \pm 5,0 \mathrm{pg} / \mathrm{mL})$ quando comparados aos grupos C $(139,7 \pm 10,6 \mathrm{pg} / \mathrm{mL})$ e AnfB/EL $(115,0 \pm 12,70$ $\mathrm{pg} / \mathrm{mL}$ ). Os níveis plasmáticos de PTH intacto e FGF-23 estão representados na tabela 2 e na figura 15. 

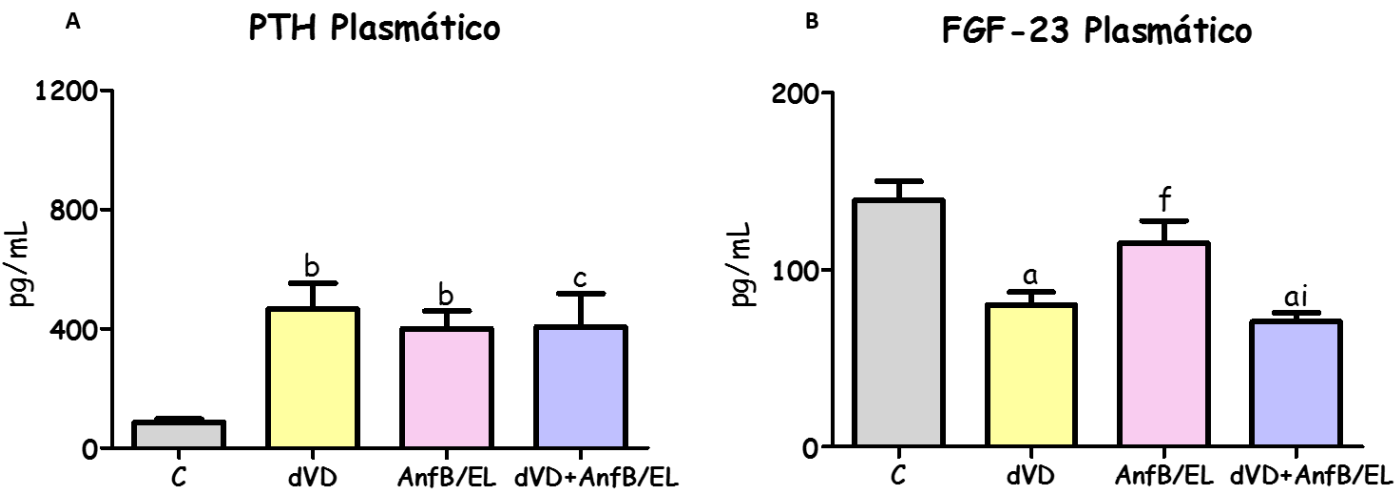

Figura 15 - Concentrações plasmáticas de PTH intacto e FGF-23. Gráfico em barras da concentrações plasmáticas de PTH intacto (A) e FGF-23 (B) de animais controles $(C, n=8$, deficientes em vitamina $D(d V D$, $n=8)$, controles que receberam $A n f B / E L(A n f B / E L, n=8)$ e deficientes em vitamina $D$ que receberam $A n f B / E L$ (dVD+AnfB/EL, $n=8$ ). Valores expressos em média \pm EPM. ${ }^{a} p<0,001,{ }^{b} p<0,01$ e ${ }^{c} p<0,05$ vs. $C ;{ }^{f} p<0,05$ vs. $d V D$ e $\mathrm{p} p<0,05$ vs. AnfB/EL.

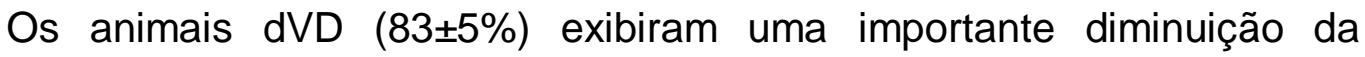

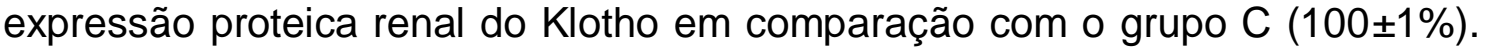

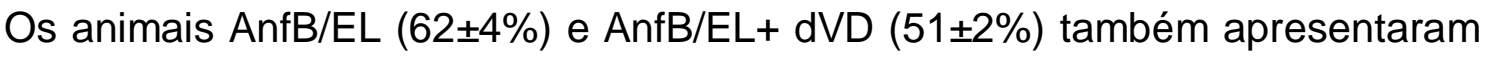
uma menor e mais acentuada expressão do Klotho em comparação com os grupos $C$ edVD. Esses resultados sugerem que tanto a hipovitaminose $D$ quanto o tratamento com AnfB/EL podem alterar o eixo PTH-Klotho-FGF-23, agravando a nefrotoxicidade. Estes dados estão representados na tabela 3 e figura 16. 


\section{Expressão Proteica de Klotho}

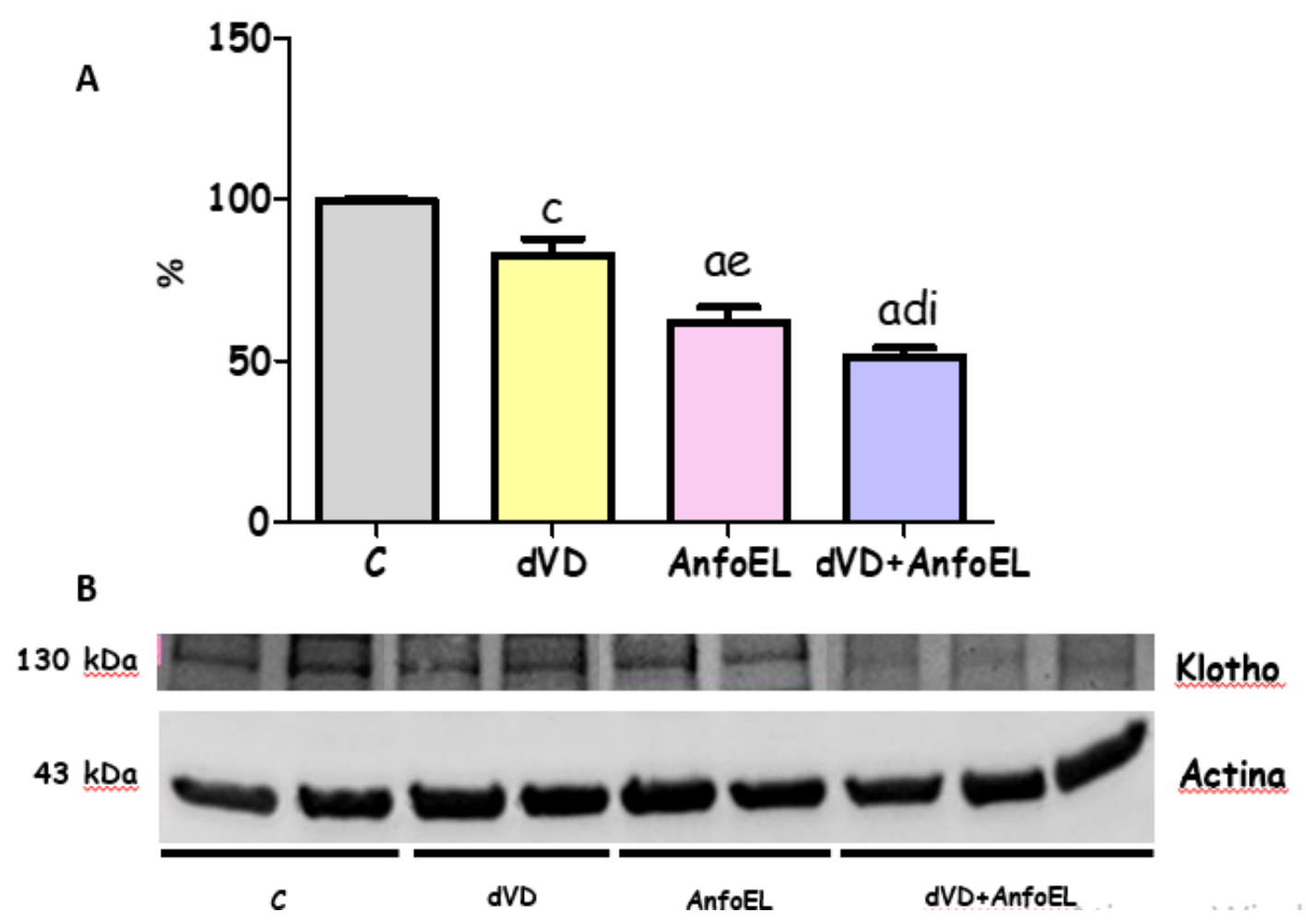

Figura 16 - Imunoblotting semiquantitativo do tecido renal para expressão proteica de Klotho. Gráfico em barras da expressão proteica de Klotho (A). Foto ilustrativa da expressão de Klotho e actina no tecido renal $(B)$ de animais controles $(C, n=8$, deficientes em vitamina $D(d V D, n=8)$, controles que receberam AnfB/EL ( $A n f B / E L, n=8$ ) e deficientes em vitamina $D$ que receberam AnfB/EL (dVD+AnfB/EL, $n=8$ ). Valores expressos em média \pm EPM. ${ }^{a} p<0,001$ e ${ }^{a} p<0,05$ vs. $C,{ }^{d} p<0,001$ e ${ }^{e} p<0,01$ vs $d V D$ e $p<0,05$ vs. AnfB/EL.

A excreção urinária de magnésio dos animais do grupo dVD+AnfB/EL $(3,2 \pm 0,3 \mathrm{mg} / \mathrm{dia})$ apresentou um aumento importante quando comparados aos demais grupos, $C(1,9 \pm 0,1 \mathrm{mg} / \mathrm{dia}), \mathrm{dVD}(1,8 \pm 0,1 \mathrm{mg} / \mathrm{dia})$ e AnfB/EL $(2,0 \pm 0,1$ $\mathrm{mg} /$ dia). Os níveis plasmáticos de magnésio foram semelhantes em todos os grupos estudados. Os dados referentes a concentração plasmática e excreção urinária de magnésio estão representados na tabela 2 e na figura 17. 


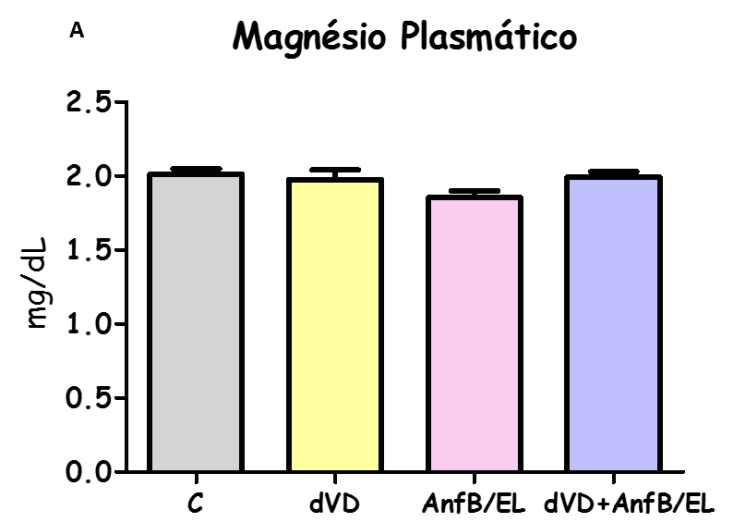

B Excreção Urinária de Magnésio

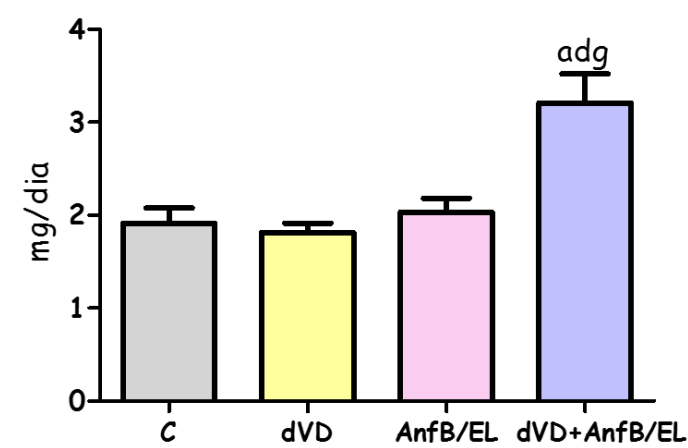

Figura 17 - Concentração plasmática e excreção urinária de magnésio. Gráfico em barras da concentração plasmática $(A)$ e excreção urinária $(B)$ de magnésio de ratos controles $(C, n=8)$, deficientes em vitamina $D(d V D, n=6)$, controles que receberam Anfotericina B Emulsão Lipídica, (AnfB/EL, $n=7)$ e deficientes em vitamina $D$ que receberam Anfotericina B Emulsão Lipídica ( $d V D+A n f B / L E, n=9$ ). Valores expressos em média \pm EPM. ${ }^{a} p<0.001$ vs. $C,{ }^{d} p<0,001$ vs. dVD e ${ }^{9} p<0,001$ vs. AnfB/EL.

A expressão proteica do transportador de magnésio (TRPM6), apresentou

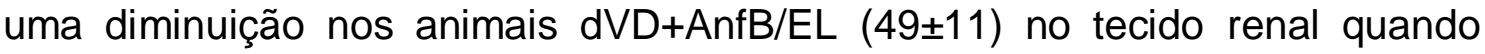

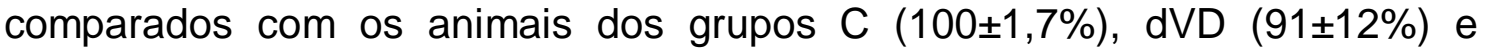

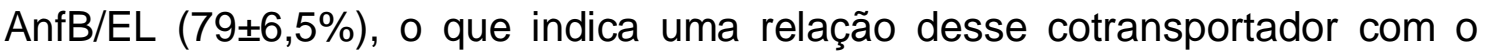
aumento da excreção de magnésio no grupo deficiente de vitamina $D$ tratados com AnfB/EL. Esses dados podem ser encontrados na tabela 3 e na figura 18. 


\section{A Expressão Proteica de TRPM6}

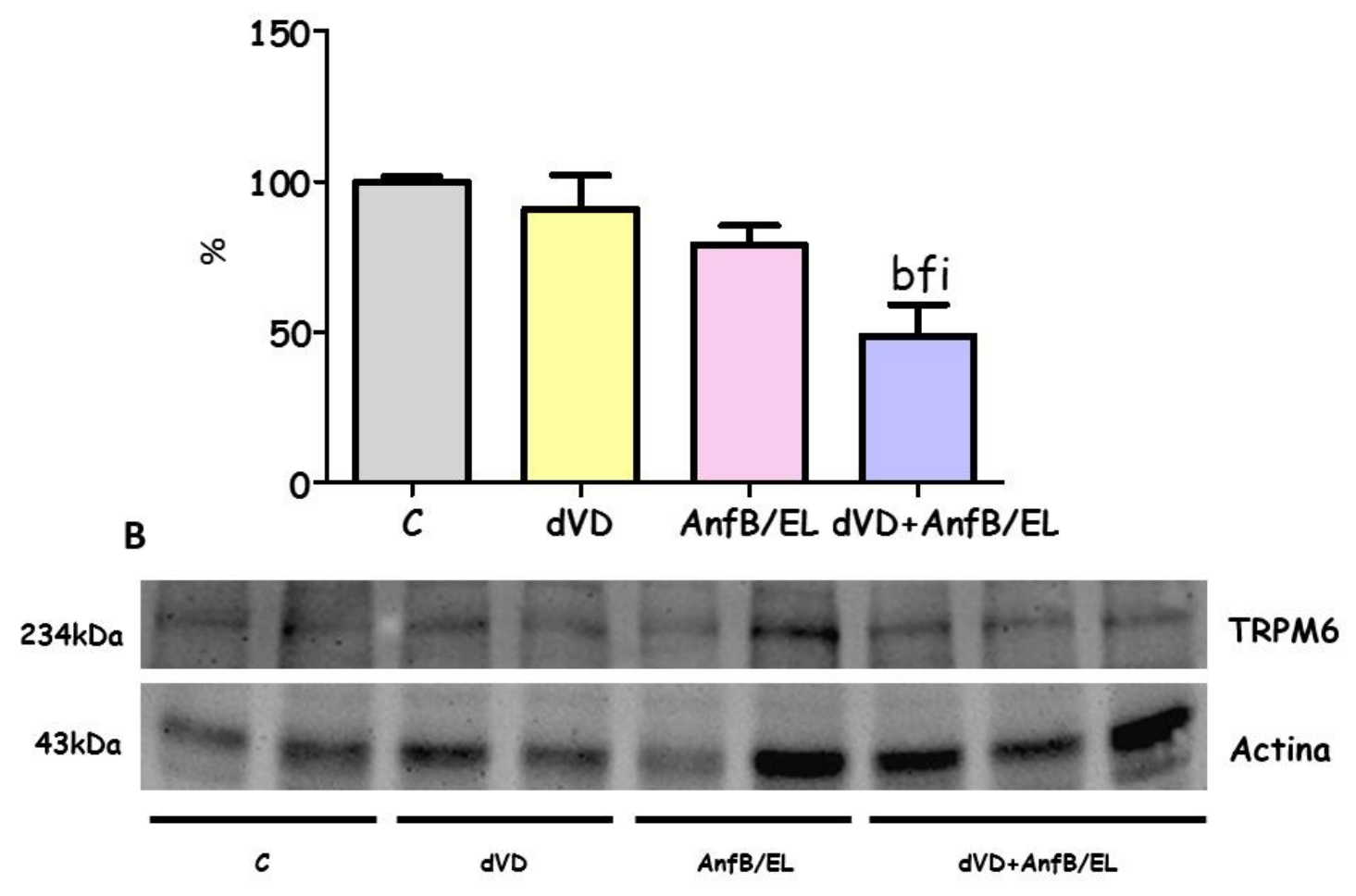

Figura 18 - Imunoblotting semiquantitativo do tecido renal para expressão proteica do transportador TRPM6. (A) Gráfico em barras da expressão proteica do TRPM6 das amostras de ratos controles (C, $n=4)$, deficientes em vitamina $D(d V D, n=6)$, controles que receberam AnfB/EL (AnfB/EL, $n=6)$ e deficientes em vitamina $D$ que receberam $A n f B / E L$ (dVD+AnfB/EL, $n=6$ ). (B) Foto ilustrativa da expressão de TRPM6 e actina no tecido renal. Valores expressos em média \pm EPM. ${ }^{b} p<0,01$ vs. $C,{ }^{p} p<0,05$ vs. $d V D$ e ${ }^{i} p<0,05$ vs. AnfB/EL. 


\section{Discussão}

A AnfB é a droga de escolha para o tratamento de IFI, no entanto, o seu uso clínico tem sido associado à toxicidade renal. Na tentativa de melhorar o efeito terapêutico e reduzir as reações adversas, principalmente a nefrotoxicidade, foram desenvolvidas formulações lipídicas [6, 26, 31]. Entre essas formulações, uma preparação extemporânea de emulsão lipídica de AnfB é uma alternativa de menor custo com benefícios semelhantes [13, 27]. Além disso, estudos têm mostrado uma alta prevalência de hipovitaminose $D$ na população em geral, refletindo sobre um pior prognóstico em casos de injúria renal aguda e nefrotoxicidade induzida por drogas [40, 41, 49]. Neste estudo, mostramos que a associação de dVD e AnfB/EL levou ao comprometimento da função renal, hipertensão e defeito de concentração urinária.

Nosso trabalho mostrou que os animais dVD apresentaram comprometimento da função renal, evidenciado pela diminuição da taxa de filtração glomerular, maior concentração urinária de ureia, hiperfosfatúria, hipermagnesúria, proteinúria e o aparecimento de lesão tubular discreta. É bem conhecido que a nefrotoxicidade induzida pela AnfB é devida a interação da mesma com o ergosterol, que constitui a parede celular fúngica, resultando na formação de poros na membrana lipídica, fluxo eletrolítico defeituoso e perda de viabilidade celular [12, 15, 50]. Além disso, estudos experimentais e clínicos relataram que o tratamento com AnfB leva à abertura de poros na membrana basal, alteração dos cilindros e detritos intratubulares, perda grave da borda em escova, vacuolização de células tubulares e protrusão de células no lúmen do túbulo proximal e necrose das células tubulares [51, 52]. No entanto, um estudo 
anterior do nosso laboratório relatou que a associação de AnfB e emulsão lipídica reduziu eficientemente a toxicidade renal [13]. Por outro lado, nossos resultados também mostraram que o AnfB/EL não alterou a TFG ou a morfologia renal, sugerindo que a deficiência de vitamina $D$ pode ter um papel importante no desenvolvimento de lesão renal em ratos com dVD + AnfB/EL.

Em nosso estudo, os animias do grupo dVD+ AnfB/EL desenvolveram hipertensão, acompanhada por um notável aumento na expressão da proteína renal do AGT e da ECA, e níveis mais altos de aldosterona plasmática. Segundo Meaudre et al., a AnfB atua diretamente nas células musculares lisas vasculares, resultando em vasoconstrição local e subseqüente elevação da pressão arterial sistêmica. No entanto, os mecanismos envolvidos no surgimento da hipertensão em pacientes tratados com AnfB ainda não estão claros [53]. Por outro lado, é bem conhecido que a vitamina $D$ é um regulador endócrino negativo do SRAA e a ativação inapropriada deste sistema tem sido relacionada à hipertensão [54, 55]. Somado a isso, estudos anteriores demonstraram que o dVD regula a pressão arterial através de efeitos diretos no endotélio vascular, promovendo a hipertensão [41, 56]. Esses fatos nos faz presumir que a dVD associada ao tratamento com AnfB/EL possa ter exacerbado a hipertensão arterial observada neste grupo.

Como esperado, os animais com dVD exibiram hipofosfatemia, hipocalcemia e aumento da concentração plasmática de PTH, uma vez que a deficiência de vitamina $D$ diminui a absorção intestinal de cálcio, resultando em diminuição da concentração de cálcio e aumento da produção de PTH [40]. Curiosamente, o PTH mais elevado tem sido associado ao desenvolvimento de hipertensão devido aos seus efeitos nas células musculares lisas vasculares, 
aumentando o tônus vascular e a pressão arterial $[57,58]$. Além disso, o próprio tratamento com AnfB/EL levou a níveis reduzidos de fosfato plasmático e a associação de dVD com AnfB/EL aumentou significativamente a hipofosfatemia. A maior concentração plasmática de fosfato foi acompanhada de aumento da fosfatúria e diminuição da expressão proteica renal do cotransportador NaPi-Ila nos grupos AnfB/EL e dVD + AnfB/EL, caracterizando uma lesão tubular proximal. É importante salientar que o PTH também induz fosfatúria e o tratamento com calcitriol diminui a excreção urinária de fósforo em um modelo de rato experimental, indicando que a vitamina $D$ pode estimular o transporte renal de fosfato $[59,60]$.

Além disso, Razzaque et al. relataram que, além do PTH e do calcitriol, o FGF-23 pode direta ou indiretamente diminuir a atividade do cotransportador renal $\mathrm{NaPI}-\mathrm{Ila}$, levando à redução da reabsorção de fosfato [61]. Em nosso estudo, verificamos níveis reduzidos de FGF-23 nos animais dVD e dVD + AnfB/EL, compatível com resultado descrito por Rodriguez-Ortiz e cols em um trabalho que avaliou os fatores envolvidos na regulação do FGF-23 [62]. Embora o FGF-23 seja um biomarcador precoce no desenvolvimento da doença renal crônica (DRC), tal decréscimo nos seus níveis se justificaria como resposta compensatória, a fim de restaurar os níveis de vitamina $D$ e o efeito hiperfosfórico [45].

Corroborando os nossos achados, estudos experimentais prévios mostraram que ratos sob progressão de hipovitaminose D e DRC também apresentaram níveis mais baixos de FGF-23 [36, 41]. Estudos recentes sugerem a relação entre o eixo fosfato e FGF-23/Klotho. A expressão proteica de klotho está relacionado ao processo de envelhecimento prematuro e sua deficiência é 
considerada o precursor de desordens minerais associadas à DRC [61, 63, 64]. Os animais com hipovitaminose D exibiram uma ligeira diminuição da expressão renal do kloto em comparação com todos os grupos, em especial, pelo grupo controle. Surpreendentemente, os ratos tratados com AnfB/EL também mostraram uma menor expressão de proteína renal de Klotho em comparação com os grupos Controle e dVD. Esses resultados apontam que a associação da hipovitaminose $D$ com o tratamento com AnfB/EL exacerbou a deficiência de Klotho. Em conjunto, estes resultados indicam que podem alterar o eixo PTHKlotho/FGF-23, agravando a nefrotoxicidade induzida pela AnfB/EL [61, 62, 64, 65].

A hipomagnesemia e a perda renal de magnésio estão bastante associadas ao uso da AnfB convencional do que com as formulações lipídicas, devido a uma alteração tubular na reabsorção de magnésio [10, 66]. Apoiando esses dados previamente mostrados, nossa formulação lipídica de AnfB não alterou a excreção urinária de magnésio. No entanto, a associação de dVD e AnfB/EL levou à hipermagnesúria. A perda renal de magnésio pode ser causada por poliúria ou defeito de reabsorção tubular [67]. A maior excreção urinária de magnésio foi acompanhada pela redução da expressão da proteína renal de TRPM6 em ratos AnfB/EL. O transportador responsável pela regulação e reabsorção do magnésio é o TRPM6, que está presente no lúmen do túbulo contornado distal [66-68]. Em nosso estudo, o dVD possivelmente desempenhou um papel importante no manejo do magnésio no túbulo renal e no aparecimento de hipermagnesúria em animais dVD e AnfB/EL.

Está bem estabelecido que tanto a dVD como o AnfB/EL levaram a um prejuizo da capacidade de concentração renal, evidenciada por maior volume 
urinário em $24 \mathrm{~h}$ e diminuição da osmolalidade urinária [13, 47]. De fato, nossos resultados mostraram que os grupos dVD e AnfB/EL exibiram aumento do volume de urina em $24 \mathrm{~h}$ e diminuição da osmolalidade urinária em comparação com o controle. Somado a isso, a expressão da proteína renal de AQP2 foi diminuída em ratos com dVD e AnfB/EL em comparação com o controle. É conhecido que a AnfB inibe a via estimulatória de sinalização do receptor de arginina vasopressina/vasopressina tipo $2\left(\mathrm{AVP} / \mathrm{V}_{2} \mathrm{R}\right)$, que é responsável pela permeabilidade da água na região medular interna do ducto coletor [69-71], resultando em diminuição da reabsorção de água via AQP2 no ducto coletor do rim $[69,70]$. A combinação de dVD e AnfB/EL resultou em uma poliúria mais severa associada à menor expressão protéica de AQP2, sugerindo que o dVD pode ter exacerbado o defeito de concentração renal na toxicidade renal induzida por AnfB/EL.

Adicionalmente aos dados de função renal, os animais deficientes em vitamina $\mathrm{D}$ apresentaram aumento na excreção urinária de proteínas. Estudos clínicos e experimentais apontam uma relação entre proteinúria e deficiência de vitamina D. Garsen et al. sugerem que a suplementação de vitamina D reduz a perda de podócitos e a proteinúria in vitro e in vivo [12, 44, 72]. Grays et al. demonstram que o tratamento com anfotericina B leva a uremia e esse aumento da toxicidade renal pode ser atribuído à incapacidade de manter os gradientes de ureia no segmento distal do néfron [73]. Os animais que receberam a AnfB/EL não apresentaram alterações nesse parâmetro, indicando que a solubilização da droga à emulsão lipídica foi eficaz na redução da nefrotoxicidade. Berdichevski et al. demonstraram que 0 tratamento com AnfB convencional eleva significativamente a concentração de ureia plasmática e a razão 
proteína/creatinina [12]. Portanto, a associação da deficiência de vitamina D e o tratamento com AnfB/EL leva ao aparecimento de proteinúria e ao aumento da uremia, demonstrando maior comprometimento da função renal neste grupo.

Os animais que receberam a dieta depletada em vitamina $D$ apresentaram hipofosfatemia e hipocalcemia. Essas alterações já eram esperadas uma vez que a dieta oferecida continha níveis reduzidos de cálcio e fósforo em relação a dieta padrão. Adicionalmente, a regulação e excreção de cálcio está associada ao PTH e a vitamina D (1,25-di-hidroxicolecalciferol). O PTH controla a secreção plasmática de $\mathrm{Ca}$ aumentando sua reabsorção no osso, liberando o $\mathrm{Ca}$ no sangue, aumentando sua reabsorção nos túbulos renais e promovendo a ativação da vitamina $D$ que aumenta a reabsorção intestinal de $\mathrm{Ca}$. A baixa concentração de cálcio circulante estimula a secreção do PTH. A hipocalcemia é detectada pelos receptores sensíveis de cálcio nas células principais das paratireoides que estimulam a produção de PTH que, por sua vez, retira cálcio dos ossos. O aumento do PTH ativa a 1a-hidroxilase renal, aumentando os níveis de calcitriol circulante $[58,74,75]$.

Em resumo, nossos resultados demonstram que a deficiência de vitamina D é um fator indutor de nefrotoxicidade associado ao tratamento com AnfB/EL, possivelmente devido ao comprometimento da função renal acompanhada de lesão tubular, aparecimento de hipertensão, alterações no eixo de sinalização PTH-Klotho-FGF-23 e disfunção do balanço hídrico. Vale a pena mencionar que uma preparação interna de emulsão lipídica de AnfB preserva propriedades terapêuticas e não é tão cara quanto as formulações lipídicas farmacêuticas. Dessa forma, é importante o monitoramento dos níveis de vitamina $\mathrm{D}$ tanto em pacientes que fazem uso da AnfB convencional como daqueles que utilizam as 
formulações lipídicas. Mais estudos devem ser realizados com o propósito de compreender os mecanismos que relacionam a hipovitaminose $\mathrm{D}$ com a nefrotoxicidade da $A n f B / E L$, a fim de garantir um melhor prognóstico no desenvolvimento de doenças renais. 


\section{Conclusão}

A partir do estudo realizado podemos concluir que a deficiência de vitamina D agrava a nefrotoxicidade da AnfB. Isso tudo é evidenciado pela a injúria renal aguda, diminuição da taxa de filtração glomerular, lesão tubular discreta, disfunção do balanço hídrico, hipertensão com alteração do SRAA e alteração do eixo PTH-Klotho/FGF23. Além disso, a AnfB/EL preparação interna é menos dispendiosa, reduz eficientemente a nefrotoxicidade da AnfB e preserva sua atividade antifúngica. Deste modo, é essencial monitorar os níveis de vitamina $D$ em ambos os pacientes tratados com formulações convencionais ou lipídicas de AnfB, a fim de garantir um melhor prognóstico no desenvolvimento de doenças renais. 


\section{Anexos}

Tabela 1 - Peso corporal, parâmetros funcionais e hemodinâmicos

\begin{tabular}{lcccc}
\hline & C & dVD & AnfB/EL & dVD+AnfB/EL \\
\hline PC & $340 \pm 7$ & $356 \pm 9$ & $332 \pm 5$ & $340 \pm 5$ \\
Cin & $0,97 \pm 0,04$ & $0,79 \pm 0,02^{\mathrm{c}}$ & $0,99 \pm 0,06^{\mathrm{f}}$ & $0,55 \pm 0,04^{\text {aeg }}$ \\
PAM & $123 \pm 3$ & $130 \pm 4$ & $131 \pm 5$ & $148 \pm 5^{\text {bfi }}$
\end{tabular}

PC, peso corpóreo $(\mathrm{g})$; Cin, clearance de inulina $(\mathrm{mL} / \mathrm{min} / 100 \mathrm{~g})$; PAM, pressão arterial média $(\mathrm{mmHg})$;. Valores expressos em média \pm EPM. ${ }^{a} p<0,001,{ }^{b} p<0,01$ e ${ }^{c} p<0,05$ vs. C; ${ }^{e} p<0,01$ e ${ }^{f} p<0,05$ vs. dVD; ${ }^{9} p<0,001,{ }^{h} p<0,01$ e ${ }^{i} p<0,05$ vs. AnfB/EL

Tabela 2 - Parâmetros bioquímicos

\begin{tabular}{|c|c|c|c|c|}
\hline & C & dVD & AnfB/EL & dVD+AnfB/EL \\
\hline $25(\mathrm{OH}) \mathrm{D}$ & $44,3 \pm 2,4$ & $4,3 \pm 0,4^{a}$ & $45,5 \pm 5,2^{d}$ & $4,4 \pm 0,7^{a g}$ \\
\hline Aldosterona & $1465 \pm 125$ & $1656 \pm 72$ & $3572 \pm 304^{\text {ad }}$ & $4274 \pm 345^{\text {adi }}$ \\
\hline PTH intacto & $86,5 \pm 11,2$ & $465,8 \pm 87,1^{b}$ & $400,9 \pm 58,4^{b}$ & $406,5 \pm 112,5^{c}$ \\
\hline FGF23 & $139,4 \pm 10,6$ & $80,2 \pm 7,2^{a}$ & $115,0 \pm 12,7^{f}$ & $70,8 \pm 5,0^{\text {ai }}$ \\
\hline Ureia & $49 \pm 1$ & $51 \pm 4$ & $77 \pm 9$ & $152 \pm 28^{\mathrm{adh}}$ \\
\hline$P_{\mathrm{Na}}$ & $138 \pm 1$ & $139 \pm 1$ & $141 \pm 1$ & $140 \pm 1$ \\
\hline$P_{K}$ & $4,5 \pm 0,1$ & $4,7 \pm 0,1$ & $4,1 \pm 0,3$ & $4,4 \pm 0,1$ \\
\hline $\mathrm{P}_{\mathrm{Ca}}$ & $1,20 \pm 0,02$ & $0,94 \pm 0,03^{a}$ & $1,17 \pm 0,02^{d}$ & $0,96 \pm 0,04^{\mathrm{ag}}$ \\
\hline $\mathrm{PP}_{\mathrm{P}}$ & $8,3 \pm 0,3$ & $6,4 \pm 0,3^{a}$ & $5,5 \pm 0,4^{a}$ & $4,6 \pm 0,3^{\text {aeh }}$ \\
\hline$P_{M g}$ & $2,01 \pm 0,03$ & $1,98 \pm 0,06$ & $1,85 \pm 0,04$ & $1,99 \pm 0,03$ \\
\hline VU & $17 \pm 1$ & $26 \pm 1^{b}$ & $24 \pm 1^{b}$ & $32 \pm 2^{\text {afh }}$ \\
\hline Uosm & $1028 \pm 89$ & $656 \pm 64^{a}$ & $635 \pm 32^{a}$ & $367 \pm 21^{\text {adg }}$ \\
\hline UPV & $16,8 \pm 1,4$ & $23,9 \pm 1,5^{b}$ & $21,7 \pm 1,0^{c}$ & $20,9 \pm 1,3^{c}$ \\
\hline $\mathrm{U}_{\mathrm{Mg}} \mathrm{V}$ & $1,9 \pm 0,2$ & $1,8 \pm 0,1$ & $2,0 \pm 0,1$ & $3,2 \pm 0,3^{\text {adg }}$ \\
\hline UProtV & $7,5 \pm 0,5$ & $13,1 \pm 0,5^{a}$ & $9,6 \pm 0,7^{e}$ & $12,7 \pm 1,0^{\text {ah }}$ \\
\hline
\end{tabular}

25(OH)D, 25-hidroxivitamina $\mathrm{D}(\mathrm{ng} / \mathrm{mL})$; Aldosterona plasmática $(\mathrm{pg} / \mathrm{mL})$; PTH intacto plasmático $(\mathrm{pg} / \mathrm{mL}) ; \mathrm{FGF} 23(\mathrm{pg} / \mathrm{mL}) ;$ Ureia $(\mathrm{mg} / \mathrm{dL}) ; \mathrm{P}_{\mathrm{Na}}$, concentração plasmática de sódio (mmol/L); $\mathrm{P}_{\mathrm{K}}$, concentração plasmática de potássio (mmol/L); $\mathrm{P}_{\mathrm{Ca}}$, concentração plasmática de cálcio $(\mathrm{mmol} / \mathrm{L})$; $\mathrm{P}_{\mathrm{P}}$, concentração plasmática de fósforo $(\mathrm{mg} / \mathrm{dL}), \mathrm{P}_{\mathrm{Mg}}$, concentração plasmática de magnésio $(\mathrm{mg} / \mathrm{dL}), \mathrm{VU}$, volume urinário $(\mathrm{mL}) ; U_{\mathrm{sm}}$, osmolalidade urinária $\left(\mathrm{mOsm} / \mathrm{kg} / \mathrm{H}_{2} \mathrm{O}\right), U_{\mathrm{P}} \mathrm{V}$, excreção urinária de fósforo $(\mathrm{mg} / \mathrm{dia})$; $\mathrm{U}_{\mathrm{Mg}} \mathrm{V}$, excreção urinária de magnésio $(\mathrm{mg} / \mathrm{dia}) ; U_{\text {Prot }} \mathrm{V}$, proteinúria (mg/dia). Valores expressos em média \pm EPM. ${ }^{a} p<0,001,{ }^{b} p<0,01$ e ${ }^{c} p<0,05$ vs. C; ${ }^{d} p<0,001$, e $p<0,01$ e ${ }^{f} p<0,05$ vs. dVD; ${ }^{p} p<0,001,{ }^{h} p<0,01$ e ${ }^{i} p<0,05$ vs. AnfB/EL. 
Tabela 3 - Avaliação da expressão proteica no tecido renal e análise histo-morfológica

\begin{tabular}{lcccc}
\hline & C & dVD & AnfB/EL & dVD+AnfB/EL \\
\hline AQP2 & $100 \pm 3$ & $75 \pm 16^{\mathrm{c}}$ & $43 \pm 2^{\text {af }}$ & $46 \pm 6^{\text {af }}$ \\
NPT2 & $100 \pm 2$ & $87 \pm 10$ & $68 \pm 11^{\mathrm{c}}$ & $57 \pm 6^{\mathrm{bf}}$ \\
TRPM6 & $100 \pm 2$ & $91 \pm 12$ & $79 \pm 6$ & $49 \pm 11^{\text {bfi }}$ \\
AGT & $100 \pm 2 \%$ & $105 \pm 9 \%$ & $121 \pm 15 \%$ & $163 \pm 6 \% \%^{\text {beh }}$ \\
ECA & $100 \pm 4 \%$ & $98 \pm 11 \%$ & $141 \pm 28 \%$ & $258 \pm 40 \% \%^{\text {bei }}$ \\
Klotho & $100 \pm 1 \%$ & $83 \pm 5 \%{ }^{\mathrm{c}}$ & $62 \pm 4 \%$ ae & $51 \pm 2^{\text {adi }}$ \\
ELT & $0,13 \pm 0,02$ & $0,31 \pm 0,04$ & $0,25 \pm 0,05$ & $0,40 \pm 0,07^{\mathrm{c}}$
\end{tabular}

AQP2, expressão proteica de aquaporina 2 no tecido renal (\%); NPT2, expressão proteica do cotransportador sódio/fosfato tipo 2 no tecido renal (\%); TRPM6, expressão proteica do transportador de magnésio tipo 6 no tecido renal (\%); AGT, expressão proteica do angiotensinogênio no tecido renal (\%); ECA, enzima conversora de angiotensina no tecido renal (\%); Klotho, fração renal do Kloto(\%); ELT, escore de lesão tubular (\%). Valores expressos em média $\pm E P M .{ }^{a} p<0,001,{ }^{b} p<0,01$ e ${ }^{\mathrm{p}} p<0,05$ vs. $C$; ${ }^{d} p<0,001,{ }^{\mathrm{e}} \mathrm{p}<0,01$ e ${ }^{f} \mathrm{p}<0,05$ vs. $d V D ;{ }^{9} p<0,001$, ${ }^{h} p<0,01$ e $p<0,05$ vs. AnfB/EL. 


\section{Referências Bibliográficas}

1. Menzin, J., et al., Mortality, length of hospitalization, and costs associated with invasive fungal infections in high-risk patients. Am J Health Syst Pharm, 2009. 66(19): p. 1711-7.

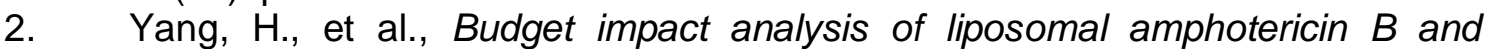
amphotericin $B$ lipid complex in the treatment of invasive fungal infections in the United States. Appl Health Econ Health Policy, 2014. 12(1): p. 85-93.

3. Sifuentes-Osornio, J., D.E. Corzo-Leon, and L.A. Ponce-de-Leon, Epidemiology of Invasive Fungal Infections in Latin America. Curr Fungal Infect Rep, 2012. 6(1): p. 23-34.

4. Procop, G.W., Molecular diagnostics for invasive fungal infections: a call for refinement and implementation. J Mol Diagn, 2010. 12(1): p. 17-9.

5. Ullmann, A.J., Nephrotoxicity in the setting of invasive fungal diseases. Mycoses, 2008. 51 Suppl 1: p. 25-30.

6. Hamill, R.J., Amphotericin $B$ formulations: a comparative review of efficacy and toxicity. Drugs, 2013. 73(9): p. 919-34.

7. Gallis, H.A., R.H. Drew, and W.W. Pickard, Amphotericin B: 30 years of clinical experience. Rev Infect Dis, 1990. 12(2): p. 308-29.

8. Wu, T.C., On the development of antifungal agents: perspective of the U.S. Food and Drug Administration. Clin Infect Dis, 1994. 19 Suppl 1: p. S54-8.

9. Tiphine, M., V. Letscher-Bru, and R. Herbrecht, Amphotericin B and its new formulations: pharmacologic characteristics, clinical efficacy, and tolerability. Transpl Infect Dis, 1999. 1(4): p. 273-83.

10. Goldman, R.D. and G. Koren, Amphotericin B nephrotoxicity in children. J Pediatr Hematol Oncol, 2004. 26(7): p. 421-6.

11. Wasan, K.M. and G. Lopez-Berestein, Diversity of lipid-based polyene formulations and their behavior in biological systems. Eur J Clin Microbiol Infect Dis, 1997. 16(1): p. 81-92.

12. Berdichevski, R.H., et al., Amphotericin B-related nephrotoxicity in low-risk patients. Braz J Infect Dis, 2006. 10(2): p. 94-9.

13. Dorea, E.L., et al., Nephrotoxicity of amphotericin $B$ is attenuated by solubilizing with lipid emulsion. J Am Soc Nephrol, 1997. 8(9): p. 1415-22.

14. Huang, W., et al., Ion channel behavior of amphotericin $B$ in sterol-free and cholesterol- or ergosterol-containing supported phosphatidylcholine bilayer model membranes investigated by electrochemistry and spectroscopy. Biophys J, 2002. 83(6): p. 3245-55.

15. Brajtburg, J., et al., Amphotericin B: current understanding of mechanisms of action. Antimicrob Agents Chemother, 1990. 34(2): p. 183-8.

16. Ghannoum, M.A. and L.B. Rice, Antifungal agents: mode of action, mechanisms of resistance, and correlation of these mechanisms with bacterial resistance. Clin Microbiol Rev, 1999. 12(4): p. 501-17.

17. Moribe, K., K. Maruyama, and M. Iwatsuru, Molecular localization and state of amphotericin B in PEG liposomes. Int J Pharm, 1999. 193(1): p. 97-106.

18. Ganis, P., et al., Polyene macrolide antibiotic amphotericin B. Crystal structure of the N-iodoacetyl derivative. J Am Chem Soc, 1971. 93(18): p. 4560-4.

19. Lopez-Berestein, G., et al., Treatment and prophylaxis of disseminated infection due to Candida albicans in mice with liposome-encapsulated amphotericin B. J Infect Dis, 1983. 147(5): p. 939-45.

20. Bagnis, C.I. and G. Deray, Amphotericin B nephrotoxicity. Saudi J Kidney Dis Transpl, 2002. 13(4): p. 481-91. 
21. Heinemann, V., et al., Pharmacokinetics of liposomal amphotericin $B$ (Ambisome) in critically ill patients. Antimicrob Agents Chemother, 1997. 41(6): p. 1275-80.

22. Yano, Y., J.L. Monteiro, and A.C. Seguro, Effect of amphotericin B on water and urea transport in the inner medullary collecting duct. J Am Soc Nephrol, 1994. 5(1): p. 68-74.

23. Alvarez-Lerma, F., et al., Effectiveness of liposomal amphotericin $B$ in patients admitted to the ICU on renal replacement therapy. Rev Esp Quimioter, 2013. 26(4): p. 360-8.

24. Alvarez-Lerma, F., et al., Impact of liposomal amphotericin $B$ on renal function in critically ill patients with renal function impairment. Rev Esp Quimioter, 2012. 25(3): p. 206-15.

25. Bowden, R.A., et al., Phase I study of amphotericin B colloidal dispersion for the treatment of invasive fungal infections after marrow transplant. J Infect Dis, 1996. 173(5): p. 1208-15.

26. Martino, R., Efficacy, safety and cost-effectiveness of Amphotericin B Lipid Complex (ABLC): a review of the literature. Curr Med Res Opin, 2004. 20(4): $p$. 485-504.

27. Mistro, S., et al., Does lipid emulsion reduce amphotericin B nephrotoxicity? A systematic review and meta-analysis. Clin Infect Dis, 2012. 54(12): p. 1774-7.

28. Kleinberg, M., What is the current and future status of conventional amphotericin $B$ ? Int J Antimicrob Agents, 2006. 27 Suppl 1: p. 12-6.

29. Moen, M.D., K.A. Lyseng-Williamson, and L.J. Scott, Liposomal amphotericin B: a review of its use as empirical therapy in febrile neutropenia and in the treatment of invasive fungal infections. Drugs, 2009. 69(3): p. 361-92.

30. Wong-Beringer, A., R.A. Jacobs, and B.J. Guglielmo, Lipid formulations of amphotericin B: clinical efficacy and toxicities. Clin Infect Dis, 1998. 27(3): p. 60318.

31. Kuti, J.L., et al., Pharmacoeconomic analysis of amphotericin B lipid complex versus liposomal amphotericin $B$ in the treatment of fungal infections. Pharmacoeconomics, 2004. 22(5): p. 301-10.

32. Martinez, R., An update on the use of antifungal agents. J Bras Pneumol, 2006. 32(5): p. 449-60.

33. Holick, M.F. and T.C. Chen, Vitamin D deficiency: a worldwide problem with health consequences. Am J Clin Nutr, 2008. 87(4): p. 1080S-6S.

34. Unger, M.D., et al., Vitamin D status in a sunny country: where has the sun gone? Clin Nutr, 2010. 29(6): p. 784-8.

35. Crew, K.D., et al., High prevalence of vitamin $D$ deficiency despite supplementation in premenopausal women with breast cancer undergoing adjuvant chemotherapy. J Clin Oncol, 2009. 27(13): p. 2151-6.

36. Allavena, C., et al., High frequency of vitamin $D$ deficiency in HIV-infected patients: effects of HIV-related factors and antiretroviral drugs. J Antimicrob Chemother, 2012. 67(9): p. 2222-30.

37. Rodriguez, M., et al., High frequency of vitamin $D$ deficiency in ambulatory HIVPositive patients. AIDS Res Hum Retroviruses, 2009. 25(1): p. 9-14.

38. Holick, M.F., Vitamin $D$ status: measurement, interpretation, and clinical application. Ann Epidemiol, 2009. 19(2): p. 73-8.

39. Dusso, A.S., Kidney disease and vitamin $D$ levels: 25-hydroxyvitamin D, 1,25dihydroxyvitamin D, and VDR activation. Kidney Int Suppl (2011), 2011. 1(4): p. 136-141.

40. Canale, D., et al., Vitamin D deficiency aggravates nephrotoxicity, hypertension and dyslipidemia caused by tenofovir: role of oxidative stress and reninangiotensin system. PLoS One, 2014. 9(7): p. e103055. 
41. Goncalves, J.G., et al., Vitamin D deficiency aggravates chronic kidney disease progression after ischemic acute kidney injury. PLoS One, 2014. 9(9): p. e107228.

42. Oliveira, R.B. and R.M. Moyses, FGF-23: state of the art. J Bras Nefrol, 2010. 32(3): p. 323-31.

43. Damasiewicz, M.J., et al., Serum 25-hydroxyvitamin D deficiency and the 5-year incidence of CKD. Am J Kidney Dis, 2013. 62(1): p. 58-66.

44. Garsen, M., et al., Vitamin $D$ attenuates proteinuria by inhibition of heparanase expression in the podocyte. J Pathol, 2015. 237(4): p. 472-81.

45. de Braganca, A.C., et al., Vitamin D Deficiency Aggravates the Renal Features of Moderate Chronic Kidney Disease in 5/6 Nephrectomized Rats. Front Med (Lausanne), 2018. 5: p. 282.

46. Burnette, W.N., "Western blotting": electrophoretic transfer of proteins from sodium dodecyl sulfate--polyacrylamide gels to unmodified nitrocellulose and radiographic detection with antibody and radioiodinated protein $A$. Anal Biochem, 1981. 112(2): p. 195-203.

47. de Braganca, A.C., et al., Vitamin D deficiency aggravates ischemic acute kidney injury in rats. Physiol Rep, 2015. 3(3).

48. Miyaji, T., et al., Role of the increase in p21 in cisplatin-induced acute renal failure in rats. J Am Soc Nephrol, 2001. 12(5): p. 900-8.

49. Palacios, C. and L. Gonzalez, Is vitamin D deficiency a major global public health problem? J Steroid Biochem Mol Biol, 2014. 144 Pt A: p. 138-45.

50. Krejcirova, L., et al., Influence of amphotericin $B$ deoxycholate or amphotericin $B$ colloidal dispersion on renal tubule epithelium in rat. Biomed Pap Med Fac Univ Palacky Olomouc Czech Repub, 2004. 148(2): p. 221-3.

51. Doubek, M., et al., Comparison of the effect of amphotericin $B$ desoxycholate and amphotericin $B$ colloidal dispersion on renal functions and renal morphology in rats. Nephrology (Carlton), 2005. 10(1): p. 57-62.

52. Sabra, R. and R.A. Branch, Amphotericin B nephrotoxicity. Drug Saf, 1990. 5(2): p. 94-108.

53. Meaudre, E., et al., [Amphotericin $B$ associated with hypertension: haemodynamic profile]. Ann Fr Anesth Reanim, 2005. 24(11-12): p. 1405-6.

54. Li, Y.C., et al., Vitamin D: a negative endocrine regulator of the renin-angiotensin system and blood pressure. J Steroid Biochem Mol Biol, 2004. 89-90(1-5): p. 38792.

55. Tamez, H., S. Kalim, and R.I. Thadhani, Does vitamin $D$ modulate blood pressure? Curr Opin Nephrol Hypertens, 2013. 22(2): p. 204-9.

56. Melamed, M.L., et al., 25-hydroxyvitamin $D$ levels and the risk of mortality in the general population. Arch Intern Med, 2008. 168(15): p. 1629-37.

57. Chen, S., Y. Sun, and D.K. Agrawal, Vitamin $D$ deficiency and essential hypertension. J Am Soc Hypertens, 2015. 9(11): p. 885-901.

58. Jorde, R., J. Svartberg, and J. Sundsfjord, Serum parathyroid hormone as a predictor of increase in systolic blood pressure in men. J Hypertens, 2005. 23(9): p. 1639-44.

59. Kurnik, B.R. and K.A. Hruska, Effects of 1,25-dihydroxycholecalciferol on phosphate transport in vitamin D-deprived rats. Am J Physiol, 1984. 247(1 Pt 2): p. F177-84.

60. Weisinger, J.R. and E. Bellorin-Font, Magnesium and phosphorus. Lancet, 1998. 352(9125): p. 391-6.

61. Razzaque, M.S., The FGF23-Klotho axis: endocrine regulation of phosphate homeostasis. Nat Rev Endocrinol, 2009. 5(11): p. 611-9.

62. Rodriguez-Ortiz, M.E., et al., Calcium deficiency reduces circulating levels of FGF23. J Am Soc Nephrol, 2012. 23(7): p. 1190-7.

63. Donate-Correa, J., et al., FGF23/KIotho axis: phosphorus, mineral metabolism and beyond. Cytokine Growth Factor Rev, 2012. 23(1-2): p. 37-46. 
64. Kuro, O.M., Phosphate and Klotho. Kidney Int Suppl, 2011(121): p. S20-3.

65. Shroff, R., M. Wan, and L. Rees, Can vitamin D slow down the progression of chronic kidney disease? Pediatr Nephrol, 2012. 27(12): p. 2167-73.

66. Barton, C.H., et al., Renal magnesium wasting associated with amphotericin $B$ therapy. Am J Med, 1984. 77(3): p. 471-4.

67. Hoorn, E.J. and R. Zietse, Disorders of calcium and magnesium balance: a physiology-based approach. Pediatr Nephrol, 2013. 28(8): p. 1195-206.

68. Woudenberg-Vrenken, T.E., R.J. Bindels, and J.G. Hoenderop, The role of transient receptor potential channels in kidney disease. Nat Rev Nephrol, 2009. 5(8): p. 441-9.

69. Kim, S.W., et al., Amphotericin B decreases adenylyl cyclase activity and aquaporin-2 expression in rat kidney. J Lab Clin Med, 2001. 138(4): p. 243-9.

70. Tonomura, Y., et al., Amphotericin B-induced nephrotoxicity: characterization of blood and urinary biochemistry and renal morphology in mice. Hum Exp Toxicol, 2009. 28(5): p. 293-300.

71. Wang, T., S. Weinbaum, and A.M. Weinstein, Regulation of glomerulotubular balance: flow-activated proximal tubule function. Pflugers Arch, 2017. 469(5-6): p. 643-654.

72. Lee, D.R., et al., Impact of vitamin $D$ on proteinuria, insulin resistance, and cardiovascular parameters in kidney transplant recipients. Transplant Proc, 2011. 43(10): p. 3723-9.

73. Gray, J.A. and R.J. Kavlock, Pharmacologic probing of amphotericin B-induced renal dysfunction in the neonatal rat. Toxicol Appl Pharmacol, 1988. 93(3): p. 360-8.

74. Isakova, T. and M.S. Wolf, FGF23 or PTH: which comes first in CKD ? Kidney Int, 2010. 78(10): p. 947-9.

75. Zemel, M.B., Calcium modulation of hypertension and obesity: mechanisms and implications. J Am Coll Nutr, 2001. 20(5 Suppl): p. 428S-435S; discussion 440S$442 S$. 


\section{Manuscrito Submetido - \\ PLOS Neglected Tropical Diseases.}




\section{Vitamin D deficiency induces acute kidney injury in rats treated with lipid formulation of Amphotericin B}

Daniela Ferreira ${ }^{1}$, Ana Carolina de Bragança², Rildo Aparecido Volpini², Maria Heloisa Massola Shimizuํㅜ, Adriana Castello Costa Girardi ${ }^{3}$, Antonio Carlos Seguro" ${ }^{2 \#}$, Daniele Canale ${ }^{1 \#^{*}}$

\footnotetext{
${ }^{1}$ Laboratorio de Investigacao Medica 12 (LIM12), Faculdade de Medicina, Universidade de São Paulo, São Paulo, Brazil.

${ }^{2}$ Laboratorio de Investigacao Medica 12 (LIM12), Hospital das Clinicas HCFMUSP, Faculdade de Medicina, Universidade de São Paulo, São Paulo, Brazil.

${ }^{3}$ Laboratorio de Cardiologia Genetica e Molecular, Instituto do Coracao, Universidade de São Paulo, São Paulo, Brazil.
}

Address for reprint requests and other correspondence: Daniele Canale, Nephrology Dept., Univ. of São Paulo School of Medicine, Av. Dr. Arnaldo, 455, 3aandar, sala 3310, CEP 01246903, São Paulo, Brazil.

\# These authors contributed equally to this work.

* Corresponding author

e-mail: dcanale@usp.br

Funding: Sao Paulo Research Foundation (FAPESP), grants n. 2015/05513-1 and 2015/11933-3

Short title: Vitamin D deficiency and Amphotericin B lipid emulsion 


\section{Abstract}

Invasive fungal infections (IFI) have been considered a worldwide serious health problem and represent a significant cause of morbidity and mortality. Amphotericin $B(A m B)$ is the drug of choice for IFI treatment and has been used for more than 30 years. Despite its efficacy, clinical use of AmB has been associated with renal toxicity. The increasing number of high-risk patients has enabled the development of modified AmBs in order to reduce nephrotoxicity. Among these formulations, an extemporaneous lipid emulsion preparation of $A m B(A m B / L E)$ is a lower cost alternative with similar benefits. Besides the prevalence of low levels of vitamin $D$ in general population, studies have been shown that hypovitaminosis $D$ may hasten the progression of kidney disease and reflect on a worse prognosis in cases of acute kidney injury and drug-induced nephrotoxicity. In view of the high worldwide incidence of hypovitaminosis $D$, the aim of this study was to investigate whether vitamin $D$ deficiency may induce AmB/LE-related nephrotoxicity. Wistar rats were divided into four groups: control, received a standard diet for 34 days; AmB/LE, received a standard diet for 34 days and $\mathrm{AmB} / \mathrm{LE}(5 \mathrm{mg} / \mathrm{kg} /$ day) intraperitoneally in the last 4 days; VDD, received a vitamin D-free diet for 34 days; and VDD+AmB/LE, received a vitamin D-free diet for 34 days and AmB/LE (5mg/kg/day) intraperitoneally in the last 4 days. At the end of the protocol, animals were euthanized and blood, urine and renal tissue samples were collected in order to evaluate the effects of the drug on renal function and morphology. Association of AmB/LE and vitamin D deficiency led to impaired renal function, hypertension and urinary concentrating defect. Hence, it is important to monitor vitamin D levels in AmB/LE treated patients, since vitamin $\mathrm{D}$ deficiency induces AmB/LE nephrotoxicity.

\section{Author Summary}

Amphotericin B $(\mathrm{AmB})$ is the treatment of choice for systemic fungal infections. Despite its efficacy, clinical use of AmB has been associated with renal toxicity. In an attempt to improve the therapeutic effect and to reduce adverse reactions, lipid formulations of AmB were developed. Among these formulations, an in-house lipid emulsion preparation of $A m B(A m B / L E)$ is a lower cost alternative with similar benefits. Furthermore, vitamin $D$ is an essential nutrient for the 
regulation of several physiological activities. Hence, vitamin D deficiency or insufficiency can contribute to the progression of diseases and increase the risk of chronic illnesses as well. Nowadays, VDD is a health problem worldwide and its prevalence in general population is high, including the sunny and industrialized countries, where vitamin D supplementation has been successfully implemented. Thus, it is essential to monitor vitamin D levels in both patients treated with conventional or lipid formulations of $\mathrm{AmB}$ in order to ensure a better prognosis in the development of renal diseases.

\section{Introduction}

Amphotericin $B(A m B)$ is a macrolide polyene antibiotic frequently used for the treatment of invasive fungal infections (IFI) based on its broad-spectrum antifungal activity $[1,2]$. Despite its effectiveness in clinical trials, conventional AmB use is hampered by several adverse reactions and significant incidence of nephrotoxicity. Typically, AMB administration results in reduction of the glomerular filtration rate, due to renal vasoconstriction, and tubular dysfunction caused by direct interaction of the AmB with tubular cell membranes, leading to defective proximal and distal electrolyte reabsorption [3-5]. In order to reduce renal toxicity and improve both tolerability and efficacy, conventional AmB has been incorporated into phospholipid vesicles resulting in highcost agents to resource-limited health centers $[5,6]$. Alternatively, studies have reported a lower cost in-house preparation of $\mathrm{AmB}$ as an extemporaneous lipid emulsion (AmB/LE), reducing side effects and preserving therapeutic properties $[4,6]$.

It is well known that vitamin D deficiency (VDD) is a public health problem, affecting different regions of the world including sunny countries $[7,8]$. Epidemiological data indicate that low $25(\mathrm{OH}) \mathrm{D}$ levels may be partly responsible for several pathological processes, such as reninangiotensin system activation and pro-inflammatory effects. In addition, hypovitaminosis $D$ has been associated with the arising of hypertension, development of cardiovascular disease, diabetes mellitus and the aggravation of chronic kidney disease (CKD) [9-11]. These effects could also reflect on a worse prognosis in cases of acute kidney injury (AKI) $[12,13]$ and drug-induced nephrotoxicity [14]. 
In view of the high worldwide incidence of hypovitaminosis $D$, the aim of this study was to investigate whether vitamin D deficiency may induce AmB/LE-related nephrotoxicity.

\section{Methods}

The experimental procedures were developed in strict conformity with local institutional guidelines and with well-established international standards for manipulation and care of laboratory animals (Guide for the Care and Use of Laboratory Animals - NCBI - NIH), approved by the local research ethics committee (CEUA-HCFMUSP, process no. 134/15). All surgeries were performed under appropriate anesthesia, and all efforts were made to minimize suffering.

Animals and experimental protocol. Forty-eight male Wistar rats (Rattus novergicus), weighing $200-250 \mathrm{~g}$, were obtained from the animal facilities of the University of Sao Paulo School of Medicine, housed in standard cages, and given ad libitum access to tap water and commercial rodent chow, standard or vitamin D-free, both obtained from MP Biomedicals (Irvine, CA, USA). Rats were randomly divided into four groups: Control $(n=12)$, received a standard diet for 34 days; $A m B / L E(n=12)$, received a standard diet for 34 days and AmB/LE $(5 \mathrm{mg} / \mathrm{kg} /$ day $)$ intraperitoneally in the last 4 days; VDD $(n=12)$, received a vitamin D-free diet for 34 days; and VDD+AmB/LE ( $n=12)$, received a vitamin D-free diet for 34 days and AmB/LE $(5 \mathrm{mg} / \mathrm{kg} /$ day $)$ intraperitoneally in the last 4 days. The dose of AmB/LE was based on a previous study from our laboratory [4]. AmB and lipid emulsion (soy oil $200 \mathrm{mg} / \mathrm{mL}$, glycerol $25 \mathrm{mg} / \mathrm{mL}$, egg lecithin 12 mg/mL - Lipovenos ${ }^{\circledR}$, Fresenius, Graz, Austria) were kindly provided by Hospital das Clinicas da Universidade de Sao Paulo and Fresenius, respectively.

Metabolic cage studies and analysis of urine samples. At the end of the protocol, rats were allocated in metabolic cages (one rat per cage), maintained on a 12-h light/dark cycle and given free access to tap water. The animals were acclimated to the housing conditions for 1 day before the experimental procedures. Twenty-four hour urine samples were collected. Urine concentrations of phosphorus, magnesium and protein were measured by a colorimetric system using commercial kits (Labtest Diagnostica, Lagoa Santa/MG, Brazil). Urinary excretions of 
phosphorus $\left(\mathrm{U}_{\mathrm{P}} \mathrm{V}\right)$, magnesium $\left(\mathrm{U}_{\mathrm{Mg}} \mathrm{V}\right)$ and protein $\left(\mathrm{U}_{\text {Prot }} \mathrm{V}\right)$ were determined. We determined urine osmolality ( $\mathrm{U}_{\mathrm{osm}}$ ) with a freezing-point osmometer (model 3D3; Advanced Instruments, Norwood, MA).

Glomerular filtration rate. To determine glomerular filtration rate (GFR), inulin clearance studies were conducted at the end of the protocol. On day 35, the animals were anesthetized with sodium thiopental (50 $\mathrm{mg} / \mathrm{Kg} \mathrm{BW}$ ) and placed on a temperature-regulated surgical table. The trachea was cannulated (PE-240 catheter) and spontaneous breathing was maintained. The jugular vein was cannulated (PE-60 catheter) for infusion of inulin and fluids. To monitor mean arterial pressure (MAP) and collect blood samples, the right carotid artery was catheterized with a PE-50 catheter. We assessed MAP with a data acquisition system (MP100; Biopac Systems, Santa Barbara, CA). To collect urine samples, the urinary bladder was cannulated (PE-240 catheter) by suprapubic incision. After completion of the cannulation surgical procedure, a loading dose of inulin (100 mg/Kg BW diluted in $1 \mathrm{~mL}$ of $0.9 \%$ saline) was administered through the jugular vein. Subsequently, a constant infusion of inulin (10 mg/kg BW in $0.9 \%$ saline) was started and continued at $0.04 \mathrm{~mL} / \mathrm{min}$ throughout the whole experiment. Three urine samples were collected at 30-min intervals. Blood samples were obtained at the beginning and at the end of the experiment. Inulin clearance values represent the mean of three periods. Blood and urine inulin were determined by the anthrone method, and the GFR data is expressed as $\mathrm{ml} / \mathrm{min} / 100 \mathrm{~g} \mathrm{BW}$ [12].

Biochemical Parameters. To assess plasma levels of 25-hydroxyvitamin D [25(OH)D], parathormone $(\mathrm{PTH})$, fibroblast growth factor 23 (FGF-23), aldosterone, urea, sodium ( $\left.\mathrm{P}_{\mathrm{Na}}\right)$, potassium $\left(\mathrm{P}_{K}\right)$, phosphate $\left(\mathrm{P}_{\mathrm{P}}\right)$, calcium $\left(\mathrm{P}_{\mathrm{Ca}}\right)$ and magnesium $\left(\mathrm{P}_{\mathrm{Mg}}\right)$, we collected blood samples after the clearance studies. We assessed $25(\mathrm{OH}) \mathrm{D}, \mathrm{PTH}, \mathrm{FGF}-23$ and aldosterone by enzymelinked immunosorbent (ELISA) using commercial kits: 25-Hydroxyvitamin D (ALPCO, Salem, $\mathrm{NH}$ ); Rat Intact PTH and Mouse/Rat Intact FGF-23 (Immutopics, Inc., San Clemente, CA); and Aldosterone (Enzo Life Sciences, Farmingdale, NY). $P_{\mathrm{Na}}$ and $\mathrm{P}_{\mathrm{K}}$ were determined with specific electrodes (AVL9140 Electrolyte Analyzer, Roche Diagnostics, Risch-Rotkreuz, Switzerland). PP, $\mathrm{P}_{\mathrm{Ca}}$ and $\mathrm{P}_{\mathrm{Mg}}$ were evaluated by colorimetric assay (Labtest Diagnostica, Lagoa Santa/MG, Brazil). 
Tissue Sample Preparation. After the clearance experiment, we perfused kidneys with phosphate-buffered solution (PBS, pH 7.4). Fragments of right kidneys were frozen in liquid nitrogen and stored at $-80^{\circ} \mathrm{C}$ for western blotting experiments. Fragments of left kidneys were fixed in methacarn solution (60\% methanol, 30\% chloroform, $10 \%$ glacial acetic acid) for $24 \mathrm{~h}$ and in $70 \%$ alcohol thereafter. Kidney blocks were embedded in paraffin and cut into $4-\mu \mathrm{m}$ sections for histology.

Total Protein Isolation. Kidney samples were homogenized in ice-cold isolation solution (200 mM mannitol, $80 \mathrm{mM}$ HEPES and $41 \mathrm{mM} \mathrm{KOH}, \mathrm{pH}$ 7.5) containing a protease inhibitor cocktail (Sigma Chemical Company, St. Louis, MO) in a homogenizer (PT 10/35; Brinkmann Instruments, Westbury, NY). Homogenates were centrifuged at $4000 \mathrm{x} \mathrm{rpm}$ for $30 \mathrm{~min}$ at $4^{\circ} \mathrm{C}$ to remove nuclei and cell debris. Supernatants were isolated, and protein was quantified by Bradford assay (Bio-Rad Laboratories, Hercules, CA).

Western Blot Assays. For western blot analysis, $25 \mu \mathrm{g}$ or $100 \mu \mathrm{g}$ of total kidney protein were separated on $8 \%, 10 \%$ or $12 \%$ SDS-polyacrylamide minigels by electrophoresis [15]. After transfer by electroelution to PVDF membranes (GE Healthcare Limited, Little Chalfont, UK), blots were blocked for $1 \mathrm{~h}$ with $5 \%$ nonfat dry milk in Tris-buffered saline solution. Blots were then incubated overnight with primary antibodies for: Aquaporin 2 (AQP2, 1/1000), Sodium/phosphate cotransport type Ila (NaPi-Ila, 1/200), magnesium channel (TRPM6, 1/200), angiotensinogen (AGT, 1/100), angiotensin converting enzyme (ACE, 1/100) and a-Klotho (1/500). Primary antibodies were obtained from Santa Cruz (Santa Cruz Biotechnology, Santa Cruz, CA). The labeling was visualized with horseradish peroxidase-conjugated secondary antibody (anti-rabbit, 1:2000, or anti-goat, 1:10000; Sigma Chemical, St. Louis, MO) and enhanced chemiluminescence (ECL) detection (GE Healthcare Limited, Little Chalfont, UK). Kidney protein levels were further analyzed with a gel documentation system (Alliance 4.2; Uvitec, Cambridge, UK) and the software Image $\mathrm{J}$ for Windows (Image $\mathrm{J}-\mathrm{NIH}$ Image). We used densitometry to quantitatively analyze the protein levels, normalizing the bands to actin expression (anti $\beta$-actin, Sigma Chemical, St. Louis, MO). 
Light Microscopy. Four-mm histological sections of renal tissue were stained with hematoxylin-eosin and examined under light microscope. For the evaluation of renal damage, 40-60 grid fields ( $x 400$ magnification) measuring $0.245 \mathrm{~mm}^{2}$ were evaluated by graded scores according to the following criteria: $(0)$, less than $5 \%$ of the field showing tubular epithelial swelling, vacuolar degeneration, necrosis, and desquamation; (I), $5-25 \%$ of the field presenting renal lesions; (II), involvement of $25-50 \%$ with renal damage; (III), $50-75 \%$ of damaged area; and (IV), more that $75 \%$ of the grid field presenting renal lesions. The morphometric examination was blinded to minimize observer bias, i.e. the observer was unaware of the treatment group from which the tissue originated. The mean score for each rat and the mean score for each group were calculated $[13,16]$.

Statistical Analysis. All quantitative data were expressed as mean \pm SEM (standard error of the mean). Differences among groups were analyzed with GraphPad Prism 5.0 software (GraphPad Software, La Jolla, CA) by one-way analysis of variance followed by the StudentNewman-Keuls test. Values of $p<0.05$ were considered statistically significant.

\section{Results}

As aforementioned, rats were maintained on a standard or a free-vitamin D diet for 34 days. At the end of the experimental period, VDD animals had lower levels of 25(OH)D compared to Control, demonstrating that vitamin D deficiency model was successfully achieved. Furthermore, it is important to highlight that $A m B / L E$ treatment itself did not modify vitamin $D$ levels (Table 1).

Table 1. Plasma levels of vitamin $\mathrm{D}$, aldosterone, PTH and FGF-23 at the end of the experimental protocol determined in Control rats, vitamin $D$ deficient rats (VDD), rats treated with AmB/LE 5

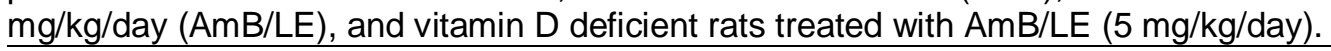

\begin{tabular}{lcccc}
\hline & Control & VDD & AmB/LE & VDD+AmB/LE \\
\hline 25(OH)D $(\mathrm{ng} / \mathrm{mL})$ & $44.3 \pm 2.4$ & $4.3 \pm 0.4^{\mathrm{a}}$ & $45.4 \pm 5.2^{\mathrm{d}}$ & $4.4 \pm 0.7^{\mathrm{ag}}$ \\
Aldosterone $(\mathrm{pg} / \mathrm{mL})$ & $1465 \pm 125$ & $1656 \pm 72$ & $3572 \pm 304^{\mathrm{ad}}$ & $4274 \pm 345^{\mathrm{adi}}$ \\
PTH $(\mathrm{pg} / \mathrm{mL})$ & $86.5 \pm 11.2$ & $465.8 \pm 87.1^{\mathrm{b}}$ & $400.9 \pm 58.4^{\mathrm{b}}$ & $406.5 \pm 112.5^{\mathrm{c}}$ \\
FGF-23 $(\mathrm{pg} / \mathrm{mL})$ & $139.4 \pm 10.6$ & $80.2 \pm 7.2^{\mathrm{a}}$ & $115.0 \pm 12.7^{\mathrm{f}}$ & $70.8 \pm 5.0^{\mathrm{aii}^{\mathrm{a}}}$ \\
\hline
\end{tabular}

25(OH)D, 25-hydroxyvitamin D; Aldosterone, plasma aldosterone; PTH, plasma intact; FGF-23. Values are mean \pm SEM. ${ }^{a} p<0.001,{ }^{b} p<0.01$ and ${ }^{~} p<0.05$ vs. Control; ${ }^{d} p<0.001$ and ${ }^{f} p<0.05$ vs. VDD; ${ }^{g} p<0.001$ and i $p<0.05$ vs. AmB/LE. 
We did not observe any difference in body weight (BW) among the groups (Table 2), since all rats exhibited similar food ingestion, approximately $25 \mathrm{~g} /$ day. VDD rats exhibited a slight decrease in GFR, evidenced by diminished inulin clearance compared to Control. Animals treated with AmB/LE did not show significant changes in GFR compared to Control. However, VDD+AmB/LE group presented significantly impaired renal function compared to all experimental groups, suggesting that vitamin D deficiency may be crucial for the development of AmB-induced renal injury (Table 2). Corroborating data previously described, plasma urea concentration was higher in VDD+ AmB/LE animals compared to Control, VDD and AmB (Table 3). Another marker of renal impairment is proteinuria. VDD and VDD+AmB/LE groups presented increased urinary protein excretion compared to Control and AmB/LE (Table 3).

Table 2. Body weight, renal function and hemodynamic parameters at the end of the experimental protocol determined in Control rats, vitamin D deficient rats (VDD), rats treated with AmB/LE $5 \mathrm{mg} / \mathrm{kg} /$ day $(\mathrm{AmB} / \mathrm{LE})$, and vitamin D deficient rats treated with AmB/LE $(5 \mathrm{mg} / \mathrm{kg} /$ day) .

\begin{tabular}{lcccc}
\hline & Control & VDD & AmB/LE & VDD+AmB/LE \\
\hline BW $(\mathrm{g})$ & $340 \pm 7$ & $356 \pm 9$ & $332 \pm 5$ & $340 \pm 5$ \\
GFR $(\mathrm{mL} / \mathrm{min} / 100 \mathrm{~g})$ & $0.97 \pm 0.04$ & $0.79 \pm 0.02^{\mathrm{c}}$ & $0.99 \pm 0.06^{\mathrm{f}}$ & $0.55 \pm 0.04^{\mathrm{aeg}}$ \\
MAP $(\mathrm{mmHg})$ & $123 \pm 3$ & $130 \pm 4$ & $131 \pm 5$ & $148 \pm 5^{\text {bfi }}$ \\
\hline
\end{tabular}

BW, body weight, GFR, inulin clearance; MAP, mean arterial pressure. Values are mean \pm SEM. ${ }^{a} p<0.001$, ${ }^{b} p<0.01$ and ${ }^{~} p<0.05$ vs. Control; ${ }^{e} p<0.01$ and ${ }^{f} p<0.05$ vs. VDD; ${ }^{9} p<0.001$ and ${ }^{i} p<0.05$ vs. AmB/LE.

Table 3. Biochemical parameters at the end of the experimental protocol determined in Control rats, vitamin D deficient rats (VDD), rats treated with $A \mathrm{mB} / \mathrm{LE} 5 \mathrm{mg} / \mathrm{kg} /$ day $(\mathrm{AmB} / \mathrm{LE})$, and vitamin D deficient rats treated with AmB/LE (5 mg/kg/day).

\begin{tabular}{|c|c|c|c|c|}
\hline & Control & VDD & AmB/LE & VDD+AmB/LE \\
\hline $\mathrm{P}_{\mathrm{Na}}(\mathrm{mmol} / \mathrm{L})$ & $138 \pm 1$ & $139 \pm 1$ & $141 \pm 1$ & $140 \pm 1$ \\
\hline $\mathrm{PK}_{\mathrm{K}}(\mathrm{mmol} / \mathrm{L})$ & $4.5 \pm 0.1$ & $4.7 \pm 0.1$ & $4.1 \pm 0.3$ & $4.4 \pm 0.1$ \\
\hline $\mathrm{PCa}_{\mathrm{Ca}}(\mathrm{mmol} / \mathrm{L})$ & $1.20 \pm 0.02$ & $0.94 \pm 0.03^{a}$ & $1.17 \pm 0.02^{d}$ & $0.96 \pm 0.04^{\mathrm{ag}}$ \\
\hline$P_{P}(m g / d L)$ & $8.3 \pm 0.3$ & $6.4 \pm 0.3^{a}$ & $5.5 \pm 0.4^{\mathrm{a}}$ & $4.6 \pm 0.3^{\text {aei }}$ \\
\hline $\mathrm{P}_{\mathrm{Mg}}(\mathrm{mg} / \mathrm{dL})$ & $2.01 \pm 0.03$ & $1.98 \pm 0.06$ & $1.85 \pm 0.04$ & $1.99 \pm 0.03$ \\
\hline Pur (mg/dL) & $49 \pm 1$ & $51 \pm 4$ & $77 \pm 9$ & $152 \pm 28^{\text {adh }}$ \\
\hline$U_{P} V$ (mg/day) & $16.8 \pm 1.4$ & $23.9 \pm 1.5^{b}$ & $21.7 \pm 1.0^{\mathrm{C}}$ & $20.9 \pm 1.3^{c}$ \\
\hline $\mathrm{U}_{\mathrm{Mg}} \mathrm{V}$ (mg/day) & $1.9 \pm 0.2$ & $1.8 \pm 0.1$ & $2.0 \pm 0.1$ & $3.2 \pm 0.3^{\mathrm{adg}}$ \\
\hline UV $(m L)$ & $17 \pm 1$ & $26 \pm 1^{b}$ & $24 \pm 1^{b}$ & $32 \pm 2^{\text {afh }}$ \\
\hline$U_{\text {osm }}\left(\mathrm{mOsm} / \mathrm{kg} / \mathrm{H}_{2} \mathrm{O}\right)$ & $1028 \pm 89$ & $656 \pm 64^{a}$ & $635 \pm 32^{a}$ & $367 \pm 21^{\text {adg }}$ \\
\hline$U_{\text {Prot }} \mathrm{V}$ (mg/day) & $7.5 \pm 0.5$ & $13.1 \pm 0.5^{a}$ & $9.6 \pm 0.7^{e}$ & $12.7 \pm 1.0^{\text {ah }}$ \\
\hline
\end{tabular}

$\mathrm{P}_{\mathrm{Na}}$, plasma sodium concentration; $\mathrm{P}_{\mathrm{K}}$, Plasma potassium concentration; $\mathrm{P}_{\mathrm{Ca}}$, plasma calcium concentration; $\mathrm{P}_{\mathrm{P}}$, plasma phosphate concentration, $\mathrm{P}_{\mathrm{Mg}}$, plasma magnesium concentration, $\mathrm{P}_{\mathrm{Ur}}$, plasma urea concentration, $\mathrm{U}_{\mathrm{PV}}$; urine excretion of phosphorus; $\mathrm{U}_{\mathrm{Mg}} \mathrm{V}$, urine excretion of magnesium; $\mathrm{UV}$, urinary volume; $\mathrm{UOsm}$, urinary osmolality; U Prot V, proteinuria (mg/dia). Values are mean \pm SEM. ${ }^{a} p<0.001,{ }^{b} p<0.01$ and ${ }^{c} p<0.05$ vs. Control; ${ }^{\mathrm{d}} p<0.001,{ }^{\mathrm{e}} p<0.01$ and ${ }^{\mathrm{f}} \mathrm{p}<0.05$ vs. VDD; ${ }^{9} p<0.001,{ }^{\mathrm{h}} \mathrm{p}<0.01$ and $\mathrm{i} p<0.05$ vs. AmB/LE. 
Our histological study revealed that both VDD $(0.31 \pm 0.04)$ and AmB/LE $(0.25 \pm 0.05)$ groups did not show significant renal tubular injury compared to Control $(0.13 \pm 0.02)$. Vitamin D deficient rats treated with $\mathrm{AmB} / \mathrm{LE}(0.40 \pm 0.08)$ exhibited higher tubular injury score compared to all experimental groups. VDD+AmB/LE histological alterations included areas of denuded basement membrane, tubular cell necrosis, flattening of proximal tubular cells with brush border loss and tubular atrophy or dilatation. It is important to point out that these alterations were focal and slight. However, the development of tubular injury may indicate that vitamin D deficiency could be responsible for the nephrotoxic effects of AmB/LE (Fig 1).

Fig 1. Tubular injury score. (A) Representative photomicrographs of tubular injury in Control, VDD, AmB/LE and VDD+AmB/LE rats. Magnification, 400x. (B) Bar graph of tubular injury score. Data are mean \pm SEM. ${ }^{c} p<0.05$ vs. Control. (VDD, vitamin D deficiency; AmB/LE, Amphotericin B lipid emulsion; VDD+AmB/LE, vitamin D deficiency + Amphotericin B lipid emulsion).

In addition to impaired renal function, VDD+AmB/LE animals also presented higher MAP compared to groups C, VDD and AmB/LE (Table 2). Supporting data above-mentioned, renal

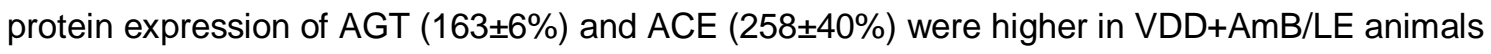
compared to Control $(100 \pm 2 \%$ for AGT and $100 \pm 4 \%$ for ACE), VDD $(105 \pm 9 \%$ for AGT and $98 \pm 11 \%$ for $\mathrm{ACE})$ and $\mathrm{AmB} / \mathrm{LE}(121 \pm 15 \%$ for $\mathrm{AGT}$ and $141 \pm 28 \%$ for ACE) groups (Fig 2). Furthermore, both groups treated with AmB/LE showed higher plasma aldosterone concentration. However, VDD+AmB/LE animals exhibited an even greater increase in this parameter compared to Control, VDD and AmB/LE (Table 1). Altogether, these data suggest a possible involvement of the Renin-Angiotensin-Aldosterone System (RAAS) in the arising of hypertension in $\mathrm{VDD}+\mathrm{AmB} / \mathrm{LE}$ rats.

Fig 2. Semiquantitative immunoblotting of kidney fractions for angiotensinogen (AGT) and angiotensin converting enzyme (ACE). (A) Densitometric analyzes of samples from 
Control, VDD, AmB/LE and VDD+AmB/LE rats. (B) Immunoblots reacted with anti-AGT and antiACE revealing a $60 \mathrm{kDa}$ and $195 \mathrm{kDa}$ bands, respectively. Data are mean $\pm \mathrm{SEM}$. ${ }^{\mathrm{b}} \mathrm{p}<0.01 \mathrm{vs}$. Control; ${ }^{e} p<0.01$ vs. VDD; ${ }^{h} p<0.01$ and $i p<0.05$ vs. AmB/LE. (VDD, vitamin D deficiency; AmB/LE, Amphotericin B lipid emulsion; VDD+AmB/LE, vitamin D deficiency + Amphotericin B lipid emulsion).

Plasma levels of sodium and potassium did not change among the experimental groups (Table 3). As expected, plasma phosphate and calcium concentrations were lower in VDD groups, since diet composition has lower concentrations of calcium and phosphorus $(0.4 \% \mathrm{Ca}$ and $0.4 \%$ P) compared to standard diet. Treatment with AmB/LE alone also led to decreased plasma phosphate levels. Combination of VDD and AmB/LE aggravated hypophosphatemia (Table 3).

Proximal tubule function was impaired in VDD, AmB/LE and AmB/LE groups compared to Control, evidenced by higher urinary excretion of phosphorus (Table 3). In addition, renal protein expression of $\mathrm{NaPi}$-lla was diminished by approximately $30 \%$ in $\mathrm{AmB} / \mathrm{LE}$ animals and $40 \%$ in VDD+AmB/LE rats compared to Control, indicating that hyperphosphaturia is possibly related to lower sodium/phosphate cotransporter expression (Fig 3). Moreover, VDD, AmB/LE and VDD+AmB/LE groups presented an increased plasma PTH concentration compared to Control (Table 1). The evaluation of plasma concentration of FGF-23 revealed lower levels of this hormone in vitamin $D$ deficient rats compared to Control and AmB/LE groups (Table 1). In order to further investigate PTH-Klotho-FGF-23 axis, we determined renal protein expression of $\alpha$ Klotho. $\alpha-$ Klotho protein expression was significantly reduced in VDD ( $83 \pm 5 \%)$, AmB/LE $(62 \pm 4 \%)$

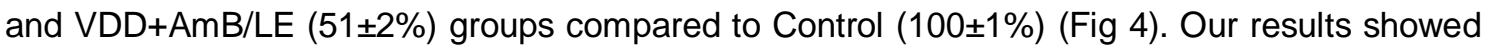
that not only VDD but also AMB/LE led to substantial changes in PTH-Klotho-FGF-23 axis, suggesting that such imbalance may contribute to the progression of AmB/LE-induced nephrotoxicity.

Fig 3. Semiquantitative immunoblotting of kidney fractions for NaPi-lla transporter. (A) Densitometric analyzes of samples from Control, VDD, AmB/LE and VDD+AmB/LE rats. (B) Immunoblots reacted with anti-NaPi-Ila revealing a $83 \mathrm{kDa}$ band. Data are mean $\pm \mathrm{SEM}$. ${ }^{\mathrm{b}} \mathrm{p}<0.01$ 
and ${ }^{\mathrm{c}} \mathrm{p}<0.05$ vs. Control; ${ }^{\mathrm{f}} \mathrm{p}<0.05$ vs. VDD (VDD, vitamin D deficiency; AmB/LE, Amphotericin $B$ lipid emulsion; VDD+AmB/LE, vitamin D deficiency + Amphotericin B lipid emulsion).

Fig 4. Semiquantitative immunoblotting of kidney fractions for Klotho. (A) Densitometric analyzes of samples from Control, VDD, AmB/LE and VDD+AmB/LE rats. (B) Immunoblots reacted with anti- $\alpha-K l o t h o$ revealing a $130 \mathrm{kDa}$ band. Data are mean \pm SEM. ${ }^{a} p<0.001$ and ${ }^{c} p<0.05$ vs. Control; ${ }^{d} p<0.001$ and ${ }^{e} p<0.01$ vs. VDD; $p<0.05$ vs. AmB/LE (VDD, vitamin D deficiency; AmB/LE, Amphotericin B lipid emulsion; VDD+AmB/LE, vitamin D deficiency + Amphotericin B lipid emulsion).

Plasma magnesium concentration did not change among the experimental groups (Table 3). Nevertheless, vitamin D deficient animals treated with AmB/LE exhibited higher urine excretion of magnesium compared to Control, VDD and AmB/LE (Table 3). Likewise, only VDD+AmB/LE rats $(49 \pm 11 \%)$ showed significant lower renal protein expression of TRPM6 compared to Control $(100 \pm 2 \%), \operatorname{VDD}(91 \pm 12 \%)$ and AmB/LE $(79 \pm 6 \%)$, indicating a possible involvement of this channel in the development of hypermagnesuria in vitamin $D$ deficient animals treated with AmB/LE (Fig 5).

Fig 5. Semiquantitative immunoblotting of kidney fractions for TRPM6 channel. (A) Densitometric analyzes of samples from Control, VDD, AmB/LE and VDD+AmB/LE rats. (B) Immunoblots reacted with anti-TRPM6 revealing a $234 \mathrm{kDa}$ band. Data are mean \pm SEM. ${ }^{b} p<0.01$ vs. Control; ${ }^{f} p<0.05$ vs. VDD; ${ }^{p} p<0.05$ vs. AmB/LE (VDD, vitamin D deficiency; AmB/LE, Amphotericin B lipid emulsion; VDD+AmB/LE, vitamin D deficiency + Amphotericin B lipid emulsion).

Association of vitamin D deficiency and treatment with AmB/LE resulted in a significant increase in urine volume and a subsequent decrease in urine osmolality compared to Control, VDD and AmB/LE. VDD and AmB/LE groups also presented a slight increase in urinary volume 
and a lower urine osmolality compared to Control (Table 3). These alterations were accompanied by a diminished renal expression of $A Q P 2$ in groups $A m B / L E(43 \pm 2 \%)$ and VDD+AmB/LE

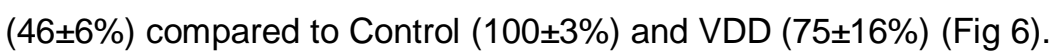

Fig 6. Semiquantitative immunoblotting of kidney fractions for Aquaporin 2 channel. (A) Densitometric analyzes of samples from Control, VDD, AmB/LE and VDD+AmB/LE rats. (B) Immunoblots reacted with anti-AQP2 revealing both 29 and $34 \sim 45 \mathrm{kDa}$ bands. Data are mean \pm SEM. ${ }^{a} p<0.001$ and ${ }^{c} p<0.05$ vs. Control; ${ }^{f} p<0.05$ vs. VDD (VDD, vitamin D deficiency; $A m B / L E$, Amphotericin B lipid emulsion; VDD+AmB/LE, vitamin D deficiency + Amphotericin B lipid emulsion).

\section{Discussion}

AmB is the drug of choice for the treatment of IFI, however clinical use of AmB has been associated with renal toxicity. The high rate of nephrotoxicity has enabled the development of modified AmBs [4,6]. Among these formulations, an extemporaneous lipid emulsion preparation of $A m B$ is a lower cost alternative with similar benefits $[4,6]$. Moreover, studies have been showing a high prevalence of VDD in general population, reflecting on a worse prognosis in cases of acute kidney injury and drug-induced nephrotoxicity $[7,10,14]$. In this study, we showed that association of VDD and AmB/LE led to impaired renal function, hypertension and urinary concentrating defect.

Our data demonstrated that vitamin $\mathrm{D}$ deficient animals treated with AmB/LE presented impaired renal function, evidenced by lower GFR, higher plasma urea concentration, hyperphosphaturia, hypermagnesuria, proteinuria and mild tubular injury. It is well known that AmB-induced nephrotoxicity is due to the interaction of $A m B$ with sterols from cell membranes, resulting in pore formation, defected electrolyte flux and loss of cell viability $[3,17,18]$. Furthermore, experimental and clinical trials have reported that treatment with AmB leads to denuded basement membrane, intratubular casts and tubular cell necrosis. These studies also described no severe morphological glomerular damage $[19,20]$. However, a previous study from our laboratory reported that the association of $\mathrm{AmB}$ and lipid emulsion efficiently reduced renal 
toxicity [4]. On this hand, our results also showed that AmB/LE did not change either GFR or renal morphology, suggesting that vitamin $D$ deficiency may play an important role in the development of renal injury in VDD+AmB/LE rats.

In this study, VDD+AmB/LE rats developed hypertension, accompanied by a notable increase in renal protein expression of AGT and ACE, and higher levels of plasma aldosterone. According to Meaudre et al., AmB acts directly on vascular smooth muscle cells resulting in local vasoconstriction and subsequent systemic higher blood pressure [21]. However, the mechanisms involved in the arising of hypertension in AmB-treated patients are still unclear [21]. On the other hand, it is well known that vitamin $D$ is a negative endocrine regulator of the RAAS and the unappropriated activation of this system has been related to hypertension $[22,23]$. Furthermore, previous studies have demonstrated that VDD regulates blood pressure through direct effects on the vascular endothelium, promoting hypertension $[10,12]$. Thus, it is possible to speculate that VDD associated with AmB/LE treatment may have exacerbated arterial hypertension observed in this group.

As expected, VDD animals exhibited hypophosphatemia, hypocalcemia and increased plasma PTH concentration, since vitamin D deficiency diminishes calcium intestinal absorption, resulting in decreased calcium concentration and increased production of PTH [14]. Interestingly, higher PTH has been associated with the development of hypertension because of its effects on vascular smooth muscle cells, increasing vascular tone and arterial blood pressure $[24,25]$. In addition, AmB/LE treatment itself led to reduced levels of plasma phosphate and the association of VDD with AmB/LE significantly increased hypophosphatemia. Higher plasma phosphate concentration was accompanied by increased phosphaturia and decreased renal protein expression of $\mathrm{NaPi}-$ Ila cotransporter in $\mathrm{AmB} / \mathrm{EL}$ and $\mathrm{VDD}+\mathrm{AmB} / \mathrm{LE}$ groups, characterizing a proximal tubular injury. It is important to point out that PTH also induces phosphaturia and treatment with calcitriol decreases urinary excretion of phosphorus in an experimental rat model, indicating that vitamin D may stimulate renal phosphate transport [26,27].

Moreover, Razzaque et al. reported that, in addition to PTH and calcitriol, FGF23 may directly or indirectly downregulate $\mathrm{NaPi}$ activity, leading to reduced reabsorption of phosphate [28]. In our study, we found diminished plasma FGF-23 concentration in VDD and VDD+AmB/LE 
groups. Although FGF-23 is an early biomarker in the development of chronic kidney disease (CKD), this may occur as a compensatory response, in order to restore vitamin $D$ levels and hyperphosphaturic effect [12]. Supporting our findings, previous experimental studies showed that rats under VDD and CKD progression also presented lower levels of FGF-23 [10,12]. Recent reports have been suggesting an interesting link between phosphate and FGF-23/Klotho axis. Traditionally, Klotho is related to aging processes in mammals and its deficiency is considered the initiator of CKD-related mineral disorders [29,30]. VDD animals exhibited a slight decrease in renal protein expression of Klotho compared to Control. Surprisingly, AmB/LE treated rats also showed a lower renal protein expression of Klotho compared to Control and VDD groups. Association of VDD and AmB/LE exacerbated Klotho deficiency. Altogether, these results indicate that disturbances in PTH-Klotho-FGF-23 axis might be responsible for the aggravation of AmB/LE-induced nephrotoxicity.

Clinical trials have reported that conventional $A m B$ is more likely to induce renal magnesium wasting and mild hypomagnesemia than lipid formulations [5,31]. Corroborating these data previously shown, our lipid formulation of AmB did not change urinary excretion of magnesium. However, the association of VDD and AmB/LE led to hypermagnesuria. Renal magnesium loss can be due to polyuria or tubular reabsorption defect [32]. Higher urinary excretion of magnesium was accompanied by reduced renal protein expression of TRPM6 in VDD+AmB/LE rats. TRPM6 is the major channel related to magnesium handling and contributes to magnesium reabsorption across distal convoluted tubule [33]. In our study, VDD possibly played an important role in the management of magnesium in the renal tubule and in the onset of hypermagnesuria in vitamin $\mathrm{D}$ deficient animals treated with AmB/LE.

It is well-established that both VDD and AmB/LE led to an impaired renal concentrating ability, evidenced by higher $24 \mathrm{~h}$-urine volume and decreased urinary osmolality $[4,13]$. Indeed, our results showed that VDD and AmB/LE groups exhibited increased 24h-urine volume and diminished urinary osmolality compared to Control. In addition, renal protein expression of AQP2 was decreased in VDD and AmB/LE rats compared to Control. Corroborating our data, previous experimental studies described that treatment with AmB alone inhibits the AVP/V2R signaling pathway, resulting in diminished water reabsorption via AQP2 in the collecting duct of the kidney $[34,35]$. Combination of VDD and AmB/LE resulted in a more severe polyuria associated with 
lower protein expression of AQP2, suggesting that VDD might have exacerbated renal concentrating defect in AmB/LE-induced renal toxicity.

In conclusion, our results confirm that vitamin $\mathrm{D}$ deficiency induces $\mathrm{AmB} / \mathrm{LE}$ nephrotoxicity possibly due to impaired renal function accompanied by tubular injury, the arising of hypertension, alterations in the PTH-Klotho-FGF-23 signaling axis and water balance dysfunction. It is worth mentioning that an in-house lipid emulsion preparation of AmB preserves therapeutic properties and is not as expensive as pharmaceutical lipid formulations. Thus, it is essential to monitor vitamin $\mathrm{D}$ levels in both patients treated with conventional or lipid formulations of $\mathrm{AmB}$, in order to ensure a better prognosis in the development of renal diseases.

\section{Acknowledgements}

The authors thank Dr. Pedro Henrique França Gois and Denise Ariane de Jesus Gomes from LIM-12 - Nephrology Department for their technical assistance. Portions of this paper were presented in abstract form at the ASN Kidney Week, Chicago/IL, November 15-20, 2016. Vitamin D deficiency induces acute kidney injury in rats treated with lipid formulation of Amphotericin B. J Am Soc Nephrol 27, 670A, 2016.

\section{References}

1. Hamill RJ. Amphotericin B formulations: a comparative review of efficacy and toxicity. Drugs. 2013; 73: 919-934.

2. Kleinberg $M$. What is the current and future status of conventional amphotericin B? Int $J$ Antimicrob Agents. 2006; 27 Suppl 1: 12-16.

3. Berdichevski RH, Luis LB, Crestana L, Manfro RC. Amphotericin B-related nephrotoxicity in low-risk patients. Braz J Infect Dis. 2006; 10: 94-99.

4. Dorea EL, Yu L, De Castro I, Campos SB, Ori M, et al. Nephrotoxicity of amphotericin B is attenuated by solubilizing with lipid emulsion. J Am Soc Nephrol. 1997; 8: 1415-1422.

5. Goldman RD, Koren G. Amphotericin B nephrotoxicity in children. J Pediatr Hematol Oncol. 2004; 26: 421-426. 
6. Mistro S, Maciel Ide M, de Menezes RG, Maia ZP, Schooley RT, et al. Does lipid emulsion reduce amphotericin B nephrotoxicity? A systematic review and meta-analysis. Clin Infect Dis. 2012; 54: 1774-1777.

7. Palacios C, Gonzalez L. Is vitamin D deficiency a major global public health problem? J Steroid Biochem Mol Biol. 2014; 144 Pt A: 138-145.

8. Unger MD, Cuppari L, Titan SM, Magalhaes MC, Sassaki AL, et al. Vitamin D status in a sunny country: where has the sun gone? Clin Nutr. 2010; 29: 784-788.

9. Allavena C, Delpierre C, Cuzin L, Rey D, Viget N, et al. High frequency of vitamin D deficiency in HIV-infected patients: effects of HIV-related factors and antiretroviral drugs. J Antimicrob Chemother. 2012; 67: 2222-2230.

10. Goncalves JG, de Braganca AC, Canale D, Shimizu MH, Sanches TR, et al. Vitamin d deficiency aggravates chronic kidney disease progression after ischemic acute kidney injury. PLoS One. 2014; 9: e107228.

11. Melamed ML, Michos ED, Post W, Astor B. 25-hydroxyvitamin D levels and the risk of mortality in the general population. Arch Intern Med. 2008; 168: 1629-1637.

12. de Braganca AC, Canale D, Goncalves JG, Shimizu MHM, Seguro AC, et al. Vitamin D Deficiency Aggravates the Renal Features of Moderate Chronic Kidney Disease in 5/6 Nephrectomized Rats. Front Med (Lausanne). 2018; 5: 282.

13. de Braganca AC, Volpini RA, Canale D, Goncalves JG, Shimizu MH, et al. Vitamin D deficiency aggravates ischemic acute kidney injury in rats. Physiol Rep. 2015; 3 (3):e12331.

14. Canale D, de Braganca AC, Goncalves JG, Shimizu MH, Sanches TR, et al. Vitamin D deficiency aggravates nephrotoxicity, hypertension and dyslipidemia caused by tenofovir: role of oxidative stress and renin-angiotensin system. PLoS One. 2014; 9(7): e103055.

15. Burnette WN. "Western blotting": electrophoretic transfer of proteins from sodium dodecyl sulfate--polyacrylamide gels to unmodified nitrocellulose and radiographic detection with antibody and radioiodinated protein A. Anal Biochem. 1981; 112: 195-203.

16. Miyaji T, Kato A, Yasuda H, Fujigaki $Y$, Hishida A. Role of the increase in p21 in cisplatininduced acute renal failure in rats. J Am Soc Nephrol. 2001; 12: 900-908. 
17. Brajtburg J, Powderly WG, Kobayashi GS, Medoff G. Amphotericin B: current understanding of mechanisms of action. Antimicrob Agents Chemother. 1990; 34: 183-188.

18. Krejcirova L, Lauschova I, Horky D, Doubek M, Mayer J, et al. Influence of amphotericin B deoxycholate or amphotericin B colloidal dispersion on renal tubule epithelium in rat. Biomed Pap Med Fac Univ Palacky Olomouc Czech Repub. 2004; 148: 221-223.

19. Doubek M, Mayer J, Lauschova I, Scheer P, Krejcirova L, et al. Comparison of the effect of amphotericin B desoxycholate and amphotericin B colloidal dispersion on renal functions and renal morphology in rats. Nephrology (Carlton). 2005; 10: 57-62.

20. Sabra R, Branch RA. Amphotericin B nephrotoxicity. Drug Saf. 1990; 5: 94-108.

21. Meaudre E, Montcriol A, Gaillard PE, Kenane N, Palmier B. [Amphotericin B associated with hypertension: haemodynamic profile]. Ann Fr Anesth Reanim. 2005; 24: 1405-1406.

22. Li YC. Vitamin D regulation of the renin-angiotensin system. J Cell Biochem. 2003; 88: 327331.

23. Tamez H, Kalim S, Thadhani RI. Does vitamin D modulate blood pressure? Curr Opin Nephrol Hypertens. 2013; 22: 204-209.

24. Chen S, Sun Y, Agrawal DK. Vitamin D deficiency and essential hypertension. J Am Soc Hypertens. 2015; 9: 885-901.

25. Jorde R, Svartberg J, Sundsfjord J. Serum parathyroid hormone as a predictor of increase in systolic blood pressure in men. J Hypertens. 2005; 23: 1639-1644.

26. Kurnik BR, Hruska KA. Effects of 1,25-dihydroxycholecalciferol on phosphate transport in vitamin D-deprived rats. Am J Physiol. 1984; 247: F177-184.

27. Weisinger JR, Bellorin-Font E. Magnesium and phosphorus. Lancet. 1998; 352: 391-396.

28. Razzaque MS. The FGF23-Klotho axis: endocrine regulation of phosphate homeostasis. Nat Rev Endocrinol. 2009; 5: 611-619.

29. Donate-Correa J, Muros-de-Fuentes M, Mora-Fernandez C, Navarro-Gonzalez JF. FGF23/Klotho axis: phosphorus, mineral metabolism and beyond. Cytokine Growth Factor Rev. 2012; 23: 37-46.

30. Kuro OM. Phosphate and Klotho. Kidney Int. 2011; 79121: S20-23.

31. Barton $\mathrm{CH}$, Pahl M, Vaziri ND, Cesario T. Renal magnesium wasting associated with amphotericin B therapy. Am J Med. 1984; 77: 471-474. 
32. Hoorn EJ, Zietse R. Disorders of calcium and magnesium balance: a physiology-based approach. Pediatr Nephrol. 2013; 28: 1195-1206.

33. Woudenberg-Vrenken TE, Bindels RJ, Hoenderop JG. The role of transient receptor potential channels in kidney disease. Nat Rev Nephrol. 2009; 5: 441-449.

34. Kim SW, Yeum CH, Kim S, Oh Y, Choi KC, et al. Amphotericin B decreases adenylyl cyclase activity and aquaporin-2 expression in rat kidney. J Lab Clin Med. 2001; 138: 243-249.

35. Tonomura Y, Yamamoto E, Kondo C, Itoh A, Tsuchiya N, et al. Amphotericin B-induced nephrotoxicity: characterization of blood and urinary biochemistry and renal morphology in mice. Hum Exp Toxicol. 2009; 28: 293-300. 